Florida International University

FIU Digital Commons

FIU Electronic Theses and Dissertations

University Graduate School

$11-14-2014$

\title{
Access to Better Education: The School Choice Experience of Families Served by Low-Performing Elementary Public Schools in Miami-Dade County
}

LeTania Severe

Florida International University, le4severe@gmail.com

DOI: $10.25148 /$ etd.FI14110730

Follow this and additional works at: https://digitalcommons.fiu.edu/etd

Part of the Educational Sociology Commons, and the Education Policy Commons

\section{Recommended Citation}

Severe, LeTania, "Access to Better Education: The School Choice Experience of Families Served by Low-Performing Elementary Public Schools in Miami-Dade County" (2014). FIU Electronic Theses and Dissertations. 1618.

https://digitalcommons.fiu.edu/etd/1618 


\section{FLORIDA INTERNATIONAL UNIVERSITY}

Miami, Florida

ACCESS TO BETTER EDUCATION: THE SCHOOL CHOICE EXPERIENCE OF FAMILIES SERVED BY LOW-PERFORMING ELEMENTARY PUBLIC SCHOOLS

IN MIAMI-DADE COUNTY

A dissertation submitted in partial fulfillment of the requirements for the degree of

DOCTOR OF PHILOSOPHY

in

COMPARATIVE SOCIOLOGY

by

LéTania P. Severe 
To: Interim Dean Michael R. Heithaus

College of Arts and Sciences

This dissertation, written by LéTania P. Severe, and entitled Access to Better Education: The School Choice Experience of Families Served by Low-Performing Elementary Public Schools in Miami-Dade County, having been approved in respect to style and intellectual content, is referred to you for judgment.

We have read this dissertation and recommend that it be approved.

$\begin{array}{r}\hline \text { Matthew Marr } \\ \hline \text { Hugh Gladwin } \\ \hline \text { Peter Cistone } \\ \hline \text { Guillermo Grenier, Major Professor }\end{array}$

Date of Defense: November 14, 2014

The dissertation of LéTania P. Severe is approved.

Interim Dean Michael R. Heithaus

College of Arts and Sciences

Dean Lakshmi N. Reddi

University Graduate School

Florida International University, 2014 


\section{DEDICATION}

I dedicate this dissertation to my mom and dad who provided the support, love, and understanding I needed to survive this dissertation process. 


\section{ACKNOWLEDGMENTS}

I wish to thank my committee chair, Dr. Guillermo Grenier, for his support and guidance throughout this long process. I would also like to thank my other committee members, Dr. Matthew Marr, Dr. Hugh Gladwin, and Dr. Peter Cistone, for their time and feedback.

I would like to thank Miami-Dade County Public Schools for allowing me to conduct this research and for providing me with the data necessary to complete it. I would like to especially thank Dr. Kristin Nichols-Lopez for pulling my data together and pushing me to finish. Additionally, I would like to thank the 22 parents who shared their stories for this study.

None of this work would have been possible without the unconditional support of my entire family. Barbara, Paul, LéTiana, Jacques, and Léandre Severe all helped me in countless ways throughout this process and I am forever grateful to them for that. Special thanks are also due to Manny Ocasio for putting up with me during the most difficult parts of this process and to my girlfriend, Renee Lamberjack, for providing the motivation and support I needed to finally complete my dissertation.

Finally, I would like to thank the Florida Education Fund for providing me a generous fellowship, which financially supported me while I completed my coursework. Also for the academic guidance and mentoring provided through the biannual conferences. 


\begin{abstract}
OF THE DISSERTATION
ACCESS TO BETTER EDUCATION: THE SCHOOL CHOICE EXPERIENCE OF FAMILIES SERVED BY LOW-PERFORMING ELEMENTARY PUBLIC SCHOOLS

IN MIAMI-DADE COUNTY
\end{abstract}

by

LéTania P. Severe

Florida International University, 2014

Miami, Florida

Professor Guillermo Grenier, Major Professor

Public school choice education policy attempts to create an education

marketplace. Although school choice research has focused on the parent role in the school choice process, little is known about parents served by low-performing schools. Following market theory, students attending low-performing schools should be the primary students attempting to use school choice policy to access high performing schools rather than moving to a better school. However, students remain in these lowperforming schools. This study took place in Miami-Dade County, which offers a wide variety of school choice options through charter schools, magnet schools, and openchoice schools.

This dissertation utilized a mixed-methods design to examine the decision-making process and school choice options utilized by the parents of students served by lowperforming elementary schools in Miami-Dade County. Twenty-two semi-structured interviews were conducted with the parents of students served by low-performing schools. Binary logistic regression models were fitted to the data to compare the 
demographic characteristics, academic achievement and distance from alternative schooling options between transfers and non-transfers. Multinomial logistic regression models were fitted to the data to evaluate how demographic characteristics, distance to transfer school, and transfer school grade influenced the type of school a transfer student chose. A geographic analysis was conducted to determine how many miles students lived from alternative schooling options and the miles transfer students lived away from their transfer school.

The findings of the interview data illustrated that parents' perceived needs are not being adequately addressed by state policy and county programs. The statistical analysis found that students from higher socioeconomic social groups were not more likely to transfer than students from lower socioeconomic social groups. Additionally, students who did transfer were not likely to end up at a high achieving school. The findings of the binary logistic regression demonstrated that transfer students were significantly more likely to live near alternative school options. 


\section{TABLE OF CONTENTS}

CHAPTER

PAGE

I. Introduction: Accessing Alternative Schooling Options Through School Choice

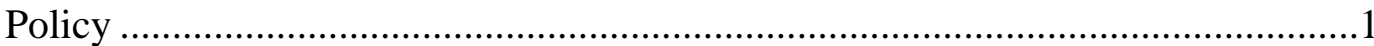

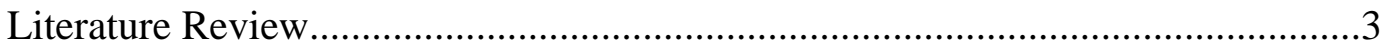

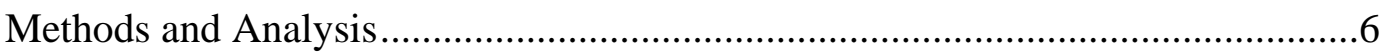

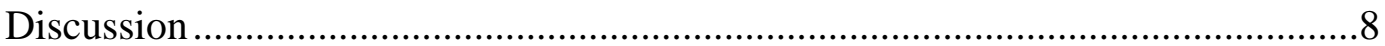

II. Literature Review: A History of Education Policy and Inequality ..............................9

Accessing Equal Educational Opportunities..................................................... 12

Equal Educational Opportunity: A History of Failed Reform ..............................14

School Choice Policy .................................................................................29

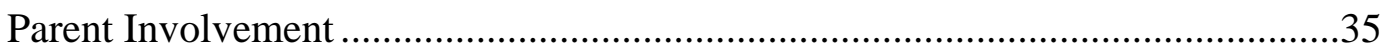

Making Schooling Decisions: Parents’ Role in School Choice.............................37

III. The Local Context: State School Choice Policy and County Programs......................45

Improving School Academic Performance ........................................................45

Expanding Competition for Students ..............................................................51

Making More Options Available to Parents ......................................................54

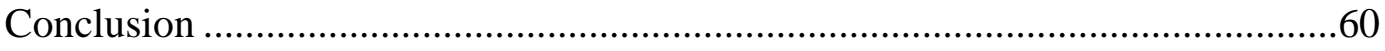

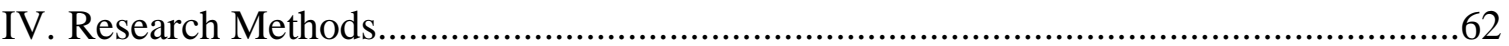

Operationalization and Conceptualization of Research Terms.............................64

Operationalizing the Hypotheses .......................................................................69

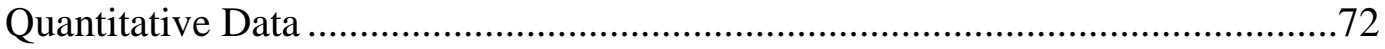

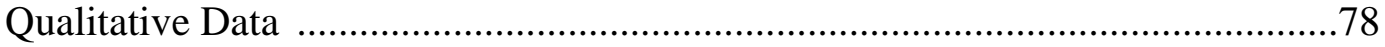

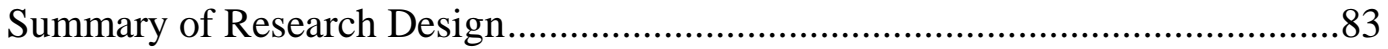

V. How Parents Access and Process Current School and School Choice Information ....84

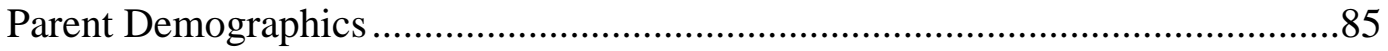

Accessing and Processing Current School Information ....................................88

Accessing and Processing School Choice Information .....................................109

Accessing Choice Information....................................................................109

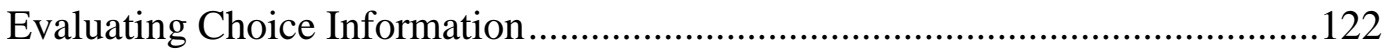


Conclusion

VI. Parents’ Resources and Constraints to School Choice Options 134

Understanding Eligibility ..... .135

Accessing Logistic Resources. .138

Social Networks 143

Conclusion

VII. Comparing the Demographic, Academic, and Geographic Characteristics of Transfer and Non-Transfer Students.............................................................150

Differentiating Transfer and Non-Transfer Students .......................................151

Transfer School Type.............................................................................158

VIII. Discussion: Addressing Parents’ School Choice Needs ......................................169

The Implications of the Study Findings.......................................................169

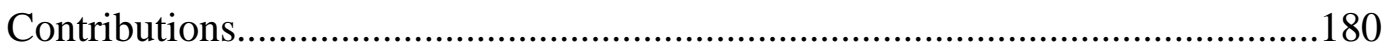

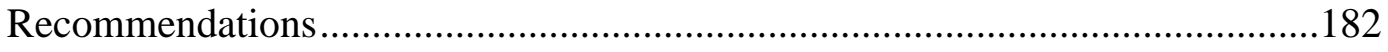

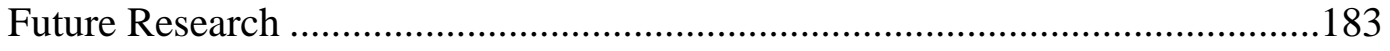

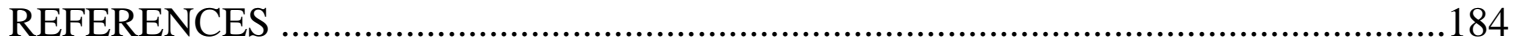

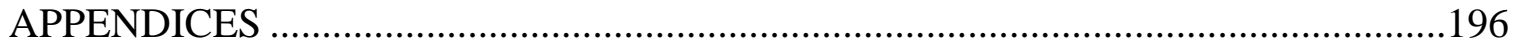

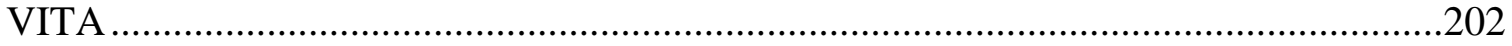




\section{LIST OF TABLES}

TABLE

PAGE

1. 2013 Miami-Dade County School Grades .48

2. Race/Ethnicity Breakdown for Opportunity Scholarships in Florida 2012 - 2013

3. Free/Reduced Lunch Status Breakdown for Opportunity Scholarships in Florida $2012-2013$.

4. Race/Ethnicity Breakdown for Florida Tax Credit Scholarship 2012 - 2013 .51

5. Race/Ethnicity Breakdown for McKay Scholarships in Florida 2012 - 2013.

6. Free/Reduced Lunch Status Breakdown for McKay Scholarships in Florida 2012 2013.

7. Low-performing Elementary School Grades ................................................................73

8. Characteristics of Parents of Non-Transfer Students in the Present Study.....................86

9. Characteristics of Parents of Transfer Students in the Present Study ..............................87

10. Parent Knowledge of School Grade

11. Distributions of demographic characteristics and academic achievement by transfer status for students attending a sample school during the 2010-11 school year $(\mathrm{n}=980)$

12. Binary logistic regression of transfer status among students served by lowperforming elementary schools in Miami-Dade County, FL

13. Binary logistic regression comparing the distance transfers and non-transfers lived from alternative schooling options.

14. Distributions of demographic characteristics, academic achievement, and school characteristics by transfer school type for students who transferred from a sample school during the 2011-12 school year $(\mathrm{n}=267)$

15. Multivariate logistic regression of transfer school type among students who transferred from low-performing elementary schools in Miami-Dade County, FL between the 2009-2010 and 2011-2012 school years. .163

16. Mean Distance students lived from transfer school by school type. .166 
17. Multivariate logistic regression comparing the distance transfer schools lived from

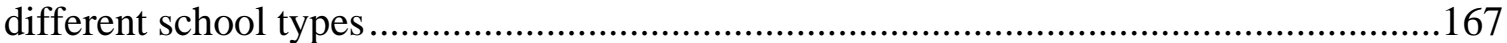




\section{LIST OF ABBREVIATIONS AND ACRONYMS}

\begin{tabular}{|c|c|}
\hline AYP & Adequate Yearly Progress \\
\hline ESE & Exceptional Student Education \\
\hline ESEA & Elementary and Secondary Education Act \\
\hline ETO & Education Transformation Office \\
\hline FCAT & Florida Comprehensive Assessment Test \\
\hline FRL & Free and Reduced Lunch \\
\hline FTE & Full-Time Equivalency \\
\hline GIS & Geographic Information System \\
\hline IEP & Individual Education Plan \\
\hline IRB & Institutional Review Board \\
\hline LEP & Limited English Proficiency \\
\hline MDCPS & Miami-Dade County Public Schools \\
\hline NCLB & No Child Left Behind Act \\
\hline PTA & Parent Teacher Association \\
\hline SFO & Scholarship Funding Organizations \\
\hline
\end{tabular}




\section{Introduction: Accessing Alternative Schooling Options Through School Choice Policy}

School choice policy has allowed the education system to create an education market that provides parents a variety of alternative schooling options from which to select (Moe 2008; Ben-Porath 2009; Loeb et al. 2011; Ravitch 2013). The policy puts schools in the position to compete to attract students with their academic programs, learning environments, and unique structures. Florida is at the forefront of the school choice movement (FLDOE 2013e). The state offers a wide variety of alternative schooling options and resources to assist families in finding the right school for their child. Families can choose from magnet schools, charter schools, controlled open enrollment, virtual instruction and a variety of other schools specifically designated as schools of choice (Florida State $\S 1002.20$ \{2012\}). Additionally, parents can utilize the Opportunity Scholarship Program, McKay Scholarships for Students with Disabilities Program, and the Florida Tax Credit Scholarship Program (Florida State § 1002.20 $\{2012\})$. During the 2012-13 school year, 30\% of the total K-12 student population attended a school using parental school choice options (FLDOE 2013e). During the same school year, Florida offered the third highest number of charter schools in the nation, with $74 \%$ of those schools earning a school performance grade of "A" or "B" during the previous school year (FLDOE 2013e).

Miami-Dade County Public Schools (MDCPS) is the largest school district in the state of Florida and also offers the widest selection of charter and magnet schools in the state (FLDOE 2014; MDCPSa). There are 127 charter schools available to students in

pre-kindergarten to $12^{\text {th }}$ grade (FLDOE 2014). There are also over 340 magnet programs 
in over 100 schools with an enrollment of over 43,000 students (MDCPSc). By offering such a large selection of innovative programs at high-performing schools, the County provides alternatives that may better serve students compared to traditional public schools. Charter schools are also afforded more freedom and flexibility to provide the academic programs that best meet the needs of their student population (Toma and Zimmer 2012; Ravitch 2013). Like traditional public schools, they are measured on the basis of student scores on state standardized tests (Cooper and Randall 2008). The County provides information about eligibility, the application process, and programs on websites that are designated for charter school information and magnet school information respectively.

Opportunity scholarships are made available to students in low-performing schools (Florida State $\S 1002.38\{2012\}$ ). Students can use these scholarships to pay for transportation to a different public school or they can use the funds to pay tuition at a private school. Parents are required to select a high performing school with a grade no lower than a "C". McKay scholarships give students with disabilities an opportunity to attend a school that can better meet their needs (Florida State § $1002.39\{2012\}$ ). Not all traditional schools are equipped to serve all special needs or all special needs students. Like the Opportunity Scholarship, McKay Scholarship recipients can use the funds to pay for transportation to a different public school or to pay tuition at a private school that serves students with disabilities. The Tax Credit Scholarship program targets low-income elementary students (Florida State $\S 1002.395\{2012\}$ ). It allows families with limited economic resources to access higher performing schools. Parents can enroll their children in eligible receiving schools. These three scholarship opportunities attempt to alleviate 
some of the possible increased costs of attending a school other than ones neighborhood school.

The education system is not the great equalizer that many Americans had hoped it would be (Ravitch 2000). On the contrary, evidence supports the notion that the education system plays a major role in maintaining social stratification (Bowles 1972; Massey and Denton 1993; Kao and Thompson 2003; MacLeod 2009). Over the last 60 years, a variety of equity focused policy initiatives have attempted to level the playing field by addressing the barriers to equal access to quality educational opportunities (Kantor 1991; Guthrie and Springer 2004; Darling-Hammond 2007; Urban and Wagoner 2009; Ravitch 2013). However, these policies have been unsuccessful in fixing the problem because they often ignore broad social and economic issues that affect access to quality education. These issues include residential segregation, racial segregation, and poverty. Additionally, some of the more recent reforms are implemented without testing the assumptions about student learning and improving low-performing schools (Davidson et al. 2012; Hansen 2012; Polikoff et al. 2013; Ravitch 2013).

\section{Literature Review}

The literature review for the present study focuses on equal education and school choice research. The sections on equal education illustrate how desegregation, the Elementary and Secondary Education Act (ESEA), and the No Child Left Behind Act (NCLB) attempt to provide better education to all students but each falls short of its goals because of unaddressed broad social issues. Historically, the education system has been stratified along gender, racial, ethnic, and social class lines. The present literature review emphasizes the social and economic constraints that affect policies as these policies try to 
implement systemic change. It highlights some of the same constraints school choice policy faces in its attempt to make high quality schools available to all students. It also illustrates how many of the new reforms were created on the basis of untested assumptions, which doomed them to fail.

The Brown v Board of Education decision of 1954, deemed segregated schools unequal (Guthrie and Springer 2004; Marshall and Gerstl-Pepin 2005). The Supreme Court determined that as a result of the unequal conditions, resources, and outcomes that blacks experienced, both black and white students were supposed to be placed into integrated schools. Unfortunately, Jim Crow laws and residential segregation significantly limited the decision's ability to implement widespread integration (Guthrie and Springer 2004). Some schools were never integrated and some are currently experiencing resegregation (Orfield and Yun 1999; Borman et al. 2004; Orfield and Lee 2005). The ESEA was part of a national priority to combat poverty (Kantor 1991; Urban and Wagoner 2009). The funds were used for Title I programs that target educationally disadvantaged students (Kantor 1991; Urban and Wagoner 2009). The ESEA suffered from lax oversight and no prescribed program (Kantor 1991). School districts were left to utilize the funds as they saw fit and this resulted in little change in the status quo. Ultimately ESEA resulted in limited changes in the education provided to disadvantaged students. The NCLB Act built on the efforts of ESEA. It set out to reduce the achievement gap between diverse races and classes (Fix and Capps 2005; DarlingHammond 2007). It requires students meet a certain level of academic achievement on standardized test scores, schools have highly qualified teachers, and students be provided more alternative schooling options through school choice programs (Arce et al. 2005; 
Darling-Hammond 2007). The federal government defines a highly qualified teacher as a teacher with a bachelor's degree, full state certification or licensure and a teacher who can prove that they know each subject they teach (USDOE 2004). The unrealistic goal of the NCLB Act of $100 \%$ of students testing as proficient at grade level by 2014 set it up for failure from the beginning. A new waiver program has alleviated some of the pressure placed on states to meet this goal and reemphasized the federal government's agenda of market driven and test specific reform initiatives (Polikoff et al 2013; Ravitch 2013).

The school choice literature review has three primary sections. The first section focuses on how schools and parents behave in the educational marketplace. The second section focuses on the parent involvement literature and how parent involvement affects student academic performance. In the third section, literature on parents' school choice decision making is reviewed. It illustrates how parent social class and social capital influence parent participation and utilization of school choice options.

The primary objectives of school choice policy are to expand the current selection of school options available to parents, give parents control over where their children attend school, and improve student academic achievement throughout the education system (Ben-Porath 2009; Lubienski et al. 2009; Ravitch 2013). These objectives are put into practice by allowing universities, individuals, non-profit groups, for-profit companies, and existing schools to offer new, innovative academic programs and unique school structures. Nearly all states offer some variation of school choice options to parents (Hoxby 2003; Lander and Lips 2008). School choice attempts to use competition to improve academic achievement (Goyette 2008; Ben-Porath 2009; Ravitch 2013). Advocates of choice policy believe it is an opportunity to equalize the education system 
by giving all students easier access to higher quality schools (Moe 2008; Ben-Porath 2009; Ravitch 2013). The market model of school choice assumes that parents are aware of their options and are equipped with the resources to make an informed decision and utilize the school option they want.

\section{Methods and Analysis}

My dissertation utilizes a mixed-methods design to examine the decision-making process and school choice options utilized by the parents of students served by lowperforming elementary schools in Miami-Dade County (Babbie 2005)). The research answers four questions: (1) Do Florida state statutes on school choice and Miami-Dade County school choice programs adequately address the perceived needs of parents of students served by low-performing schools so they can access school choice options and make informed school choice decisions? (2) What characteristics differentiate students who transfer from and those who stay in low-performing schools? (3) What characteristics are most influential in predicting the type of school transferring students will attend? (4) How do economic and social factors differentiate the decision making process of parents who transfer their children from and those who keep their children in low-performing schools?

Quantitative data from 980 records of students who were served by lowperforming public elementary schools in Miami-Dade County during the 2010-11 school year were analyzed utilizing SPSS statistical software. Qualitative data from 22 semistructured interviews were analyzed utilizing Atlas.ti software. Mapping with GIS software was conducted incorporating county school data with the quantitative data utilizing ArcMap. The combination of all methods provides a full picture of how the 
parents of students served by low-performing schools navigate the school-choice process. For the purpose of this research, low-performing schools were defined as elementary schools that were graded an "F" or "D" 3 of 5 of the years between the 2006-07 and 2010-11 school years. A review of all elementary schools with at least 3 years of state designated grades yielded 8 low-performing elementary schools.

Data for students attending the 8 low-performing schools during the 2010-11 school year were obtained from the Miami-Dade County Public Schools' Office of Program Evaluation. The 2010-11 dataset included student demographic and academic data. An additional dataset for the 2011-12 school year included students' current school and parent information for the students in the first dataset. These datasets were used to determine students' transfer status between the 2010-11 and 2011-12 school years. It also provided parent information so that parents could be sampled and interviewed. Lastly, it provided student home addresses to conduct the geographic analysis.

These datasets were used to conduct binary and multinomial logistic regressions to compare transfers and non-transfers and to evaluate the type of schools that transfer students choose. These datasets were also used to map student home addresses to determine the distance between student homes and the nearest alternative schooling option using GIS. Transfer student homes were also mapped and used to determine the distance between transfer students' homes and their transfer school using GIS. These distances were then used to run a binary and multinomial logistic regression.

A stratified sample of five schools was taken from the eight schools for parent interviews. Twenty-two semi-structured interviews were conducted with the parents of student who attended five of the eight low-performing elementary schools during the 
2010-11 school year. Eleven interviews were conducted with the parents of transfer students and eleven interviews were conducted with the parents of non-transfer students. A comparative analysis was conducted to evaluate the difference between parents of transfers and non-transfers. Specifically, it analyzed what parents knew about their school choice options, how parents made school choice decisions, and the constraints that parents face during the school choice process.

Discussion

The final chapter provides a discussion of the implications of the findings of the present study. The findings illustrate how parents' needs are not being met by the current school system. Therefore, the parents and their children continue to face barriers to equal access to quality education even with the efforts of state school choice policy and MiamiDade County Public Schools' choice programs. The chapter makes recommendations for improving parent access to better schooling for their children. It also illustrates how the current study contributes to school choice and educational equity literature. Lastly it provides an overview of the future research that should be done to further advance the findings of this research. 


\title{
II. Literature Review : A History of Education Policy and Inequality
}

\author{
Introduction
}

Access to quality education has been disproportionately difficult for low-income and minority students throughout the history of the American education system (Kozol 1992; Walters 2001; Urban and Wagoner 2009; Ravitch 2010; Holme et al. 2013). These students attend schools that lack adequate resources, high quality teachers and an environment conducive to learning. While schooling options have increased and geographical restrictions have been lifted through school choice education policy, many of these students remain in the low-performing schools that serve their neighborhoods (Deluca and Rosenblatt 2010; Ravitch 2010; Holme et al. 2013). The high concentration of low-performing students in a school "creates a social context within which poor performance is standard and low expectations for student performance predominate (Massey and Denton 1993, 141).” However, these low-performing neighborhood schools are often conveniently located, serve family members and friends, and are frequently the same schools that the child's parents attended. Therefore, convincing parents to transfer their children from these schools to seek better schooling is not as simple as making high achieving schools available to them. Parents need useful information regarding those high achieving schools and the necessary resources to use them. In many cases, parents simply want their child's assigned neighborhood school to improve, making school choice options unnecessary.

Public school choice education policy creates an education marketplace in which schools compete for students and parents are given control over where their children 
attend school (Chubb and Moe 1990; Schneider et al. 2000; Apple 2004; Ravitch 2013). School choice represents an umbrella term for various market-driven schooling options such as charter schools, interdistrict choice, homeschooling, magnet schools and vouchers. Advocates of this policy argue that the market model gives all families an opportunity to receive a quality public school education at both traditional neighborhood public schools and new schools of choice, most of which are not restricted to any particular neighborhood (Moe 2008; Ben-Porath 2009; Toma and Zimmer 2012; Ravitch 2013). In the choice model, schools deemed inadequate will be motivated to improve themselves for fear that students will seek alternative schooling options, taking their perpupil expenditures with them (Cooper and Randall 2008). Public school choice policy seeks to provide alternative schooling options to all families, improve the academic achievement of all schools and give parents control of the school their child attends (Goyette 2008; Moe 2008; Lubienski et al. 2009; Ben-Porath 2009; Ravitch 2013). Opponents of school choice argue that there is little evidence of its ability to improve education for all students and it is detrimental to the neediest students because they are often the students left in depleted traditional public schools after other students have left to utilize choice schooling options (Loeb et al. 2011; Holme et al. 2013; Toma and Zimmer 2012; Ravitch 2013).

Although school choice gives parents the opportunity to transfer their children to a high performing school or to a school that provides a desirable academic program, many parents continue to have their children subjected to a subpar education (AndreBechely 2007; Ferryman et al. 2008; Goyette 2008; Lubienski et al. 2009). For parents seeking an alternative schooling option, choosing a school is a process that requires 
resources both for making a schooling choice and for getting their child to the chosen school. These resources are not equally distributed or easily accessible to all. Some parents have access to superior resources, such as quality information and social networks, which are crucial to their ability to take advantage of the policy. As research has established, social stratification has an impact on educational stratification (Coleman 1988; Kozol 1992; Ravitch 2013). Because of the strong correlation between social stratification and educational opportunity, educational stratification has been largely impervious to previous equity policies (Apple 2001a; Urban and Wagoner 2009; Ravitch 2013). Historically, ignoring broad social issues has stifled attempts to develop policy to provide equal educational opportunities to all students (Marshall and Gerstl-Pepin 2005; Urban and Wagoner 2009). Additionally, some recent reforms are implemented using untested assumptions about student learning and improving low-performing schools (Davidson et al. 2012; Hansen 2012; Polikoff et al. 2013; Ravitch 2013). The evidence on school choice to date suggests that its effort to combat stratification have been largely ineffective (Andre-Bechely 2007; Sikkink and Emerson 2008; Lubienski et al. 2009; Ravtich 2013).

The present dissertation explores the components of school choice policy and how the reform attempts to provide equal access to quality educational opportunities to all students. The chapter provides a historical overview of past policies that have attempted to do the same thing. It illustrates how social and economic constraints have hindered these policies' ability to provide equal educational opportunity to all students. It also illustrates how untested assumptions about ways to improve the education system have 
caused more problems than they have solved. Understanding how these constraints and assumptions affected past policies is important to the success of the school choice initiatives evaluated in the present study. Additionally, the review chapter illustrates the important role parents play in students' access to equal educational opportunities made available through choice policy and programs.

\section{Accessing Equal Educational Opportunities}

Like American society, the American education system is stratified. The hierarchical structure of educational opportunity and achievement is mediated by class, race, ethnicity, and gender (Massey and Denton 1993; Kao and Thompson 2003). Attempts to provide quality education and equalize outcomes have been largely ineffective (Kantor 1991; Guthrie and Springer 2004; Darling-Hammond 2007; Ravitch 2013). The education system has proven to be unyielding to the attempts of various policies focused on providing equal access to quality educational opportunities to students served by the public school system. The unequal distribution of resources and subsequent differential academic outcomes contribute to the reproduction of class status. Essentially, ones position in the class structure of American society can mostly be predicted by one's place in it at birth. The education system participates in helping some along while putting up constraints for most others (Collins 1971; Apple 2004; MacLeod 2009; Ravitch 2013).

Social reproduction theorists use economic determination theory to illustrate how education contributes to social reproduction (Collins 1971; Bowles 1972). Economic determination theorists describe the school as an arena of class conflict (Collins 1971; 
Bowles 1972). Additionally, these theorists argue that the social division of labor is a crucial aspect of the class structure and is an important barrier to the achievement of social-class equality in schooling (Collins 1971; Bowles 1972; Karabel and Halsey 1977). The correspondence between the economy or the division of labor and the education system is predicated on the ideology that students should be taught a specific set of skills to prepare them for a specific type of work determined by their appropriate social class background (Collins 1971; Bowles 1972).

In an important study, Randall Collins’ (1971) evaluated the effect of education and stratification on occupational attainment. He found that educational achievement is a strong determinant of occupational achievement, and social origin affects student educational attainment. "Careers are thus increasingly shaped within the education system (Collins 1971, p. 1004).” Using a Weberian theoretical framework, his argument presents the education system as an arena shaped by conflicting interest, not systemic needs (1971). According to Karabel and Halsey (1977), Collins utilizes Weber’s belief that "power is the crucial variable in the setting of educational requirements (31)." The role of power has always been evident in the curriculum, pedagogy, and structure of the educational system (Karabel and Halsey 1977; Apple 1982). According to conflict theory, there are status groups that share a common culture and some are better able to win advantage over the limited amount of wealth, power and prestige (Karabel and Halsey 1977). Education serves to reinforce these status cultures, which identifies insiders and creates barriers for those classified as outsiders. 
According to Bowles (1971) "the ideological defense of modern capitalist society rests heavily on the assertion that the equalizing effects of education can counter the disequalizing forces inherent in the free market system (p. 137).” However, schools serve to supply the labor needs of the free market with skilled, disciplined workers. The division of labor which separates the worker from the control of production in capitalist society is mirrored in the classroom and ultimately results in a barrier to creating social class equality in schooling. Bowles (1971) concludes that "the social relations of the school ... replicate the social relations of the workplace, and thus help young people adapt to the social division of labor (p. 139)." Schools prepare students for discipline, punctuality, acceptance of authority outside the family and individual accountability for one's work.

The fight for equal access to quality education has been a long one. Policy has tried to alleviate the disparities but has only been effective in doing so for some subsets of the student population. The next section illustrates how some of the most important national education policies focused on equity have attempted to break down barriers to quality education. It provides an overview of the specific equity issues the policies tackled, their effectiveness, and how it informs school choice policy. It also demonstrates how this newer policy attempts to tackle lingering equity issues within the education system.

Equal Educational Opportunity: A History of Failed Reform

The American education system has proven to be impervious to the attempts of various policies focused on providing equal educational opportunities to students served 
by the public school system. Access to equal educational opportunities is often hindered by governmental hierarchy, along with poor oversight, and enforcement of policy regulations. However, policies' have ignored broad social issues, which has been particularly detrimental to their ability to effectively provide equitable educational opportunities to all students. Among other things, the lack of equal educational opportunities to all students has allowed the education system to play a major role in the social reproduction of the stratified American society. Additionally, some of these reforms are built on untested assumptions, which have misguided attempts to improve access to quality education to all students. A brief overview of some of the most widespread education policies of the modern education system will illustrate how broad social class equity issues and assumptions about what improves student achievement have hindered education policy success. Additionally, it provides insight into the obstacles that school choice policy is currently facing and is likely to face in the future.

\section{Brown v. Board of Education}

The Brown v. Board of Education decision, which outlawed segregation in American schools, is one of the most significant decisions that addressed education access inequality in the US (Guthrie and Springer 2004; Marshall and Gerstl-Pepin 2005). In 1954, the Supreme Court found that separate educational facilities are inherently unequal. The court decision ruled that separate but equal was unconstitutional because of the unequal conditions, resources and outcomes between black and white segregated schools (Marshall and Gerstl-Pepin 2005). Black segregated schools lacked adequate facilities, qualified teachers, advanced courses, necessary resources, and bus transportation that white schools had (Verstegen 1994; Orfield and Yun 1999; Borman et 
al. 2004; Orfield and Lee 2005). Separate but equal was supposed to give blacks the same schooling opportunities that whites had been provided; the court ruled it did not.

The initial Brown decision lead to little change and resulted in the passing of Brown II in 1955 (Urban and Wagoner 2009). Brown II required that public schools accept students on racially nondiscriminatory terms "with all deliberate speed (Urban and Wagoner 2009, p. 341).” Brown was implemented during a time when racial issues were tense. Jim Crow laws required that blacks and whites live separate but equal lives (Guthrie and Springer 2004). However, their lives were everything but equal. At the time of the passing of Brown, the American people, especially those in the South were not ready to accept the required changes of the law, providing equal educational opportunities to all students. The Eisenhower administration was also indecisive in enforcing the mandate, and Congress, out of loyalty to Southern legislators, took part in resistance and/or inaction, both of which resulted in stagnant implementation (Urban and Wagoner 2009). It was obvious that although de jure segregation had ended, de facto segregation would prove nearly impossible to end in the South.

Resistance to desegregation was widespread in the South and included acts of violence, intimidation and new policies passed by state and local politicians (Moore 2004; Urban and Wagoner 2009). One of the most well-known acts of resistance took place in Little Rock Arkansas and involved a group of black students dubbed the Little Rock Nine. Nine carefully selected black students were to integrate Little Rock's Central High School, but were blocked by the Arkansas National Guard who was ordered by the Governor to do so (Urban and Wagoner 2009). Some states discontinued funds for 
districts that complied with federal desegregation law. Others provided vouchers to white students so they could attend private schools and avoid desegregated public schools (Guthrie and Springer 2004; Urban and Wagoner 2009).

Only with the passage of the Civil Rights Act of 1964 and subsequent legislation, was the court afforded the necessary power to begin to substantially enforce the Brown ruling (Verstegen 1994). In 1969, the Court ruled that districts must terminate dual school systems and operate a unitary one or federal funding would be withheld (Guthrie and Springer 2004). While adequate power was provided to force implementation of desegregation, the Supreme Court policy was not adequate enough to influence the social context in which it was taking place. The racial and economic situation outside the school grounds remained largely disparate (Wong and Nicotera 2004).

School districts made student assignments on the basis of race, busing, and the creation of magnet schools to desegregate their schools (Ravitch 2000; Moore 2004; Urban and Wagoner 2009). However, there was great variation in the success they experienced (Moore 2004). Many desegregation methods forced blacks to shoulder the burden of desegregation. Since the methods used were voluntary they were ineffective in significantly reducing dual school systems. Some argued that integration alone was not enough (Wong and Nicotera 2004). Moore (2004) concluded, "It appears that parents and students prefer the benefits, both real and perceived, in attending neighborhood schools and would like to avoid the hardships associated with leaving their communities (2004, p. 292).” The finding is an explicit recognition of some limitations of the school-choice policy. Current school-choice policy also encourages parents to leave their neighborhood 
schools for high performing schools, a practice many resist for various reasons, included convenience, familiarity and the community (Schneider et al. 2000; Bulkley and Fisler 2003; Lubienski 2005).

By failing to address the institutional and societal racism that permeated the US, school desegregation could only be moderately effective (Marshall and Gerstl-Pepin 2005). Marshall and Gerstl-Pepin (2005) argue that desegregation policy cannot be recognized so long as it is "disconnected from the realities of embedded institutional and cultural forms of discrimination experienced by the many individuals who populate public schools (2005, p. 72).” While desegregation has been able to provide better educational opportunities for some racial and economic minorities, it has not been able to improve the racial or economic gaps between students largely because of unaddressed institutional issues (Marshall and Gerstl-Pepin 2005).

Housing discrimination prevented blacks from moving into white neighborhoods where they could readily enroll their children in white neighborhood schools (Guthrie and Springer 2004). Therefore, the only way that blacks could attend white neighborhood schools was through busing. Busing took black students out of their communities, away from their friends and family often to attend schools in hostile environments (Moore 2004). Additionally, black parents could not be as involved in their children’s schooling because the schools they attended were far from their homes (Moore 2004). The burden of desegregation disproportionately fell on the shoulders of black families. Whites frequently refused to transfer their children to predominately black schools so black schools were often closed and those students were relocated to predominately white 
schools as a means of integration (Moore 2004). It was also difficult for blacks to access better schools because of economic inequality. They lacked the necessary funds to relocate their residence or provide transportation to commute to a school located several miles away from their home.

After substantial movement toward desegregation during the seventies, the eighties initiated the period of resegregation, which continues today (Orfield and Yun 1999; Guthrie and Springer 2004). In the current education reform environment, desegregation takes a backseat to standardized testing and school choice (Marshall and Gerstl-Pepin 2005). School segregation as the result of residential segregation by race is no longer the responsibility of the school system (Borman et al. 2004; Darling-Hammond 2007). Segregation, while still detrimental to student achievement, is no longer a problem the education system wishes to address. School choice strives to improve academic achievement regardless of the social and ethnic background of the students in a particular school.

The rapid rate of resegregation illustrates how important it is to address broad social issues to assure education policies have a chance to succeed (Orfield and Yun 1999). Instead of addressing the issues, the education system has decided that schools are not responsible for residential segregation and therefore should not be held accountable for school segregation (Borman et al. 2004; Orfield and Lee 2005). Therefore, resegregation trends are ignored and the education system is determined to illustrate that even without desegregation, other policies such as NCLB and school choice can still provide equal educational opportunity to all students. 


\section{Elementary and Secondary Education Act}

Another significant educational reform, the 1965 Elementary and Secondary

Education Act (ESEA), established the federal role in defining the nation's educational priorities (Kantor 1991; Urban and Wagoner 2009). A centerpiece of President Lyndon B. Johnson's War on Poverty, ESEA was passed to attack poverty by improving the educational opportunities for poor children and children who had been educationally disadvantaged (Kantor 1991). The education of African Americans and other minority students in cities was considered to be extremely substandard. These schools faced high numbers of early dropouts and were disadvantaged from the start (Kozol 1992). The Act's primary role was to supply states and local school districts with funding to provide poor children with much needed tools to earn a better income through education (Kantor 1991; Michelman 2012). It was the hope of the President and policymakers that this reform would encourage schools to change the way they functioned to assure that all students, particularly poor and disadvantaged students, would receive a quality education (Urban and Wagoner 2009). They believed that education was the vehicle to future opportunities for social mobility and that federal government funding would be a sufficient enough incentive to motivate schools to provide the neediest students the additional help necessary to benefit from those opportunities for social mobility (2009). The ESEA essentially required that school districts treat disadvantaged students more equitably (Kantor 1991; Michelman 2012).

The majority of the funds were appropriated to various Title I programs geared towards the needs of educationally disadvantaged children (Kantor 1991; Urban and Wagoner 2009). Instead of providing an adequate amount of funds to the most 
impoverished school districts, funding was provided to nearly all school districts since most served some students living in poverty. Equal opportunity was to be provided through the already established universal education system (Kantor 1991). However, many districts used the money to create separate programs for eligible students, pulling students out of class for remedial learning (1991). Instead of institutional change, minimal changes occurred within schools and the day-to-day activities remained unchanged. Since there was no incentive for widespread institutional change, local school districts focused on their own agendas. The ESEA claimed that school districts that were unable to provide an adequate education to its impoverished students would be able to do so if provided with additional funds (1991). The belief that schools could be reformed from within, without mandating change to pedagogy, procedure or school organization left ESEA very weak in its ability to produce major system wide change (1991).

The act was meant to combat the culture of poverty by improving the education of disadvantaged students. Low income students were targeted for additional resources such as funds to improve teacher quality, parental involvement and educational outcomes (Urban and Wagoner 2009). It also included standards to push districts toward more equitable treatment of disadvantaged students who had largely been treated like all other students prior to the passing of ESEA (Kantor 1991; Michelman 2012). The act was meant to create programs specifically for educationally deprived students, but it had little effect on these students' academic outcomes (Kantor 1991). Like the Brown decision, ESEA tried to avoid disturbing the status quo and was ultimately ineffective in improving the educational disparities of economically disadvantaged students (Kantor 1991). Focus 
was not placed in understanding and addressing the reasons low-income students were disadvantaged in schools. There was no concern for labor market discrimination or income inequality.

Independent studies of ESEA's effectiveness found it did not significantly improve student achievement (Kantor 1991). The act became associated with deficient students instead of deficient schools (Valverde 2004). Additionally, minorities became synonymous with deficient students. Therefore the act's programs were devalued and emphasized remediation instead of enrichment (2004). Lee Rainwater argued that the class problem could not be addressed or ameliorated in isolation from the social, economic, and ecological setting that produced it (Kantor 1991). An attack on poverty that only emphasizes changing the individuals facing it and not the society that produced and perpetuated it, can never truly alleviate the problem (Marshall and Gerstl-Pepin 2005). Even if a child receives a better education through the funding provided by ESEA, without the destruction of the stigma that consumes individuals in poverty, progress and change remain a mirage for most of these individuals. The ESEA made the education of the children of the poor a national priority but it did not actually require schools to change much about their routine (Kantor 1991). It was not until ESEA was reauthorized, almost forty years later in 2002, as the No Child Left Behind Act (NCLB), that the federal role in education shifted from strictly financial funding for low-income students to a larger role in shaping the goals and outcomes of the education system (Finn and Hess 2004; Fusarelli 2004; Arce et al. 2005; Michelman 2012). 


\section{No Child Left Behind Act}

The No Child Left Behind Act set out to raise the achievement levels of disadvantaged students and close the achievement gap between diverse races/ethnicities and classes (Fix and Capps 2005; Darling-Hammond 2007). It required that all students have access to high academic standards and highly qualified teachers (Arce et al. 2005; Darling-Hammond 2007). Expanding alternative educational choices through school choice policy also played a large role in this process (Ravitch 2013). While ESEA focused on improving students' assigned schools, NCLB required that parents have more freedom to choose alternative schooling options. School choice policy utilizes competition to encourage schools to make the necessary changes to keep students (Moe 2008; Ben-Porath 2009; Ravitch 2013).

The NCLB Act placed emphasis on the need to improve access to quality education for all students, especially those who had been lacking it for so long, such as minority, low-income and limited English proficient (LEP) students (Fix and Capps 2005). Schools submitted an annual report documenting their Adequate Yearly Progress (AYP). If they were unable to reach high achievement for all student subgroups, schools were labeled failing even if the school had high achievement overall and was making improvements (Darling-Hammond 2007; Sims 2013). Students are grouped by racial, ethnic, economic and special needs backgrounds. The policy attempted to focus on the neediest students (Fusarelli 2004; Fix and Capp 2005). Since data are disaggregated by student subgroups, low-performing students no longer could fall between the cracks (Fusarelli 2004). 
The NCLB Act required transparency of schools, faculty and staff, students and school districts (Michael and Dorn 2007). School performance was made public so that parents would be more informed about their children's school and the other school options in their area (Fusarelli 2004). The result was an increase of information made available to parents so that they could make a more informed decision whether to keep their child in a particular school or use school choice options to seek alternative schooling. Students attending habitually failing schools were offered an opportunity to transfer to non-failing schools (Darling-Hammond 2007; Ravitch 2010).

Just like opponents of NCLB feared, the policy lead to a widening of the achievement gap, teachers leaving schools labeled failing, private schooling options replacing failing schools, and the curriculum being narrowed to tested subjects (Neal and Schanzenbach 2010; Davidson et al. 2012; Michelman 2012; Ravitch 2013). With NCLB, all race/ethnicity and economic target groups were required to make the AYP benchmarks outlined in the accountability reports for the school to make AYP goals. Therefore, the more subgroups a school had, the harder it was to meet requirements, which proved to be a problem for schools who serve the neediest students (DarlingHammond 2007; Hernández 2013).

The NCLB Act also mandated that teachers must be well trained and perform at a high level of excellence. Michelman (2012) found that the high quality teacher mandate did not improve teacher quality. Since quality teachers are inequitably distributed throughout the school system, some states lowered the standards for teachers to meet the demand (Darling-Hammond 2007). Additionally, as more schools were identified as 
failing because of their inability to meet AYP guidelines, teacher turnover rates increased because no one wants to remain at a failing school (Davidson et al. 2012).

The testing and accountability requirement of NCLB resulted in states lowering standards and 'dumbing' down their curriculum and tests so that more students could exhibit adequate yearly progress towards the ultimate goal of proficiency (Neal and Schanzenbach 2010; Ravitch 2010; Davidson et al 2012; Michelman 2012). Some states pushed low-performing students into special education classes and GED programs (Finn and Hess 2004; Salinas 2006). As a result of the amount of weight given to the subjects that were tested, teachers felt pressured to spend considerable amounts of time on preparing students for state tests and often times ignored untested subjects all together (Hursh and Martina 2003; Davidson et al 2012; Dee et al 2012). Additionally, testing has resulted in a narrowing of the curriculum to tested subject areas, resulting in a decline in the overall quality of schooling for most students (Darling-Hammond 2004; Finn and Hess 2004; Salinas 2006).

One of the primary criticisms of NCLB is that school performance focused on a single indicator, a standardized test (Michelman 2012). In a study conducted of the Chicago Public Schools, Neal and Schanzenbach (2010) found that with accountability systems emphasizing proficiency, schools focused primarily on the bubble students, those who were close to reaching proficiency. Schools ignored students who they believed would not reach proficiency with intervention. Schools also ignored students who they believed could reach proficiency without intervention. With this type of accountability system in place, NCLB was not linked to student learning but to the accountability 
system itself (Ravitch 2010; Davidson et al 2012). Ravitch (2010) argues that NCLB allowed testing to replace the curriculum. States were given full control of creating their accountability systems. However, there was little federal oversight of the validity or reliability of the measures being used (Weiss and May 2012). Although rating schools using an "A-F” grading system provided an easy means for parents to evaluate school quality, school grades were not always the most accurate measure of school quality and could provide more favorable results that were not true (Weiss and May 2012; Polikoff et al 2013).

The NCLB Act set an unattainable goal of $100 \%$ of students proficient at grade level by 2014 (Ravitch 2010; Michelman 2012). The remedies have produced modest gains and there is no evidence these remedies can help turnaround low-performing schools (Ravitch 2010; Ravitch 2013). The NCLB Act “assumed that higher test scores on standardized tests of basic skills are synonymous with good education (Ravitch 2010, p 11).” Although the many issues with NCLB's structure and accountability system have produced many ill-effects with only modest gains, it still continues to play a major part of the way the education system functions. In an attempt to improve the act and alleviate some of the pressure on schools to reach its unattainable goal, in 2011 the federal government offered states the opportunity to apply for a waiver program that would give them flexibility for the NCLB requirements "in exchange for rigorous and comprehensive state-developed plans designed to improve educational outcomes for all students, close achievement gaps, increase equity, and improve the quality of instruction (USDOE).” Currently 45 states, the District of Columbia, and Puerto Rico have been approved for flexibility waivers. 
Flexibility was granted to states with four principles required in exchange (Polikoff et al. 2013). States must first identify which subject areas they will assess, outline new annual measurable objectives that result in 100\% of students becoming proficient at grade level by the 2019-2020 school year, determine how they will include subgroups in their accountability policy and lastly, outline their evaluation plan (Polikoff et al 2013). Like NCLB, waivers are test driven and the curriculum will account for that. Hernández (2013) argues that the new requirements of waivers is not sufficient to assure students in various racial/ethnic, economic, and special needs subgroups will not fall through the cracks. Polikoff and his coauthors (2013) conclude that "overall, the waivers provide a mixed bag of improvements over, and duplications of, the problems of NCLB.” They also recommend that the waiver program avoid following the same path as NCLB. The issues with NCLB were known but no changes were made to alleviate them. With the waiver program, Polikoff and his coauthors (2013) recommend reviewing its effectiveness and making adjustments as needed.

The market based, test-driven tenants of NCLB continue to permeate education reform. In another attempt to fix some of the damages caused by NCLB, the federal government introduced the Race to the Top competition in 2009 (USDOE 2009). Race to the Top provided billions of dollars to states that were implementing and achieving the outcomes the federal government felt were most pertinent to improved student achievement (USDOE 2009; Ravitch 2013). These included implementing innovative reform, achieving significant improvements in student achievement on standardized tests, closing achievement gaps, improving high school graduation, preparing students for success in college and careers and implementing a common core curriculum (USDOE 
2009; Ravitch 2013). Ravitch (2013) argues that Race to the Top allows the federal government to attach money to the common core reform structure, something the feds could not do with NCLB. Additionally, she argues that Race to the Top is built on the same assumptions as NCLB with unrealistic goals such as students improving test scores annually (Ravitch 2013).

Common core has become an integral part of the nation's current education reform (Hess and McShane 2013). It raises standards from basic proficiency to college and career readiness. Critics argue it will be too expensive to implement without the funds provided through Race to the Top (Ravitch 2013). While all states will not receive reward funds through this competition, states are attempting to implement common core in hopes of being awarded funds in the future (Ravitch 2013). Common core will require a new curriculum that aligns with new tests, just as NCLB did when it was implemented (Hess and McShane 2013; Ravitch 2013). As long as education reform continues to ignore the mistakes of its antecedents, it will continue to struggle to provide high performing schools to all students and achieve the goal of $100 \%$ of students proficient at grade level.

School choice policy has not attempted to sidestep the mistakes of past reforms so it has produced some of the same undesired results. However, like NCLB, choice is still very much a significant part of the education system and is actually growing and evolving in many ways. Although research has shown that many low-income and minority students still fail to access high achieving schools even with expanded school choice, more research is needed to better understand why and understand what needs to be done to establish equality in access to quality educational opportunities. Even less is known 
about the students served by low-performing schools, the very students who market theory would expect to be first in line to use school choice options. An overview of school choice literature will illustrate these points. The next section provides an overview of the school choice literature. It focuses on the behavior of schools in the educational marketplace, parent involvement in schools and parent decision making as it relates to school choice options.

\section{School Choice Policy}

Market driven school reform that is focused on choice and competition was first introduced in the 1950s and 60s by Milton Friedman as a potential way to restructure the education system (Lubienski 2005; Moe 2008; Ravitch 2010; Loeb et al. 2011). He argued it would empower people to make choices by increasing competition in the educational marketplace. He believed voluntary and individual choices would improve both the demand and supply side of education with parents making the best schooling choices for their children (Lubienski 2005; Ravitch 2013; Loeb et al. 2011). Today, there is some form of school choice policy in nearly all states (Hoxby 2003; Lander and Lips 2008). Much like Friedman's market driven school reform ideas, current school choice policy creates an education market in which parents are provided more school options from which to choose and schools are put in a position to compete for their business (Moe 2008; Ben-Porath 2009; Ravitch 2013; Loeb et al. 2011).

Advocates of the market policy argue that the model gives all families an opportunity to receive a quality public school education at both traditional neighborhood public schools and new schools of choice, most of which are not restricted to any 
particular neighborhood (Moe 2008; Ben-Porath 2009; Ravitch 2013; Loeb et al. 2011). In the model, schools deemed inadequate will be forced to improve themselves for fear that students will seek alternative schooling options, taking their per-pupil expenditures with them (Cooper and Randall 2008). If schools are unable to improve, they may be forced to close as a result of low student enrollment. While this is rare, the threat of closure is a fear that school administrators believe is real and efforts to combat that threat have been effective in raising student achievement in some cases (Holme et al. 2013). Public school choice policy seeks to provide alternative schooling options to all families, improve the academic achievement of all schools and give parents more control of the school their child attends (Goyette 2008; Moe 2008; Ben-Porath 2009; Lubienski et al. 2009). Choice policy has increased in popularity over the last two decades. There is great support from both conservatives and liberals about the ability of school choice options to improve the education system (Loeb et al. 2011; Ravitch 2013).

School choice policy acknowledges that not all students have access to quality education. However, the market takes for granted that all parents are equally informed and capable of making the best schooling choice for their children. Critics argue that choice has only produced modest effects on student achievement (Loeb et al. 2011; Toma and Zimmer 2012; Zimmer et al. 2012; Ravitch 2013). Additionally, evidence suggests that choice is not equally available to all students (Deluca and Rosenblatt 2010; Ravitch 2010; Horn et al. 2014). Moe (2008) and Ben-Porath (2009) fault the structure of choice programs for failure to achieve desirable results. With the current structure of choice programs, the notion of real access to alternative schooling options with high academic 
achievement for all families appears to be an improbable one. According to Michael Apple (2001, p. xxii), market driven school policy “will place price tags on schools so that the market can function. The private sector for the affluent will expand and there will be a fiction of choice for the poor and working class.” Over a decade later, the evidence about school choice improving education for low-income students continues to support Apple’s early assertion (Loeb et al. 2011; Toma and Zimmer 2012; Ravitch 2013).

\section{The Education Marketplace}

Charter schools are the fastest growing market driven reform in the country (Zimmer et al. 2012). They are publicly funded schools that can be run by individuals or various organizations including school districts, private companies and community leaders (Ravitch 2010; Toma and Zimmer 2012). The first charter school law was passed in Minnesota and provided alternative educational programs to a diverse population of students (Bulkley and Fisler 2003; Ravitch 2010). Some charter schools serve predominately urban and at-risk students, while others cater to a more affluent white student population (Bulkley and Fisler 2003; Ravitch 2010). Many charter schools can be found in urban districts where academic performance in traditional public schools is low and there is a greater demand for alternative schooling options (Ravitch 2010). However, Ravitch (2010) found that in many situations, charters avoid serving the neediest students. They can pick motivated students and enforce a strict code of discipline (Ravitch 2010). However, Zimmer and Guarino (2013) found no evidence that charter schools exclude low-performing students. Charter students transferred at a rate similar to students of their academic achievement level in traditional public schools (Zimmer and 
Guarino 2013). Lubienski and his coauthors (2009) found evidence that some charter schools in Washington, D.C., along with private schools catered to underserved communities.

In an evaluation of schools of choice in Detroit, Lubienski (2005) found that even though students were allowed to attend any school regardless of residency, inner-city students, many of whom were African-American, were excluded from suburban school options. Students were excluded on the basis of their residency; non-resident students were simply excluded from suburban schools because they lived outside the county. The exclusionary practices were not mandated by Michigan school choice policy, but a practice carried out by individual districts (Lubienski 2005). Lubienski (2005) suggested the exclusionary practices illustrated these students' status within the local market hierarchy, which placed them towards the bottom. They were overlooked for a more preferred student from more economically resourceful neighborhoods. Additionally, the study found that success in the market, which was measured by producing high achievement, dictated behavior, not equality of educational opportunity. The schools' locations resulted in the best choices being less available to poor students and students of color; options were unequally distributed and shaped by race, geography and policy barriers.

Lubienski and his coauthors (2009) also found exclusionary district practices in another comparative study on Detroit, New Orleans, and Washington, D.C., in which all of the schools in the study positioned themselves, geographically, in areas to exclude high need areas. There was no leveling of the playing field in any of the locations. In 
Detroit, profit oriented charter schools located in more affluent neighborhoods to cater to a preferred population (Lubienski et al. 2009). These students were believed to produce high scores on state tests and demonstrate high achievement for the school. In New Orleans, schools focused on maintaining an advanced market position by using favorable locational and admission strategies which effectively excluded high-need areas. The majority of the schools in the study by Lubienski and his coauthors (2009) positioned themselves in areas to exclude high need areas. Their locations put them closer to more advantaged students and limited access to high need more disadvantaged students. These students rarely had the means to consider these schools as realistic options. The authors illustrated how new schools located themselves along a ring bordering the more advantageous neighborhoods, situated just out of reach of most of the highest need students (Lubienski et al. 2009).

Another exclusionary practice, ability skimming, which refers to giving preference to the top performing students, has also been found to disadvantage high need students (Lacireno-Paquet et al. 2002). Betebenner and his coauthors (2005) found, in a study in a large western school district, that there was skimming by ability with high achieving students being the primary choosers. With low-income students disproportionately affected by low-performing schools, these high achieving students are less likely to be from poor or working class families. Goldhaber and Eide (2002) also found, in a study done on Chicago high school students, that high ability students were the primary choosers. 
The actions of schools and school districts were not the only factors that contributed to schools of choice being a mirage for many poor and working class families. Parents' resources and school selection processes were found to be particularly influential to these students access to schools of choice (Teske et al. 2007). The school choice decision making process requires an investment of time, money, and energy (Tedin and Weiher 2011). Low-income parents tend to have the least useful information, focus more on school familiarity than data on quality, and desire assistance during the school choice decision making process when compared to parents of moderate incomes (Teske et al. 2007). However, given the control to make a schooling choice empowers parents and can lead to more parent involvement which is positively associated with improved student achievement (Lee and Bowen 2006; Kuperminc et al. 2008). It is important that school-choice programs make more attempts to provide resources to lowincome families to assist with the decision making process (Ben-Porath 2009; Tedin and Weiher 2011).

Using an ethnographic study, Bartlett and his coauthors (2002) illustrated how an elite group of North Carolina citizens fought for school choice to be used for the advancement of their children. The economic expansion was promoted and made accessible by a privileged group of middle-class elites determined to give their children an edge in the competitive global economy. They argued that the marketization of education in North Carolina harmed the working class and minority population because they were excluded from the options made available through the market. 
The market model of school choice requires that parents become involved with their child's school. In the past, parent involvement focused on attending school events, interacting with teachers and volunteering at the school (Desimone 1999; Lee and Bowen 2006). In today's education market, parents select schools, which often times requires them to access information from alternative schooling options through school personnel, attending recruitment events, or online. The new model of school selection is very different from how parents were involved in their child's education in the past. Prior to school choice, parents had limited alternative schooling options. These included private schools or moving into the school zone of the school they wanted their child to attend. With school choice, parents have even more incentive to get involved in their child's school so that they can fully assess its compatibility to their child's needs. The next section provides an overview of parent involvement literature. It focuses on how parents have interacted with schools in the past and the benefits of parent involvement to students’ academic achievement.

\section{Parent Involvement}

Parent involvement takes many forms, ranging from reading with your children at home to attending Parent Teacher Association (PTA) meetings at your children’s school. The effects of parent involvement also takes many forms, ranging from improved student achievement on standardized tests to improved teacher expectations, which, in turn, can have positive effects on a student's achievement and attainment (Desimone 1999; Lee and Bowen 2006; Kuperminc et al. 2008). Parents must perceive involvement as part of their responsibilities as parents. They must feel confident in their ability to be involved 
parents and their ability to positively influence their children's educational achievement. Many parents initiate the collaboration between family and school while many others, for various reasons, do not. Some parents do not feel comfortable in the school setting and some do not feel they have the capacity to work with school personnel (Reay 1996).

Parent involvement, both at home and at school, provides crucial benefits passed on to their children to give them an added advantage in school (Desimone 1999; Lee and Bowen 2006; Kuperminc et al. 2008). The benefits of parent involvement range from higher student attendance to higher parent satisfaction and higher achievement in math and reading (Hiatt-Michael 2008). Parent involvement includes attending school activities, meeting with the child's teacher, volunteering, participating in PTA, and maintaining an active role in the child's education at home, such as overseeing homework and reading (Lee and Bowen 2006; Kuperminc et al. 2008).

Lee and Bowen (2006) examined the level and impact of different types of parent involvement between various racial/ethnic groups with varying income levels and the effect of cultural capital. The dominant culture, defined as middle class European American, is compared with the non-dominant culture, classified as minority and/or lowincome. Lee and Bowen's (2006) study illustrates the disadvantage that families of the non-dominant culture experience when trying to do their part as parents and get involved in their children's education. Often times there are dissimilarity between what teachers expect from parents and what parents are doing at home and how they engage with the school. Lee and Bowen (2006) found that the expectations for parent involvement of the 
dominant culture corresponded with that of the school, putting these families at an advantage and the families of the non-dominant culture at a disadvantage.

Some parents are disadvantaged by the way that parent involvement opportunities at the school are structured (Lee and Bowen 2006; Kuperminc et al. 2008). They face constraints which include lack of childcare, inflexible work hours and limited access to transportation (Lee and Bowen 2006; Kuperminc et al. 2008). Communication helps both parents and school personnel to understand what is expected and what is realistic (Berger 1991). By addressing such constraints and making parent involvement more convenient, school administrators can increase the probability of parental involvement in the schools (Desimone 1999). By getting involved, parents not only benefit from the resources obtained from school personnel but also from other parents that they may meet at the school (Lee and Bowen 2006). The relationships and resources gained from connections with other parents may prove even more useful than those with school personnel (Goldring and Phillips 2008).

\section{Making Schooling Decisions: Parents’ Role in School Choice}

The parent role in school choice goes beyond what has been considered good parent involvement in the past. School choice requires parents to research schooling options, visit potential schools, talk to school faculty and staff, complete application forms, and in some cases advocate for their child to be placed in a particular school (Teske et al. 2007; Ravitch 2010; Tedin and Weiher 2011). The expanded role for parents demonstrates the varied ability of parents to navigate the educational landscape that is the 
American public education system (Bartlett et al. 2002; Campbell et al. 2005; Lee and Bowen 2006; Teske et al. 2007).

Most parents make school choice decisions from a small set of realistic options (Teske et al. 2007; Ben-Porath 2009). Parents consider a number of factors when evaluating their options (Teske et al. 2007). These factors include but are not limited to, location, academic achievement, student demographics, safety, and the academic programs offered. According to the literature, all of these factors have strong correlations to parents' social class characteristics and parents' access to social capital (Ball 1993; Schneider et al. 1997; Weidner and Herrington 2006; Teske et al. 2007). Parents’ social class and access to social capital are the primary factors that account for the variation in the use of school choice options among parents.

\section{Parent Social Class}

Social class has long been an essential theoretical concept for the evaluation of individuals within societies. Various social scientists have used it to illuminate the social structure of societies, illustrate inequities, and demonstrate the social relations that link individuals within a social structure (Tucker et al. 1978; Gerth and Mills 1958; Wright 1996). In education literature, it has been used to illustrate the power structure within schools and educational stratification (Bowles 1971; Collins 1971; Karabel and Halesey 1977; MacLeod 2009).Coleman (1988) found that parents' social class is correlated with student academic achievement and attainment. Social class has also proven to be a crucial factor to consider in studies of school choice (Bartlett et al. 2002; Bulman 2004; Teske et al. 2007; Ravitch 2013). 
A parent's social class consists of variables associated to education, income and occupation. As the catalyst in the school choice process, parents' capacity to navigate the school choice landscape is crucial to their ability to access alternative schooling options for their children. Academic attainment is at the forefront of that ability. The school choice decision-making process requires that parents research and understand whether their child is qualified to use school choice options, what options are available and the characteristics of those options (Howell 2006; Teske et al. 2007; Tedin and Weiher 2011). Parents' education level has been found to be influential in a parent's ability to work through school information to make a decision regarding schooling (Lee and Bowen 2006; Teske et al. 2007; Ben-Porath 2009). However, parents are resourceful and even with less information and being less informed, parents can still successfully choose an appropriate school for their children (Teske et al. 2007). But more must be done to provide accurate and comprehensive information to assist all parents in their decision making process (Ben-Porath 2009).

In school-choice research, income is also important because it is associated with the amount of time parents have for collecting information about various schools. Schools of choice often open their doors to prospective parents for recruitment meetings, tours, and informational sessions. However, since these events vary in time and day of the week, parents will not always be able to take advantage. Parents' with less income would be expected to be less likely to be able to visit as many schools as those with higher income because they might not have transportation, child care for younger 
children or the ability to miss time from work to attend (Lee and Bowen 2006;

Kuperminc et al. 2008).

Parents' occupation is influenced by their education and is directly linked to income, making it a key component of social class (Collins 1971). Although occupation is scarcely mentioned in the school choice literature, some studies illustrate how a parents' occupation can constrain the use of school choice because of time and convenience (Bulman 2004; Bell 2007). Additionally, parents’ occupation can influence their access to quality social networks useful in making schooling decisions (Horvat et al. 2003). These social networks can provide quality information about schooling options, navigating the education marketplace and various other resources useful to parent decision making.

In a study of parent decision making, Teske and his coauthors (2007) found that there are many similarities among most parents who utilize school choice options. However, low-income parents, those with income less than $\$ 20,000$, had noticeable differences from parents with moderate incomes. Low-income parents had less useful information, focused their decision more on school familiarity than data, and were less satisfied with their chosen schools (Teske et al. 2007). While proximity was important to most parents, low-income parents were more likely to pick proximity as their primary factor for choosing a school. There were also differences based on education level. Sixty percent of parents with a high school education or less made their school choice decision solely on the basis of location compared to less than $30 \%$ of parents with a college 
education (Teske et al. 2007). However, there were no differences associated with race/ethnicity or socio-economic status.

\section{Parent Social Capital}

Social capital can be defined as the aggregate of the resources that are linked to social networks, relationships and interactions that can be activated by individuals or communities and used to achieve some goal (Bourdieu 1986; Coleman 1988). These social networks can take many forms and provide a number of benefits to the individuals within them. Social networks and parent participation have proven particularly influential to parents’ school choice decision-making (Bulman 2004; Bell 2007; Goldring and Phillips 2008). Social capital, which is influenced by social class, is directly linked to how parents make school choice decisions and their ability to use those schooling choices (Bulman 2004; Bell 2007; Goldring and Phillips 2008). Research has shown that high social class status is positively associated with the number of social networks a parent has, the quality of those social networks and parent participation in school activities (Schneider et al. 1997; Horvat et al. 2003; Lee and Bowen 2006).

Social networks have been extremely useful to parents making school choice decisions and for parents needing assistance in transporting their children to alternative schooling options (Bell 2007; Teske et al. 2007; Goldring and Phillips 2008). Goldring and Phillips (2008) differentiate social networks into two groups: interpersonal networks and formal networks. Interpersonal networks include neighbors, friends, family and coworkers. An interpersonal network is one of the primary means for parents to access information regarding school choice options (Goldring and Phillips 2008). Formal 
networks refer to institutionalized resources for the acquisition of information such as websites, brochures, published school information and school personnel. Since the majority of parents use formal networks less often than they use informal networks, the quality of the information on which to base school choice decisions is not always high (Neild 2005; Goldring and Phillips 2008). However, Teske and his coauthors (2007) found that parents were able to make the right school choice match for their child with the limited quality information they had.

Parents' participation in school related activities influences the number of social networks they have and the quality of those networks (Horvat et al. 2003; Lee and Bowen 2006). Many studies illustrate the importance of parent involvement in their child's education (Desimone 1999; Lee and Bowen 2006; Kuperminc et al. 2008). Parent participation at their child's school gives them access to interpersonal and formal social networks (Lee and Bowen 2006; Goldring and Phillips 2008). These networks can provide the necessary resources to make school choice decisions and can improve a parents' ability to use school choice options. Bulman (2004) illustrated how social networks have helped to expand parents' schooling options. When parents can call on friends to assist with transportation or to provide quality information about a school's academic programs, they can consider more schools using quality information and are more likely to choose the school they really want their child to attend.

In a study of parent school choice decision making, Teske and his coauthors (2007) found that although most parents felt well informed, parents making less than $\$ 20,000$ annually felt they needed assistance, preferably from a school counselor; these 
parents were less likely to have other parents as trusted sources (Teske et al. 2007).

Parents who made less than $\$ 20,000$ annually also had smaller and less useful social networks than parents with an annual income that was higher than $\$ 20,000$. The network disparity put these parents at a great disadvantage because the study also found that the most important source for all parents was word of mouth. A lack of trusted, informed sources in ones social network makes the school choice process more difficult. Without the assistance of informal resources such as other parents, friend or family, low-income parents would have to rely solely on formal resources such as school personnel or information on the internet. Information through formal sources can sometimes be more difficult to find and can be overwhelming for parents because of their lack of access to technology, computer skills, or knowledge of how to access information from their child's school district (Schneider et al. 1997).

The national effort to expand equal educational opportunity to all students has been a long and difficult process. By focusing solely on fixing problems in the education system and ignoring the broad social issues outside that system, major education policies have struggled to be effective. Disregard for economic and social issues has hindered policies' full implementation, enforcement of policies, and evaluation of effects (Kantor 1991; Fusarelli 2004; Guthrie and Spinger 2004; Urban and Wagoner 2009). Additionally, recent reforms, including school choice have not tested the assumptions about student learning and improving low-performing school, which have been largely ineffective to date (Davidson et al. 2012; Hansen 2012; Polikoff et al. 2013; Ravitch 2013). School choice reform has the potential to benefit all students. However, students 
served by low-performing schools can benefit the most by gaining access to higher quality schooling options or seeing improvement in the quality of their current school as a result of competition.

The subsequent chapters will focus on the Florida school choice policy and what it offers parents and students. They will evaluate the constraints that parents of students served by low-performing schools face when making decisions about where their child will attend school and the constraints they face in getting their child to the chosen school. These parents are constrained by limited quality information, small social networks with limited knowledge of choice policy, and the logistics of changing schools. Analyses of parent interview data and student data provide an overview of how families served by low-performing schools in Miami, Florida navigate the school choice process. The unmet needs of these families provide areas for policy improvement and the greater expansion of equal educational opportunities. 


\section{The Local Context: State School Choice Policy and County Programs}

An important aspect of the present study is the examination of the way local programs mesh with state policy. Title XLVIII, K-20 Education Code, of the Florida State Statutes provides a blueprint of the programs that local school districts must provide to parents and the standards they must meet. As illustrated in the literature review chapter, current school-choice policy creates an education market in which parents are provided more school options from which to choose and schools are put in a position to compete for parents’ business (Schneider et al. 1997; Bartlett et al. 2002). Public school choice policy seeks to improve the academic achievement of all schools, gives parents more control of the school their child attends using a competitive educational market and provide a wide selection of alternative schooling options to all families (Buckley and Schneider 2003; Goyette 2008; Lubienski et al. 2009). Chapter III examines how these objectives of Florida’s school choice policy are fulfilled by Miami-Dade County’s school choice programs.

Improving School Academic Performance

Schools of choice are expected to improve upon the quality of education already being offered at other public schools. By providing better academic programs and learning environments, schools of choice can challenge other schools to improve (Schneider et al. 1997; Bartlett et al. 2002). If traditional public schools cannot measure up to the quality of schools of choice, they risk losing current students and become unable to attract new ones. Florida attempts to improve school academic performance through the school choice options of developmental research schools and charter schools. 
According to Florida State $§ 1002.32$, the purpose of developmental research schools "is to enhance instruction in” math, science, computer science and foreign language (Florida State $\S 1002.32\{2012\}$ ). Developmental research schools are affiliated with a college of education within a state university. In addition to enhancing instruction, these schools must also enhance research, demonstration and evaluation. They are tasked with studying a problem facing the public school system.

According to Florida State §1002.33, charter schools are public schools that must “improve student learning and academic achievement (Florida State § 1002.33 \{2012\})." In addition to meeting the same high standards of academic achievement that all public schools must strive for, charter schools are required to do more. These schools must also “increase learning opportunities for all students, with special emphasis on lowperforming students and reading. Encourage the use of innovative learning methods (Florida State $\S 1002.33$ \{2012\}).” As mentioned in the previous chapter, while charter schools are public schools, they differ from traditional public schools. Although they are under the authority of the school district, they are not operated by the local school district (Florida State § 1002.33 \{2012\}; Bulkley and Fisler 2003). Instead, charter schools are typically operated by a group of parents, teachers, municipalities, institutions, universities and/or a combination of more than one group (MDCPSb). Charter schools are afforded more freedom and flexibility than traditional public schools to operate in a way that best meets the needs of their students (Bulkley and Fisler 2003). However, charter school students are still required to take standardized tests like traditional public school students (Cooper and Randall 2008). 
In keeping with the objective of the state policy, Miami-Dade County's school choice programs strive to improve school academic performance by offering a large selection of charter schools (FLDOE 2014; MDCPSa). While the County does not have any developmental research schools, it offers the largest selection of charter schools in the state (FLDOE 2014; MDCPSa). By offering a variety of innovative programs, charter schools provide alternatives that may better serve certain students compared to traditional public schools. While charters schools are available to all students, they are especially expected to address the needs of low-performing students. At a national level, these schools have historically served minority, low-income and special needs students (Bulkley and Fisler 2003; Lubienski et al. 2009). According to Miami-Dade County, charter schools are effective because they "allow teachers and principals to respond immediately and accurately to specific educational needs within a community (MDCPSb).”

Held to a higher standard, charter schools must produce passing state grades or risk being closed. Traditional schools are rarely faced with such a solution to poor academic quality. Twenty-nine charter schools have been closed in Miami Dade County since 2001 (FLDOE 2013). Charter schools are typically closed because of failing state grades and/or financial instability. Charter schools are also responsible for keeping their finances in order. Table 1 illustrates the school grade differences between charter and traditional schools in Miami-Dade County for the 2012-2013 school year (FLDOE 2013a). These numbers include elementary, middle, high, and combination schools. Seventeen percent of schools were excluded from the table because they either had no 
grade, an incomplete, or a pending grade. Seventy-eight percent of the schools excluded were high schools. Table 1 illustrates that the majority of charter schools, $41 \%$, were A schools compared to $28 \%$ of traditional schools that were A schools. Both charter and traditional public schools had 17\% of their schools designated as D or F schools.

Table 1. 2013 Miami-Dade County School Grades

Traditional

Public Schools Charter Schools

\begin{tabular}{lrrrr}
\hline School Grade & $\mathrm{N}$ & $\%$ & $\mathrm{~N}$ & $\%$ \\
\hline $\mathrm{A}$ & 199 & $28 \%$ & 66 & $41 \%$ \\
$\mathrm{~B}$ & 194 & $28 \%$ & 30 & $19 \%$ \\
$\mathrm{C}$ & 190 & $27 \%$ & 37 & $23 \%$ \\
$\mathrm{D}$ & 91 & $13 \%$ & 15 & $9 \%$ \\
$\mathrm{~F}$ & 25 & $4 \%$ & 12 & $8 \%$ \\
\hline
\end{tabular}

Source. 2013 School Grades (FLDOE 2013a)

In addition to improving academic achievement by creating new school opportunities and programs, school choice policy also includes provisions to provide resources to enhance student learning. These resources include the Opportunity and Tax Credit Scholarships (Florida State $§ 1002.38$ \{2012\}; Florida State $§ 1002.395\{2012\}$ ). They allow students to seek a better education at a different public or private school. Faced with the threat of losing students through these avenues, it is the hope of policymakers that all schools will improve the quality of their academic programs (Schneider et al. 1997; Goldhaber and Eide 2002; Goyette 2008). The “opportunity scholarship program’s purpose is to provide enhanced opportunity for students in [the] state to gain the knowledge and skills necessary for postsecondary education, a career education, or the world of work (Florida State $\S 1002.38$ \{2012\}).” The opportunity scholarship program allows students attending failing schools to seek alternative 
schooling options at the expense of the district. Eligible students must be currently enrolled or assigned to an " $F$ " school or a school that has received a grade of " $D$ " for three consecutive years. Students can use these scholarships through their completion of high school. Parents must select a high-performing alternative school with a grade no lower than a "C".

During the 2012-13 school year, 3,649 students throughout the state of Florida utilized the Opportunity Scholarship Program (FLDOE 2013b). The program is primarily used by high school students who account for $61 \%$ of the total scholarships awarded (FLDOE 2013b). Tables 2 and 3 illustrate the demographic breakdown of users of this option.

Table 2. Race/Ethnicity Breakdown for Opportunity Scholarships in Florida 2012 - 2013

\begin{tabular}{lrr} 
Race/Ethnicity & $\mathrm{N}$ & $\%$ \\
\hline White, Non-Hispanic & 657 & 18 \\
Black, Non-Hispanic & 2,299 & 63 \\
Hispanic & 547 & 15 \\
Others & 146 & 4 \\
\hline
\end{tabular}

Source. Opportunity Scholarship Program Fast Facts (FLDOE 2013b)

Table 3. Free/Reduced Lunch Status Breakdown for Opportunity Scholarships in Florida 2012 - 2013

\begin{tabular}{lrr}
\hline Lunch Status & $\mathrm{N}$ & $\%$ \\
\hline Free Lunch & 2,299 & 63 \\
Reduced Lunch & 292 & 8 \\
Did not apply & 1,022 & 28 \\
Not Eligible & 73 & 2 \\
\hline
\end{tabular}

Source. Opportunity Scholarship Program Fast

Facts (FLDOE 2013b) 
The “Florida Tax Credit Scholarship Program’s purpose is expanding educational opportunities and improving the quality of educational services within the state" (Florida State $\S 1002.395\{2012\})$. Like opportunity scholarships, tax credit scholarships are also meant to make sure all students can receive a high-quality education. The tax credit scholarship differs in that eligibility is not determined by the quality of the assigned school but on students’ economic disadvantage (Florida State § 1002.395 \{2012\}). Students must receive free or reduced lunch and be in elementary school to qualify. Scholarships can be used to pay for tuition and fees at an eligible private school or to pay for transportation to a public school located outside of the district.

Through the Florida Tax Credit Scholarship Program, children from families with limited financial resources are given an opportunity to seek a better education. The program is funded through private, voluntary contributions. Scholarship Funding Organizations (SFO) are non-profit organizations given the tasks of determining eligible students and issuing scholarships to these students (Florida State § 1002.395 \{2012\}). Eligible students include the following: children in foster care, students qualifying for Free or Reduced lunch who are entering kindergarten through fifth grade or the student's household income level does not exceed 230 percent of the federal poverty level (Florida State $\S 1002.395\{2012\}$ ). Parents of scholarship recipients must enroll their child in an eligible school and their child must remain in attendance for the entire school year.

For the 2012-13 school year, students enrolling in eligible private schools received scholarships of \$4,335 for tuition and fees (FLDOE 2013c). During the 2012-13 school year, 51,075 eligible students utilized the Tax Credit program to seek better 
schooling options (FLDOE 2013c). Students in Miami-Dade County accounted for 13,221 or $25.9 \%$ of the total students receiving tax credit scholarships in the state, during the 2012-13 school year (FLDOE 2013d). These students attended 273 different private schools throughout the county (FLDOE 2013d). Elementary students, kindergarten to fifth grade, accounted for $73 \%$ of students using the scholarship. Table 4 illustrates the demographic breakdown of the race/ethnicity of students throughout the state utilizing this program during the 2012-13 school year.

Table 4. Race/Ethnicity Breakdown for Florida Tax Credit Scholarship 2012 - 2013

\begin{tabular}{lrr}
\hline Race/Ethnicity & $\mathrm{N}$ & $\%$ \\
\hline White, Non-Hispanic & 12,751 & 25 \\
Black, Non-Hispanic & 16,909 & 33 \\
Hispanic & 17,718 & 35 \\
Others & 2,488 & 5 \\
Not Reported & 1,209 & 2 \\
\hline
\end{tabular}

Source. Florida Tax Credit Scholarship Program

June 2013 Quarterly Report (FLDOE 2013d)

\section{Expanding Competition for Students}

Proponents of school choice believe that the competition for students between schools will improve the overall academic achievement of all schools (Schneider et al. 1997; Bartlett et al. 2002). By having to compete for students, it is believed that schools will make the necessary improvements to offer high-quality education to prospective students (Schneider et al. 1997; Goldhaber and Eide 2002; Goyette 2008). Therefore, school choice policy often includes measures to expand competition among schools. Florida choice policy is no different. While there is no great emphasis on expanding 
competition and this objective is solely up to the local school district, the state policy does include it as a means for improving the quality of education throughout the state. The policy recognizes the potential for competition to encourage all schools to make the necessary changes to improve their students' academic achievement.

The provisions focused on charter schools and the tax credit scholarship program illustrates how competition can be beneficial. "Charter schools may provide rigorous competition within the public school district to stimulate continual improvement in all public schools (Florida State $\S 1002.33$ \{2012\}).” The key word is “may”. Competition is not a required function of charter schools but it is clear that state policy sees competition's potential to affect the quality of education offered at other public schools within the same district.

Miami-Dade County encourages competition for students by offering a variety of schooling options for parents throughout the county. Schools of choice are located throughout the county, giving parents options for magnet, charter, combination or traditional schools. Figure 1 illustrates the elementary public school options available throughout Miami-Dade County. Additionally, students who are eligible for a Tax Credit, McKay or Opportunity scholarship can use them to attend an alternative public or private school. By making all options available and assisting parents in utilizing these options, the county creates a competitive atmosphere in which schools must provide high quality education in order to keep their current students and attract new ones. Whether schools actually have to compete for students or alternative schooling options are simply alleviating overcrowding in other schools is beyond the scope of this study. Nevertheless, 
the interview analysis produced evidence that some parents will transfer their child from their assigned traditional school and place them in one of the aforementioned alternative schooling options if they feel the assigned school is not meeting the needs of their child. However, this was not the norm among interview subjects.

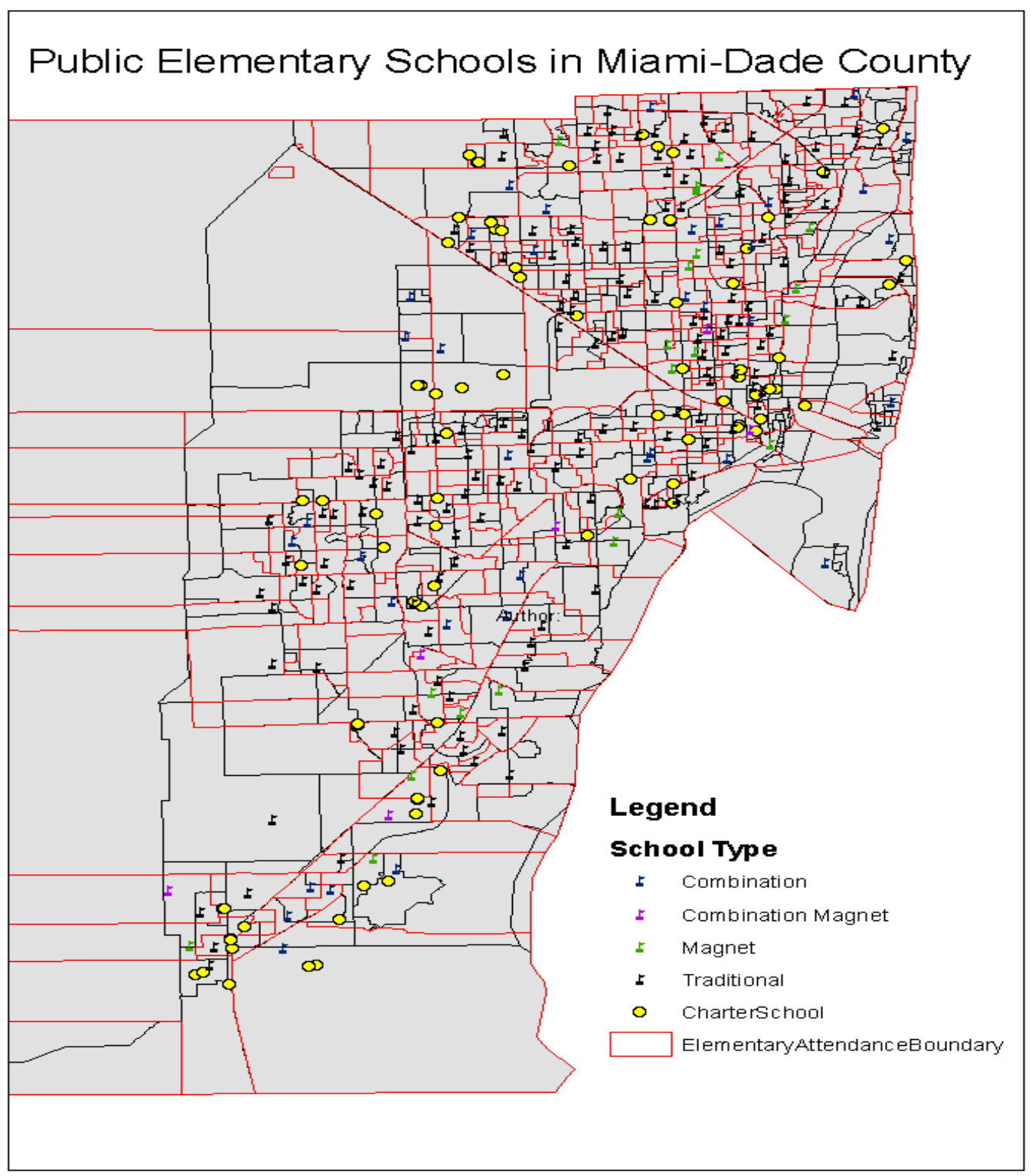

Figure 1 
Miami-Dade County charter schools attempt to expand competition for students by offering high-quality alternatives. As illustrated in Table 1, $60 \%$ of charter schools in the County are "A" or "B" schools. Additionally, by offering innovative and diverse academic programs, charter schools can provide something different from traditional schools. Miami-Dade County offers the largest selection of charter school options in the state of Florida (FLDOE 2014). By offering such a wide variety of schooling options, located throughout the County, the school district improves its local educational marketplace. The better the marketplace, the more ideal it is for competition.

In similar fashion, the provisions for the tax credit scholarship program illustrate how competition can affect schools within and outside the district. These scholarships, by expanding education opportunities, promote "healthy competition critical to improving the quality of education in the state (Florida State $\S 1002.395$ \{2012\}).” Parents can use these scholarships to access public schools in other districts or private schools. Scholarships provide another avenue for competition, further expanding and improving upon the local educational marketplace.

\section{Making More Options Available to Parents}

The primary focus of Florida school choice policy is expanding the schooling options that are available to parents. As described in chapter III, Florida State $§ 1002.20$ $\{2012\}$ lists school choice options in great detail. School choice options include, but are not limited to virtual schools, charter schools, magnet schools, International Baccalaureate programs, Opportunity Scholarships, Mckay Scholarships, and private 
schools. State policy puts parents' preference at the forefront. There are provisions to assure that there are alternative schooling options for all students.

Charter schools are available to all eligible students equally, including students with disabilities and students in Limited English Proficiency (LEP) programs. These schools are to be made available specifically to low-performing students. If the number of applicants does not exceed the number of available spaces, then all eligible students are accepted. Otherwise, a random selection process must be conducted to assure that all students have an equal chance of being accepted. Miami-Dade County offers 127 charter schools for students in Pre-k to $12^{\text {th }}$ grade (FLDOE 2014). They provide information on selecting and applying to a charter school on the county’s website.

Magnet schools are also available to all eligible students. The first magnet school opened in 1973 as a means of desegregating Miami schools (Dunn 1997). Today the district’s magnet schools try to emphasize innovation. These schools are federally supplemented by the Magnet Schools Assistance Program and the Voluntary Public School Choice Grant (MDCPSc). There are over 340 choice programs in over 100 schools with an enrollment of over 43,000 students (MDCPSc). The magnet programs fall within six themes of study which include - Careers and Professions, International Programs, Liberal Arts, Mathematics, Science and Technology, Virtual Offerings and Visual and Performing Arts.

Parents can apply to magnet schools each year between October $1^{\text {st }}$ and January $15^{\text {th }}$ (MDCPSd). Applications can be completed online or by mail. Applications are available in English, Spanish and Creole, which are the three most frequently spoken 
languages at home for the families served by the district (MDCPS 2013). Additionally, the entire county magnet website is available in these three languages. Parents can choose up to five schools on the application. With the exception of the Visual Performing Arts magnet schools, students are selected randomly if they meet all eligibility requirements. The Visual Performing Arts schools require auditions, which are done through the specific school.

If a parent applies to more than 1 school, their child may be randomly selected to all the schools he/she applied to, with the maximum being 5 schools (MDCPSd). The parent will then be required to select one of the schools. If a parent is dissatisfied with the magnet school they select, the only other schooling option is their home school until the following school year when he/she can complete a new magnet school application. Eligible students applying to magnet schools where a sibling who lives in the same household as them is currently attending and will be in attendance the concurrent year, the student will be given preference (MDCPSd). Therefore, parents do not have to have students in multiple schools if they do not desire to, if all children meet the requirements. If a student is selected through the lottery process, notification is sent to the address on record with the school district (MDCPSd). Therefore, parents must make sure the address on file with the child's current school is always up-to-date. At least one parent interviewed for this study had a problem with receiving an acceptance letter because she moved. Unfortunately, that parent did not get her child's magnet school acceptance letter until after the deadline to accept had passed. 
The state also has made provisions to offer online and distant learning opportunities to students throughout the state (Florida State $\S 1002.37\{2012\}$ ). While these classes can be taken by any eligible student, this option is particularly useful for students who are limited by the courses offered at their school, home-school students or students trying to graduate early. Additionally, the state offers a full-time K-8 Virtual School, which provides online and distance learning for students throughout the state. Students can take online classes full-time or part-time. Miami-Dade County also offers virtual instructions through its Miami-Dade Online Academy for students in K-12 (MDCPSf). Online programs expand the course offerings provided by the state.

The John M. McKay Scholarships for Students with Disabilities Program was created to meet the needs of students with disabilities (Florida State $\S 1002.39\{2012\}$ ). The program allows students to either transfer to another public school or obtain a scholarship to attend a private school that serves students with disabilities. Students selecting public schools have an opportunity to receive transportation from the district. Parents are also offered assistance in obtaining information about participation in this program. However, the majority of the parents in this study who had students with special needs, found it extremely difficult to get information and find an appropriate program for their child.

The McKay Scholarship Program gives parents of students with disabilities the choice to choose the best school, public or private, for their child. Students, who were enrolled in a public school the prior year and who have an Individual Education Plan (IEP) or 504 Accommodation Plan, are eligible to apply for the McKay Scholarship 
Program (Florida State $\S 1002.39\{2012\}$ ). “An IEP is a written plan for the special education of a child with a disability (FLDOE 2010).” Eligible students with disabilities include K-12 students who are documented as having an intellectual disability, a speech or language impairment, a hearing impairment, including deafness, a visual impairment, including blindness, a dual sensory impairment, an emotional or behavioral disability, a specific learning disability, including, but not limited to, dyslexia, dyscalculia, or developmental aphasia, a traumatic brain injury, a developmental delay, or autism spectrum disorder (FLDOE 2010).

McKay recipients can attend another public school within the district, a school in an adjacent district that provides services specific to the needs of the student, or the student can attend an eligible private school (Florida State $§ 1002.39\{2012\}$ ). The McKay scholarship remains in effect until the student returns to their neighborhood school, graduates from high school or reaches the age of 22, whichever occurs first. Parents can apply for the scholarship online. Parents are also encouraged to contact their local district ESE office for further assistance (FLDOEa). The school district will only provide transportation for students attending a public school that falls within the districts choice plan. Parents selecting a public school outside the district or a private school are responsible for their child's transportation.

During the 2012-13 school year, 26,611 students in the state of Florida utilized the McKay scholarship program to seek enhanced educational opportunities (FLDOE 2013f). The average cost per student during this time was $\$ 7,019$ (FLDOE 2013f). In Miami-Dade County, 4,717 or $17.7 \%$ of students utilized the McKay scholarship program 
(FLDOE 2013f). Tables 5 and 6 display an overview of the demographics of students throughout the state of Florida who utilized the scholarship.

Table 5. Race/Ethnicity Breakdown for McKay Scholarships in Florida 2012 - 2013

\begin{tabular}{lrr}
\hline Race/Ethnicity & $\mathrm{N}$ & $\%$ \\
\hline White, Non-Hispanic & 12,475 & 47 \\
Black, Non-Hispanic & 6,633 & 25 \\
Hispanic & 6,365 & 24 \\
Others & 1,138 & 4 \\
\hline
\end{tabular}

Source. McKay Scholarship Program June 2013 Quarterly Report (FLDOE 2013f)

Table 6. Free/Reduced Lunch Status Breakdown for McKay Scholarships in Florida 2012 - 2013

\begin{tabular}{lrr}
\hline Lunch Program & $\mathrm{N}$ & $\%$ \\
\hline Free Lunch & 11,214 & 42 \\
Reduced Lunch & 2,050 & 8 \\
Did not apply & 11,691 & 44 \\
Not Eligible & 1,165 & 4 \\
Not Reported & 491 & 2 \\
\hline
\end{tabular}

Source. McKay Scholarship Program June 2013

Quarterly Report (FLDOE 2013f)

There are also provisions in the policy for home schooling (Florida State § $1002.41\{2012\})$. Parents who wish to provide an educational program within their home are allowed to do so. However, the quality of the educational program provided must meet state academic standards. Additionally, the state provides resources for home schooled students, such as an opportunity to take online courses offered through the states Virtual Instruction Program (Florida State § 1002.37 \{2012\}). Miami-Dade County students can also take online classes through the County’s online academy (MDCPSf). 


\section{Conclusion}

A review of the Educational Choice sections of the state's education policy illustrates how specific school choice objectives are implemented by Miami-Dade County school choice programs. State policy overwhelmingly emphasizes expanding schooling options for parents. At the local level, Miami is a leader in school choice options by offering the largest selections of school choice options in the state. Miami offers 127 charter schools and has over 340 choice programs in over 100 magnet schools. Coupled with opportunity, tax credit, and McKay scholarships, charter and magnet schools provide an educational marketplace that attempts to meet the needs of all families served by the school district.

Florida school choice policy places much less emphasis on improving school academic performance and expanding competition for students. Miami’s school choice programs similarly focus less emphasis on these two objectives. While school choice rhetoric always points towards improving academic performance, no direct requirements are included in state policy. However, charter schools can be shut down for failing state grades and/or financial instability. Although traditional public and magnet schools are not subjected to the same threat of closure, choice policy utilizes competition to improve academic performance. To enhance competition, Miami continues to expand the number of choice schools and programs located throughout the entire county so that all families have access (see Figure 1). As long as schools of choice provide a variety of programs that meet the needs of families and students are able to perform well on standardized tests, the educational marketplace will fulfill the objectives of school choice policy. 
It is important to understand how these objectives of the state policy are implemented in local programs. The wide variety of school choice programs at the local level and the state policy language that emphasizes meeting the needs of all parents, suggest that the needs of the parents in this study should be met. Chapters five and six provide an overview of how policy and programs meet the needs of parents served by low-performing schools so they can access school choice options. While all parents are in need of information about their child's current school, choice options, and choice eligibility, the parents of students served by low-performing schools face barriers to information and choice options. An evaluation of parents' knowledge of these things illustrates the deficiencies in state policy and local programs. 


\section{Research Methods}

This chapter summarizes the research design, procedures and analysis undertaken for the dissertation research. The current study utilizes a mixed methods research design to examine the decision-making process and school-choices options utilized by parents of students served by low-performing public elementary schools in Miami-Dade County. A mixed-method design utilizes both qualitative and quantitative data collection and analysis (Bernard 1999; Babbie 2005). A mixed-method design is most appropriate for the present study because it provides the necessary variety of data sources to investigate the single phenomenon of parent use of school choice options.

The data gathering and analytical design of the project methodology focused on answering the following research questions: (1) Do Florida state statutes on school choice and Miami-Dade County school choice programs adequately address the perceived needs of parents of students served by low-performing schools so they can access school choice options and make informed school choice decisions? (2) What characteristics differentiate students who transfer from and those who stay in low-performing schools? (3) What characteristics are most influential in predicting the type of school transferring students will attend? (4) How do economic and social factors differentiate the decision making process of parents who transfer their children from and those who keep their children in low-performing schools? Hypotheses were developed and tested or assessed for each question; they are explained in detail below. The data gathering and analysis strategy is also detailed below. The results of the analysis are presented in Chapters 5, 6, and 7. 
The mixed methods design included three means of analysis: (1) Quantitative data from 2,768 records of students who were served by low-performing public elementary schools in Miami-Dade County during the 2010-11 school year were analyzed utilizing SPSS statistical software; (2) Qualitative data from 22 semi-structured interviews were analyzed utilizing Atlas.ti software; (3) GIS mapping was conducted incorporating county school data with the quantitative data utilizing ArcMap. The combination of these methods provided a more accurate overall description of the target population's behavior, while utilizing the interviews to explore in detail the decision making processes which lead to specific behaviors.

Eight low-performing elementary schools, which served 2,768 students, were identified using their state designated grade during a five year period (2006-2007 to 2010-2011). Schools designated a D or F, three of the five years, were defined as lowperforming. Interviews were conducted with parents of students served by five of the eight low-performing schools. However, data from all eight schools were used for the statistical analysis. A more detailed overview of the sampling process is presented below. Data from the 8 low-performing schools were taken from the Miami-Dade County Public Schools’ Full-time equivalency (FTE) reports. The FTE reports include data for the students who are present in the classroom on at least one day during an eleven day window period of the month (Burks 2011). A more detailed overview of the student data that were pulled is presented below.

The dissertation was complemented by the researcher's participative experience working in the Office of Program Evaluation at MDCPS on a school choice grant evaluation which provides additional funding to schools of choice, specifically for 
magnet programs throughout the district. Working for the school board has provided the researcher with the opportunity to observe how schools recruit students, the type of parents schools recruit, and the type of parents most likely to transfer their child to a magnet school. The knowledge gained while working for the school district proved useful in constructing the interview guide and the overall design for the present study. The potential for bias because of the researcher's involvement in the school district is noted. When interviewing parents, the researcher described herself as affiliated with the university, rather than the school district so that the parents did not feel inhibited about commenting on their school experience. The researcher did disclose her relationship with the school district if it came up, however no parent expressed concerns in that area. On the contrary, most parents took the opportunity to probe the researcher for information about problems they had experienced with their school or the school district and about gaining additional information on schooling options. In an effort to reduce bias, the researcher also referred to Miami-Dade program documentation instead of memory in writing the county section.

Operationalization and Conceptualization of Research Terms The following terms and their relevance to the present study are defined below: school choice, low-performing school, social class, social capital, transfer and nontransfer. These terms are operationalized using the literature or the state's policy.

School Choice is described by the 2012 Florida Statues Chapter 1002.20 (6a) and (6b) as follows:

Parents of public school students may seek whatever public school choice options that are applicable and available to students in their school districts. These options may include controlled open enrollment, singlegender programs, lab schools, virtual instruction programs, charter 
schools, charter technical career centers, magnet schools, alternative schools, special programs, auditory-oral education programs, advanced placement, dual enrollment, International Baccalaureate, International General Certificate of Secondary Education (pre-AICE), Advanced International Certificate of Education, early admissions, credit by examination or demonstration of competency, the New World School of the Arts, the Florida School for the Deaf and the Blind, and the Florida Virtual School. These options may also include the public school choice options of the Opportunity Scholarship Program and the McKay Scholarships for Students with Disabilities Program.

Parents of public school students may seek private school choice options under certain programs. Under the McKay Scholarships for Students with Disabilities Program, the parent of a public school student with a disability may request and receive a McKay Scholarship for the student to attend a private school in accordance with the provisions of s. 1002.39. Under the Florida Tax Credit Scholarship Program, the parent of a student who qualifies for free or reduced-price school lunch may seek a scholarship from an eligible nonprofit scholarship-funding organization in accordance with the provisions of s. 1002.395.

Therefore, parents have public school options if these options are applicable to their child and not simply because they would like to choose another school for their child. While eligibility requirements can significantly limit the number of options some parents have, the abundance of options suggest there should still be sufficient opportunity to seek alternative schooling options within a particular school district. Additionally, with the private school scholarships available to students with disabilities and students from low-income families, the needs of all students, including those served by low-performing schools should be met.

As defined by the statute, for the purpose of the current study, indicators of school choice will include all schooling options listed in the statues. It should be noted that these options are not linked to an individual's home address. Historically, the school students attended was directly linked to their home address. The primary feature of 
school choice policy, and the main argument used by advocates, is that this policy gives students alternative schooling options regardless of where they live (Schneider et al. 1997; Goldhaber and Eide 2002; Goyette 2008).

Low-performing schools, for the purpose of this study, are schools in which a low number of students have scored at or above Achievement Level 3 in reading, mathematics, science or writing on Florida Comprehensive Assessment Test (FCAT). Additionally, in these schools, a low number of students have made learning gains in reading or mathematics. Lastly, in these schools, a low number of the lowest performing students made learning gains in reading or mathematics. The state awards schools a point for each student using these assessment components (FLDOE 2011). The higher the number of students meeting high standards and making learning gains, the higher the school's grade.

For the purpose of this study, low-performing school is operationalized using state designated school grades. Schools consistently scoring low grades over a five year period are designated low-performing as compared to the rest of the schools serving the same grade level. The state of Florida grades every school each year using the scores of their students’ FCAT and their students learning gains on the FCAT (FLDOE 2011). The FCAT is a standardized test measuring what students know and are able to accomplish in reading, writing, mathematics, and science. It was created using the Sunshine State Standards, which are broad statements that describe what a child should know and be able to do at each grade level. The FCAT is scored on a five-point scale with 5 being the highest and 1 being the lowest. Students scoring at Level 3 or above are considered 
proficient at grade level. Students scoring a Level 1 have little success with the challenging content of the Sunshine State Standards.

Social class will be operationalized by using the socioeconomic status variables of total income, years of education and occupational industry (Bowles 1972; Tucker et al. 1978; Wright 1996). All three variables were collected during interviews with parents. These variables have been used in school choice research to assess social class status (see Parent Social Class section).

Social capital, as defined in the literature review chapter, is the aggregate of the resources that are linked to social networks, relationships and interactions that can be activated by individuals or communities and used to achieve some goal (Bourdieu 1986; Coleman 1988). For the purpose of this study, significant resources are those which assist parents in accessing educational information as well as making and using school choice options. These include educational information, transportation assistance, and childcare. Social capital is operationalized by evaluating parent social networks. Social networks will be evaluated for their quality. Network quality was measured as strong or weak, a measure developed by Schneider and his coauthors (1997) in a study of segregation and stratification in social networks. Relatives were considered strong ties and non-relatives were weak ties (Schneider et al. 1997).

A non-transfer is a student who attended one of the eight low-performing elementary schools used in this study during the 2010-11 school year and attended the same school during the 2011-12 school year. These students were attending the sample 
school during the time that the second dataset was pulled on September 9, 2011. Students may have transferred after this date.

A transfer is a student who attended one of the eight low-performing elementary schools selected for this study during the 2010-11 school year and who did not attend the same school during the 2011-12 school year. These students transferred after the 2011 FTE reports were pulled and before September 9, 2011 when the second year dataset was pulled.

Transfer schools are categorized as traditional public schools, combination public schools, charter schools, magnet schools, and combination magnet schools. Traditional elementary schools serve students in pre-kindergarten or kindergarten through fifth grade. Combination public schools serve students in at least one traditional elementary grade, pre-kindergarten through fifth grade, and students in additional grades. The combination of grades can be anything, such as K-8, 4-8, or 4-12. Charter schools are public schools, which operate free of many of the regulation traditional public schools are held to but they are still responsible for specific academic and financial outcomes (Florida State $\S 1002.33$ \{2012\}; Bulkley and Fisler 2003; MDCPSb). These schools are operated by a person, persons or an entity outside of the county school board.

Magnet schools are either schools offering a school wide magnet program or schools offering magnet programs within the school. School wide magnet programs provide magnet learning to all students in the school. Schools providing magnet programs within schools, still maintain traditional education among some portion of the student population. Magnet programs offer unique curricula focused on specific themes such as careers and professions; international studies; liberal arts; mathematics, science, and 
technology; virtual learning/online classes; and visual and performing arts (MDCPSc). Combination magnet schools are magnet schools that serve students in at least one traditional elementary grade, pre-kindergarten through fifth grade, and students in additional grades.

\section{Operationalizing the Hypotheses}

Research Question 1 asked: Do Florida state statutes on school choice and MiamiDade County school choice programs adequately address the perceived needs of parents of students served by low-performing schools so they can access school choice options and make informed school choice decisions? The following hypotheses were designed to answer the first question.

- The less state policy and county programs provide parents services to access and process information about their child's current school, the less likely the policy will adequately address parents' perceived needs to make an informed school choice decision

- The less state policy and county programs provide parents services to access and process information about school choice programs, the less likely the policy will adequately address parents' perceived needs to make an informed school choice decision

- The less state policy and county programs provide parents information to understand their eligibility to place their child in an alternative schooling option, the less likely the policy will adequately address parents' perceived needs to access school choice options

- The less state policy and county programs provide parents logistical resources to utilize alternative schooling option, the less likely the policy will adequately address parents' perceived needs to access school choice options 
These hypotheses are assessed using data collected through semi-structured interviews with parents of students served by low-performing public elementary schools. The methodology for these interviews is described below. Specific variables utilized included educational resources, sources providing educational information, means of transportation and access to logistic resources. Additionally, variables examined parent's knowledge of their eligibility to transfer their children.

Research Question 2 asked: What characteristics differentiate students who transfer from and those who stay in low-performing schools?

- Compared to students who stay in low-performing schools, students who transfer will exhibit higher socioeconomic status, controlling for gender, race/ethnicity, ESE status, LEP status, FCAT math scale scores, and FCAT reading scale scores.

- Compared to students who stay in low-performing schools, students who transfer will have higher academic achievement on the state standardized tests, controlling for gender, race/ethnicity, ESE status, LEP status and FRL status.

- Compared to students who stay in low-performing schools, students who transfer will live closer to alternative public schooling options, controlling for gender, race/ethnicity, ESE status, LEP status and FRL status.

These are examined through the statistical analysis of records of students who transferred from and those who remained in low-performing public elementary schools. The data set is described below. Specific variables included Year 1 school, Year 2 school, race/ethnicity, sex, Year 1 grade level, Year 2 grade level, date of birth, free/reduced lunch status, limited English proficiency status, exceptional student status, and state standardized test scores. Additionally, the third hypothesis is examined through the 
spatial analysis of the proximity of student home addresses to schooling options and the number of schooling options within close proximity.

Research question 3 asked: What characteristics are most influential in predicting the type of school those who transfer will attend?

- The race/ethnicity, free and reduced lunch status, exceptional student status and English language learner status of the students will influence the type of school that a transfer student chooses.

- The school grade will influence the type of school that a transfer student chooses, controlling for gender, race/ethnicity, ESE status, LEP status and FRL status.

- The number of miles away from the student's home the school is will influence the type of school that a transfer student chooses, controlling for gender, race/ethnicity, ESE status, LEP status and FRL status.

These are examined through the statistical analysis of records of students who transferred from low-performing public elementary schools. Additionally, data on the schools' students transferred to and geographic data are examined. These data are described below.

Research Question 4 asked: How do economic and social factors differentiate the decision making process of parents who transfer their children from and those who keep their children in low-performing schools?

- Compared to parents of students who stay in low-performing schools, parents of students who transfer will have a higher income, a higher level of education and have more stable employment.

- Compared to parents of students who stay in low-performing schools, parents of students who transfer will have stronger social networks. 
The first hypothesis is examined through the statistical analysis of records of students who transferred from and those who remained in low-performing public elementary schools. The second hypothesis is examined using data collected through semi-structured interviews with parents of students served by low-performing public elementary schools.

\section{Quantitative Data}

The target population for the present study includes parents of students attending low-performing Miami-Dade County traditional public elementary schools during the 2010-11 school year. Initially, the population of low-performing public elementary schools was determined using the definition of low-performing conceptualized for the present study. The population consisted of eight schools. From those schools, quantitative data regarding the demographics, academics, and geographic information was analyzed, including 2,768 students. The data were obtained from the MDCPS student data warehouse through a request to the district's Office of Program Evaluation. Information for all public school students is available in the database. Each student has a unique ID, which follows them throughout their time attending school in the county. The unique ID allowed student attending low-performing schools during the 2010-11 school year to be tracked during the 2011-12 school year, regardless of which public school they attended. However, if a student left the school district or transferred to a private school, that student's information was not available.

In 2011, nearly 350,000 student records were in the system; about 164,500 were elementary school students. Of the elementary school students, 2,768 were served by low-performing schools. These student records were available for research purposes through the Office of Program Evaluation. However, these data were only provided after 
a formal review of the research project. In order to obtain student data, a Research Review Application was required, along with a prospectus, Institutional Review Board (IRB) letter, consent form, and data collection instrument. A copy of the interview consent form can be found in Appendix A and the data collection instrument can be found in Appendix B. A research committee reviewed these documents prior to providing access to these data.

\section{Low-performing Elementary Schools}

To obtain the population of low-performing elementary schools, the school grades provided by the state for the 2006-07 to 2010-11 school years were reviewed for all traditional elementary schools with a grade for at least 3 of the 5 years. Three years out of five was used because it illustrates the consistent inability of low-performing schools to produce high achieving students or produce substantial student gains. Information on performance was obtained from the Florida Department of Education website's Bureau of K-12 Assessment section and included data from 186 schools. Of these 186 schools, eight met the criteria for low-performing. Table 7 illustrates the grades that the eight lowperforming schools received over the course of the five-year period.

Table 7. Low-performing Elementary School Grades

\begin{tabular}{llllll}
\hline Year & A & B & C & D & F \\
\hline $2006-07$ & 0 & 0 & 3 & 4 & 1 \\
$2007-08$ & 0 & 0 & 3 & 5 & 0 \\
$2008-09$ & 0 & 1 & 4 & 3 & 0 \\
$2009-10$ & 1 & 0 & 1 & 2 & 4 \\
$2010-11$ & 1 & 0 & 1 & 4 & 2 \\
\hline
\end{tabular}

All numbers represent the total number of low-performing schools receiving a specific grade in the year listed. 
Low-performing charter schools were excluded from this study because, unlike public schools, students are not assigned to charter schools. The K-8 Centers were also excluded because although they serve elementary grade levels, the overall structure of these schools differs substantially from traditional elementary schools. Middle and high schools were excluded because parents of students in these levels of schooling face different schooling issues than those of students at the elementary grade level, and therefore are incomparable. Additionally, the elementary level was chosen, instead of the other school levels, because elementary schools make up the majority of all the traditional public schools in the county and as a result provided the largest population of low-performing schools from which to analyze parents' school choice decision making (MDCPS 2012).

\section{Students}

For this study, two datasets were obtained from the Miami-Dade County Public Schools' Office of Program Evaluation. These datasets were pulled from the FTE reports, which are used to track student membership data necessary for funding requirements (Burks 2011). The FTE reports include the students who are present in the classroom on at least one day during an eleven day window period of the month (Burks 2011). The FTE data are collected countywide in July, October, February, and June.

The first dataset (Year 1) included demographic, geographic and academic information of students attending the eight low-performing elementary schools in the county during the 2010-2011 school year. The Year 1 data were pulled from the February 2011 FTE report. The study utilizes data from the February 2011 FTE because it is the most reliable data to link enrollment to FCAT scores. Students are most likely to take 
their FCAT at the school in which they were enrolled during February. Since the school grade is largely a reflection of overall student FCAT scores, it is important that the students whose scores are reflected in the school grade are included with the school data.

The second dataset (Year 2) included all students in the Year 1 dataset along with the name of the school which students were attending during Year 2, their current grade level, previous year standardized test scores and parent contact information. Year 2 data were pulled on September 9 of the 2011-12 school year in an attempt to capture the majority of students, some of whom do not start attending school until after Labor Day, which was September 5, 2011. The Year 1 dataset was merged with the Year 2 dataset to identify students who transferred from the eight low-performing schools before September of the 2011-2012 school year.

\section{Limitations of the Data}

While the school district does provide sufficient data to evaluate the research questions posed in the current study, the nature of the data presents some limitations. The data are entered by staff members at each of the eight low-performing schools and the 138 schools that some of the students transferred to in Year 2. Additionally, these staff members rely on parents to update contact information when applicable. However, parents' contact information was not always up-to-date. Several individuals were not given an opportunity to participate in the interview portion of the study because of incorrect or disconnected phone numbers. Address data were also found to be outdated in a handful of cases dealing with interview participants. While parents and school staff regularly update contact information, especially at the beginning of the school year, 
which is when these data were extracted, it can be assumed that some addresses are outdated.

\section{Quantitative Data Analysis}

The school district data were provided via two Excel documents. These were imported into SPSS for cleaning, and were then merged into one document for analysis. The first document contained 2010-11 school year data for the students attending the eight low-performing elementary schools, as mentioned above. This document contained variables for race/ethnicity, sex, Year 1 grade level, Year 1 school, date of birth, free/reduced lunch status, limited English proficiency status, exceptional student status, and state standardized test scores. The second document included variables for Year 2 school, Year 2 grade level, parent/guardian phone numbers and parent/guardian home address. The two documents were merged using student IDs.

Initially, there were 3,396 elementary students in the Year 1 dataset. It included all elementary students attending the 8 schools identified as low-performing. Only students in $3^{\text {rd }}$ and $4^{\text {th }}$ grades during Year 1 were kept in the sample because these students had standardized test scores and they remain in elementary school between Year 1 and Year 2. One hundred and fifty-one $3^{\text {rd }}$ and $4^{\text {th }}$ grade students who did not have a school for Year 2 were removed from the sample because these students could not be classified as transfer or non-transfer. Two students who skipped a grade, from $4^{\text {th }}$ in Year 1 to $6^{\text {th }}$ in Year 2 were also removed because they were no longer in elementary school. The sample included $9803^{\text {rd }}$ and $4^{\text {th }}$ grade students from the 8 low-performing schools.

These data were used to perform a logistic regression analysis to determine the demographic, economic, and academic characteristics that influenced the likelihood a 
student would be transferred from their low-performing school between years 1 and 2 . Logistic regression allows “a researcher to explore how each explanatory variable affects the probability of the event occurring (Long and Freese 2006; 131).” Additionally, logistic regression, using the nominal outcome transfer school type, was performed to determine demographic and economic characteristics that influence the likelihood a student will transfer to a certain type of school. Transfer schools are first categorized by the school's characteristics, such as combination school, traditional elementary school, charter school, magnet school, or combination magnet school. Transfer schools are also categorized by their school grade and whether or not it is higher, equal to or lower than the student's previous school. Two separate multinomial logit models are used to analyze transfer school type.

\section{Quantitative Data Analysis - Geographic Information Systems}

Data were also examined utilizing ArcMap 10.1, which is Geographic Information System (GIS) software, to illustrate the schooling options in close proximity to students' home address. In addition to student home addresses, data regarding student free/reduced lunch status, race/ethnicity, exceptional student status and standardized test scores were exported from SPSS into ArcMap, where it was laid over Miami-Dade County maps illustrating school boundaries and census tracts, obtained from the 2010 U.S. Census. These data are used to analyze patterns of students using specific characteristics and how these characteristics influence the schooling options in close proximity to student homes. The Point Near tool in ArcMap is used to determine the closest school to each student's home address. Binary logistic regression is used to determine if distance influences student likelihood to transfer. The Point Near tool was 
also used to determine the miles between transfer student home addresses and transfer schools. Multinomial logistic regression is used to determine if distance influences the type of school a transfer chooses.

\section{Qualitative Data}

The qualitative data necessary to address the research questions were collected during October 2011 utilizing well established and carefully monitored procedures. Initially, a sample of low-performing public elementary schools was obtained using random stratified sampling procedures. Next, a sample of the students attending these schools was obtained, also using random stratified sampling procedures. The stratification of schools and parents prior to pulling the random sample ensured greater representativeness, making for a more precise sample (Bernard 1999; Babbie 2005). By using random selection, each school and each parent had an equal chance of being selected in their respective samples, which minimized selection bias (Utts 2004; Babbie 2005). Random stratified sampling is useful for studies comparing groups as this study does. The stratified structure allowed for the analysis of parents by their child's transfer status and the low-performing school their child attended during the 2010-11 school year.

\section{Sampling - Low-Performing Elementary Schools}

To obtain the random stratified sample of low-performing schools, the population of schools was divided into strata using their school board assigned regional location (Utts 2004; Frankfort-Nachmias and Leon-Guerrero 2006). Regions included the North, North Central, South, South Central and Education Transformation Office (ETO) regions. The North and South regions each had only one school; both were included in the sample of schools. Since the South Central region did not have any low-performing elementary 
schools and the ETO region had the largest number of low-performing schools, a random sample of two schools were selected from the ETO region. The North Central and ETO regions had 2 and 4 schools, respectively, so a random number generator from www.stattrek.com was used to select the schools for the sample. A total of 5 schools were selected. This sample of low-performing schools was then used to obtain the random stratified population of parents. The next section discusses the steps taken to obtain this sample of parents.

\section{Sampling - Parent}

From the five schools that made up the sample of low-performing schools, a random stratified sample of four parents was pulled from each of the five schools in the sample, with an additional two parents pulled from one of the schools to conduct pilot interviews. The sample was stratified by both school and transfer status. Parents of students who were in a different school in Year 2 than the school they were in during Year 1 were classified as transfers. Parents of students who were in the same school in Year 1 and Year 2 were classified as non-transfers. Parents in the population were numbered within their school and by their child’s transfer classification. School populations ranged from 61 to 202 parents. Parents were randomly ordered using a random number generator from www.stattrek.com.

\section{Recruitment Procedures}

Parents were called to participate in the semi-structured interviews using their number order within their child's particular school and transfer status grouping. A total of 153 calls were made to parents from the five schools, with $22 \%$ answering the phone or calling back. Once a parent was reached via telephone, they were informed that the 
researcher was a Florida International University graduate student conducting research for her dissertation. Parents were then informed about the topic of the dissertation, its voluntary nature and the $\$ 50$ contribution provided to participants. Lastly, they were asked if they were interested in participating in the study. If a parent was interested, an interview was set up for a time and place that was convenient for the parent. If a parent was not interested, the next parent on the list was called. If the parent did not answer the phone, a message was left either on the answering machine or with the person who answered the phone. If the parent did not call the researcher back, two attempts were made over the following seven days to contact the parent. If the researcher was still unable to reach the parent, he/she was skipped and the next parent in the list was called. Several phone numbers were either disconnected or incorrect, these parents were excluded from the interview sample and the next parent was called.

\section{Semi-structured interviews}

Parents who agreed to participate in the semi-structured interviews chose a location and time to meet with the researcher. Interviews were primarily conducted at parents’ place of residence. However, some interviews were conducted in public places such as fast food restaurants, neighborhood parks and the public library. It was the goal of the research to make sure that parents felt comfortable in the location chosen to conduct the interview.

Interviews were conducted over a month period in October 2011. All 22 interviews were recorded using an audio recorder to assure their accurate transcription. At the beginning of each interview, participants were reminded that the information collected in the interview would remain confidential. Additionally, participants were 
reminded that their participation was voluntary and there were no foreseeable risks for participating in this study. The researcher then read the IRB approved informed consent form verbatim to each participant and verbal consent was obtained, which was recorded. Interviews lasted approximately 45-60 minutes.

Interviews utilized an interview guide with clear instructions for the interviewer, specifically regarding where to probe interview participants, while still leaving room for discretion to follow leads when appropriate (Bernard 2002). The interview guide also assured that all interviews were done in the same manner, which provided for more reliable qualitative data (2002). Additionally, it allowed the researcher to control the direction of the interview but remain flexible for digression, if appropriate. An interview guide was also used to make sure that the major themes of this research were addressed. These themes include parent background, resources, social networks, constraints, and the decision making process. At the same time, the semi-structured interview instrument allowed the interview subjects to elaborate on issues not directly addressed by the interview questions and permitted the interviewer to probe for more details.

The interview guide started with questions about parents' background. These initial questions focused on education, employment and living situation. The second section of questions was about parents' access to resources and constraints to school choice. Particularly, parents were asked about the resources they use to make schooling decisions and any difficulties they have experienced in accessing resources. The last section of the interview concentrated on how parents made decisions about where their child attended school and parent knowledge of their schooling options. For the parents of 
transfer students, there was an additional section about the transfer process and the transfer school. The interview guide can be found in Appendix B.

Twenty-two total interviews were conducted with parents; 11 with parents of transfer students and 11 with parents of non-transfer students. The first two interviews were pilot interviews, which were meant to test the research instrument for its validity in answering the study's research questions. One interview was conducted with the parent of a transfer student and one with the parent of a non-transfer student. After conducting these interviews, it was determined that the research instrument was sufficient in answering the necessary research questions and parents understood what was being asked of them. Therefore, the two pilot interviews are also included in the analysis, which is described below.

\section{Qualitative Data Analysis}

Semi-structured interviews were analyzed using the qualitative analysis tool, Atlas.ti. Since all interviews were recorded, they were fully transcribed verbatim in a Microsoft Word document and then imported into Atlas.ti. A list of theme focused codes was created while analyzing each interview. Codes were created using the following themes: parent background, resources, sources, decision making, social networks, parent involvement, constraints, knowledge of options and knowledge and opinion of the lowperforming school their child attended in Year 1. Interviews with parents of transfer students also included a theme related to the school their child was transferred to in Year 2.

The interviews were analyzed individually, and then grouped by the school the parent's child attended in Year 1 and lastly by transfer status. Interviews were first 
analyzed individually to illustrate personal experiences with the Miami-Dade County public school system and making schooling decisions about the school(s) their child has attended. Interviews were then analyzed by the low-performing school the parent's child attended in Year 1 to look for patterns within schools among both transfers and nontransfers. The final analysis grouped interviews by transfer status to illustrate patterns among transfers as compared to non-transfers. Specifically this part of the analysis looked for differences in the types of resources and sources used, parent knowledge and constraints to utilizing the schooling options parents wanted to use.

\section{Summary of Research Design}

Understanding the relationship between education policy and the families it affects is a complex task. To gain a more comprehensive view of that relationship, this study was designed employing a mixed methods approach. The analysis of the district data on all elementary schools classified as low-performing is intended to provide a broad overview of the behavior of parents served by these schools, the characteristic differences between those who transfer and those who do not and the types of schools transfers choose. Additionally, through the spatial analysis, these data illustrate the schooling choices families have in close proximity to their home address. The semi-structured interviews provide more details about the resources parents have access to, their decisionmaking process and the things that constrain that process. Ultimately, the study results should reveal any disconnect between what state policy and county programs intend to do and what is actually occurring. 


\section{How Parents Access and Process Current School and School Choice Information}

Chapter V discusses some of the findings from the parent interviews. The first research question in the current study evaluates whether or not state choice policy and county choice programs adequately address the perceived needs of parents served by lowperforming schools so they can access school choice options and make informed school choice decisions. Chapter V will discuss the first two hypotheses assessed to answer this question:

- The less state policy and county programs provide parents services to access and process information about their child's current school, the less likely the policy will adequately address parents’ perceived needs to make an informed school choice decision

- The less state policy and county programs provide parents services to access and process information about school choice programs, the less likely the policy will adequately address parents’ perceived needs to make an informed school choice decision

Twenty-two semi structured interviews were conducted with parents who transferred their children from and those who kept their children in the low-performing elementary schools in the sample. The first section of chapter V provides an overview of the demographics of the parents interviewed for the current study. The subsequent sections provide the results of the first two hypotheses assessed to answer research 
question one. Pseudonyms are used for all parent, student and school names included in this document.

\section{Parent Demographics}

The interviews of 22 parents were conducted in Miami-Dade County during the month of October in 2011. Eleven of the parents interviewed transferred their child from their low-performing neighborhood school between the 2010-11 and 2011-12 school years. The remaining 11 parents did not transfer their child. Eighteen (81\%) of those interviewed were mothers, three (14\%) were grandmothers and one $(5 \%)$ was a father. Eighty-two percent of households were single-parent.

Tables 8 and 9 summarize some additional characteristics of the parents interviewed for the current study, including their educational background, income, and employment status. The average number of years that the parents of non-transfers reported completing in school was 10.7, while the average number of years for parents of transfers was 11.8 , respectively. The majority of parents of transfers, $73 \%$, had at least a high school diploma. Only 36\% of parents of non-transfers had at least a high school diploma. This is important because education influences a parent's socioeconomic status, which influences the likelihood of them using school choice options (Ball 1993; Neild 2005; Sikkink and Emerson 2008). Although the parents of transfers had one year more of education on average than that of non-transfers, they were less likely to be employed. Seven (64\%) parents of non-transfer students were employed, while only $45 \%$ of the parents of transfers were employed. However, parents of transfer students had a higher average household income compared to non-transfers, taking home $\$ 4,913$ more per year. 
Table 8. Characteristics of Parents of Non-Transfer Students in the Present Study

\begin{tabular}{|c|c|c|c|c|c|c|c|c|}
\hline \multirow[b]{2}{*}{ Pseudonym } & \multirow{2}{*}{$\begin{array}{r}\text { Relationship } \\
\text { to Student } \\
\end{array}$} & \multirow{2}{*}{$\begin{array}{r}\text { Education } \\
\text { (years) }\end{array}$} & \multicolumn{2}{|c|}{ Employment } & \multicolumn{4}{|c|}{ Unemployment } \\
\hline & & & Status & Frequency & Type & Length & Reason & Income \\
\hline Charmaine & mother & 12 & Employed & Part-time & Seasonal & N/A & $\begin{array}{r}\mathrm{N} / \mathrm{A} \\
\text { can't find }\end{array}$ & $\$ 13,000$ \\
\hline Tammy & mother & 11 & Unemployed & N/A & N/A & 1 year & work & Unknown \\
\hline Gwen & mother & 13 & Unemployed & N/A & N/A & 1 year & student & $\$ 10,000$ \\
\hline Angela & mother & 11 & Employed & Full-time & Permanent & N/A & N/A & $\$ 18,500$ \\
\hline Briana & mother & 12 & Employed & Part-time & Permanent & N/A & $\begin{array}{r}\text { N/A } \\
\text { raising }\end{array}$ & $\$ 25,000$ \\
\hline Crystal & grandmother & 11 & Unemployed & N/A & N/A & $\begin{array}{r}10 \\
\text { years }\end{array}$ & $\begin{array}{l}\text { grand- } \\
\text { children }\end{array}$ & Unknown \\
\hline Tamara & grandmother & 11 & Employed & Part-time & temporary & N/A & N/A & $\$ 18,000$ \\
\hline Grace & mother & 11 & Employed & Part-time & Permanent & $\begin{array}{r}\text { N/A } \\
24\end{array}$ & $\begin{array}{r}\text { N/A } \\
\text { raising }\end{array}$ & Unknown \\
\hline Jada & mother & 5 & Unemployed & N/A & N/A & years & children & Unknown \\
\hline Jeneka & mother & 12 & Employed & Full-time & Permanent & N/A & N/A & $\$ 24,000$ \\
\hline Adriana & mother & 9 & Employed & Part-time & Permanent & N/A & N/A & $\$ 13,000$ \\
\hline
\end{tabular}


Table 9. Characteristics of Parents of Transfer Students in the Present Study

\begin{tabular}{|c|c|c|c|c|c|c|c|c|}
\hline \multirow[b]{2}{*}{ Pseudonym } & \multirow{2}{*}{$\begin{array}{c}\text { Relationship } \\
\text { to Student }\end{array}$} & \multirow{2}{*}{$\begin{array}{c}\text { Education } \\
\text { (years) }\end{array}$} & \multicolumn{2}{|c|}{ Employment } & \multicolumn{4}{|c|}{ Unemployment } \\
\hline & & & Status & Frequency & Type & Length & Reason & Income \\
\hline Donna & mother & 11 & Unemployed & N/A & N/A & 4 years & $\begin{array}{r}\text { can't find } \\
\text { work } \\
\text { can't } \\
\text { afford day }\end{array}$ & $\$ 40,000$ \\
\hline Leslie & mother & 11 & Unemployed & N/A & N/A & 4 years & care & $\$ 4,800$ \\
\hline Mya & mother & 12 & Employed & Full-time & Permanent & N/A & N/A & $\$ 32,000$ \\
\hline Sylvia & mother & 12 & Unemployed & N/A & N/A & 3 years & $\begin{array}{r}\text { student } \\
\text { medical }\end{array}$ & $\begin{array}{l}\$ 22,800 \\
\text { Unknow }\end{array}$ \\
\hline Barbara & mother & 13 & Unemployed & N/A & N/A & 2 years & reasons & $\mathrm{n}$ \\
\hline Regina & mother & 12 & Employed & Part-time & Permanent & N/A & N/A & $\$ 13,500$ \\
\hline Kia & mother & 12 & Employed & Full-time & Permanent & N/A & $\begin{array}{r}\mathrm{N} / \mathrm{A} \\
\text { medical }\end{array}$ & $\$ 24,500$ \\
\hline Diana & mother & 13 & Unemployed & N/A & N/A & 1 year & reasons & $\$ 8,100$ \\
\hline Kenneth & father & 12 & Employed & Full-time & Permanent & N/A & $\begin{array}{r}\mathrm{N} / \mathrm{A} \\
\text { medical }\end{array}$ & $\$ 17,000$ \\
\hline Jennifer & grandmother & 9 & Unemployed & N/A & N/A & N/A & reasons & $\$ 20,000$ \\
\hline Pauline & mother & 13 & Employed & Full-time & Permanent & $\mathrm{N} / \mathrm{A}$ & N/A & $\$ 40,000$ \\
\hline
\end{tabular}


It is important to note that some of the unemployed parents supported their families with child support payments and social security benefits.

\section{Accessing and Processing Current School Information}

Hypothesis 1: The less state policy and county programs provide parents services to access and process information about their child's current school, the less likely the policy will adequately address parents’ perceived needs to make an informed school choice decision.

State policy and county programs include provisions to make sure parents are well-informed about the quality of their child's school. According to Florida state $\S 1002.20\{2012\}$, “parents of public school students are entitled to an easy-to-read report card about the grade designation, school accountability including the school financial report, and school improvement rating of their child's school.” Dade County Public Schools complies with this statute by providing information via its website. Additionally, parents are provided this information directly from the school. A variety of District Departments can also assist parents with accessing information about their child's school such as the Parent Academy and the Office of Assessment, Research, and Data Analysis.

Parents must be informed about the quality of their child's current school in order to make informed decisions about where their child should attend school. With an understanding of whether or not their child's current school meets his/her needs, parents can consider if using school choice options would better service their child's educational needs. Hypothesis one was assessed by evaluating whether or not parents knew their 
child's current school's state designated grade. Parents were also asked to describe the academic quality, teachers, administration and environment of their child's current school. This is the type of information parents believed was necessary for them to make an informed school choice decision. Parents demonstrated their ability to process this information by illustrating that they could use this information to assess the school's ability to meet their child's needs. This section presents the results related to parents' access to information about the school their child attended during the 2010-2011 school year. This section also includes the findings of how parents process current school information for decision making purposes.

\section{School Grade}

Parent knowledge of their child's school quality was measured by their knowledge of the school's state designated grade. The state designated school grade is the most utilized assessment of a school's academic quality. When asked what their child's neighborhood school's grade was, 13 of 22 (59\%) parents provided the correct grade (see Table 10). The majority, 82\%, of parents of non-transfers knew the correct school grade or at least knew that the grade was low. Only $45 \%$ of parents of transfers knew this information. Of parents who did not know the exact school grade, three knew that it was low. Of the remaining six parents, four parents thought the school grade was better than what it actually was and two parents thought it was worse.

Parents were also asked if they were concerned about the low-school grade. The majority of both the parents of non-transfer and transfer students were aware of the quality of their child's school but only $36 \%$ were concerned about it. According to the 
literature on the parent school choice decision making, parents with knowledge of the inadequacies of their child's neighborhood school should be expected to transfer their child to a better school (Schneider et al. 1997; Goldhaber 1999; Bartlett et al. 2002). However, this was not the case for the parents interviewed for the current study. Only 5 of 22 parents were concerned enough about the school grade to consider transferring their child.

Table 10. Parent Knowledge of School Grade

\begin{tabular}{lll}
\hline & $\begin{array}{l}\text { Parents of Non- } \\
\text { Transfers }\end{array}$ & $\begin{array}{l}\text { Parents of } \\
\text { Transfers }\end{array}$ \\
\hline Knew correct grade & 8 & 5 \\
Knew grade was low & 1 & 3 \\
Thought grade was higher & 1 & 1 \\
Thought grade was lower & 1 & 2 \\
\hline
\end{tabular}

Source. Semi-structured Interviews

Briana, who knew her child’s school grade, is the parent of a student who is doing well academically. Although she expressed concern about the school's low grade, she is still satisfied with the school's quality because of her daughter is doing so well. She did not link the quality of her child's education to the school's overall ability to provide a high quality education to all students. Gwen, the mother of three elementary school students, also knew her children's school grade and was concerned about how low it was because she understood that the school's overall grade reflected the quality of the education that her children were receiving. Likewise, Kenneth, the father of a student who had to repeat the $3^{\text {rd }}$ grade, also expressed concern for the school's low grade. However, he did not know what the school grade was but knew it was low. To address his concerns, he communicates with the teachers to remain informed about what the 
school is doing to improve. Below is each parent's response to the question, "Does the school grade concern you?”

Briana: Yes I was concerned, [but] she’s doing excellent. She’s doing great.

Gwen: Um, kind of because then they tell me what they really doing with the kids. If they really is learning something or just putting grades down or something like that.

Kenneth: Of course because it shows overall and then being that my daughter failed before. She stayed back in $3^{\text {rd }}$. It's very concerning but when it's like that I just go try to meet the teachers, to see they heart and value, they passion. I think I surprise most teachers that I'm so stern. Like hey what's goin on? I'm concerned with my child's education. The teachers I met so far, it was one on one. It's work.

The parents who were not concerned about the school grade emphasized that they were only concerned with how their children were performing academically and not how the other students in the school were performing. Some parents, like Leslie and Regina, do not value the state designated school grade at all. They do not believe that it is an accurate assessment of the quality of the education the school provides.

Leslie: Cause I mean I can't say it's my kids' fault because they're a D school. Yeah, I don't care about that, long as my child is doing ok, I'm ok. Yeah, because you can't help everybody. And I don't even know why they grade the schools like that because you can have an A school but when the following year come, you have kids coming from here, kids coming from here, and coming here and now your grade is dropping. So I don’t get that at all.

Regina: Not really because you know cause my thing was really with her, trying to get her to learn, it wasn't grade, no... I'm not worried about the grade of the school, just with her. Yeah it's not bout the grade of the school it's like how yo child doing in that school, cause that could be a A school, and at the same time she not learning nothing. That's my thing, parents gotta look at, lotta parents don't look at it, they go by the grade of the school. Yo child go to an A school but then she ain't learning nothing. My thing I want the best for my kids.

The state designated school grade illustrates how the students at a school perform on the state standardized tests. It also is an indicator of student improvement on these 
tests from one year to the next. Since the school grade is often used as the primary indicator of the overall quality of a school in the state of Florida, it is important that parents know what it is. The school grade is vital information that can be useful to parents as they make decisions about where their children should attend school.

\section{Learning Environment}

All parents had some knowledge of the academic quality of their child’s school. However, the amount of knowledge and the way this information was used to make schooling decisions varied widely. When asked about the academic quality of their child's neighborhood school, 10 of 22 (45\%) parents expressed dissatisfaction with the learning environment. Dissatisfied parents believed the learning environment was not compatible with their child’s academic needs. Fifty percent of parents who were dissatisfied with the learning environment were parents of non-transfers and $50 \%$ were parents of transfer students. Parents found the learning environment was incompatible for the following reasons: their child's class was too disruptive, their child was distracted by other students, or their special needs child was not in the appropriate class setting to meet their needs.

Of the 10 parents who were dissatisfied with their child's learning environment, three were dissatisfied because the classroom was disruptive. Barbara, the mother of two students, decided to transfer her children because she was worried one of her children was not going to be prepared for standardized testing because of the amount of time the teacher had to waste getting her classroom under control. Jennifer, the grandmother of a student and Tammy, the mother of two students also found that the behavior of the other 
students, along with the teacher's inability to control these students was negatively affecting the learning environment. Barbara explains her concerns about the learning environment.

Barbara: Yes and that was another problem that I saw with my $2^{\text {nd }}$ grader. Her class, her teacher would constantly have to stop what she's doing to discipline a child. And I'm like ok if you're constantly stopping all day, you're not gonna have time to teach my daughter what she needs to know to move to the next grade. And that was another problem that just like really, I'm like she's not gonna be ready because you have to stop every two minutes to discipline one of the children or put them out of the classroom or call somebody to take them to the office and you constantly do that all day.

Five of the ten parents who were dissatisfied with the learning environment explained that their children were not learning in the environment provided by the school. Regina decided to transfer her daughter because she was talking too much to her friends. Regina’s decision to transfer her daughter was not a reflection of the school's inadequacies, but more of a reflection of how the learning environment provided by the school no longer was compatible with the needs of her daughter. Regina explained that her problem was not with the school but with her daughter's behavior at school. Barbara, the mother of two transfer students, explained that her son was being picked on in the classroom, which inhibited his learning. Both Regina and Barbara felt they had no other choice but to transfer their children because in the learning environment provided by their home schools, they were unable to get the education they need.

Regina: It's been rough, not easy. Especially at Monroe Elementary it was really rough for my daughter. I really didn't have no, like rough dealing with like the school, no, not with the school. But with my daughter yes. Not with the school. It was just you know when you have a lotta friends that you know you not gone be focused on your work. She was focused on friends and talking. The school is fine. I don't know was it just her friends, the teachers kept calling me. Too much and to 
her friends, I got tired of that. My thing is I would tell her you talk when you go to lunch. When you in class, be quiet, listen to the teacher.

Barbara: My son was... he was constantly getting in trouble, picked on about him being too smart or him knowing too much or him talking a certain way. Or him not cursing and his pants hanging off his behind.

Parents of students with special needs had a particularly difficult time matching their neighborhood school's learning environment to their child's needs. The difficult time parents experienced was a result of the tedious process required to get a child tested and properly placed. Sylvia, the mother of five elementary school students, had an extremely long and difficult time getting her oldest child diagnosed as having ADHD and finally being transferred to a school that served ADHD students. Gwen also experienced similar difficulties with her special needs daughter. Gwen was ready to transfer her child but the school finally placed her in the proper class. Sylvia and Gwen parents express their frustrations when asked about the academic quality of their child's school.

Sylvia: When she as at Copeland Elementary, maybe cause she was ADHD and they didn't have the program for her. When she was at Copeland she didn't wanna go to school. She would stay in fights. I been working on this since 2007. Um um, it was difficult, it was hard, I had to fight. I had to talk to this one, talk to that one but eventually I got through. I had to do the footwork myself.

Gwen: Yes, because I was trying to, I was on like all type of stuff cause I'm like, yo, something different. Um, I ain't never experienced or I never seen it. And I noticed she is lacking. Jasmine is the the $3^{\text {rd }}$ child and I gotta $4^{\text {th }}$ child and she more advanced than her. So I'm like, no, something wrong, like, she is, how she's doing her homework and she can't even do her homework. I was like oh my god, ya'll not doing nothing. I know it's not no regular thing. I know it's like some kinda medical thing. She look normal but when she doing this work, I know if I'm helping her with her homework, it's like a hour or two and that's just one paper and then we gotta go to, that's math, then had to go to reading. I'm like, what is going on in school. And I see the other kids don't have no problem. My other kids don't have no problem doing the work. So I'm like it's not the work. And then, probably teachers. But it's not the teachers cause they have like the same teacher. So I'm like something going on. But then, she don't know the work, she frustrated, she get mad, don't wanna do nothing. So I'm like, ya'll gotta. Like the 
next year, they keep putting her the next year and I'm like how you going to the next year. And if you see her, that's not a progress report, it's the report card, Fs and probably like P.E. and art, A and B or something. But it's F, 3 F, F, F, F and I'm like how she going to the next level and she don't know nothing. I'm like...what's going on? They show me her work, it's a disaster.

Tamara and Grace did not believe that the other students' academic achievement level affected the quality of their children's education. They believed their children could learn in any school environment. Tamara wanted her granddaughter to focus on her work and not worry about what the other students were doing. Similarly, Grace wanted her son to worry less about what the other students did not know and focus on what he had to do and even help the other students with their work.

Tamara: Long as she focus on what she have to focus on and not what the school, not what the students are doing. It's not about the students. It's about you in particular. You as one getting out what you suppose to get out of there. If you feel like your teachers are giving you what you need, then ok fine.

Grace: Well, they went from an F school to an A school within 2, 3 years. So they're really focused on the kid getting it right. I mean he's always had good grades and he's always been able to pass his tests, but he tells me there are a couple of kids. He said mostly the girls. He's the only boy that has good grades. But mostly all the girls have good grades. So he communicates more with the girls because they're on his level. Cause he's sometimes I don't understand, oh did you know that some kid had the audacity to say he didn't know what a noun was and we learned that in first grade. I was like, you don't judge people though. He's like, but it's so common sense mom. And I was like maybe their parents are not teaching them or whatever the case maybe but don't make fun of them. Maybe if you get some time, you can help them.

Both Tamara and Grace were satisfied with their child's neighborhood school.

Their children's school was the only school in the sample, at the time of the interviews in 2011 that recorded a grade higher than a "C" during the previous five years. The school was rated an " $A$ ” during the 2010-11 school year. 


\section{School Academic Improvement}

Parents also evaluated their child's neighborhood school's academic quality on how it has changed over time. Some parents have had their child in their neighborhood school for several years and they also have older children in these schools. Seven parents stated that a lack of improvement led them to contemplate transferring their children. Lack of improvement led 57\% of these seven parents to transfer their children. Jennifer had two grandchildren complete elementary school at the neighborhood school. However, her youngest grandson was not improving academically and did not seem to be learning anything at all so she transferred him.

Jennifer: They're lack of improvement has been not too well for me and the way they're teaching them is not up to standards I guess. This is the reason why I removed the child from that school, they're performance. And I have been in that school a long time, they still haven't improved as far as the academics go and stuff like that. He's at the point that he's not understanding a lot of things. He wasn't getting the help that he needed there. He wasn't basically getting the education. He did not get the attention that he needed. He was always angry, frustrated cause he could get some of the things that he needed in school at LBJ Elementary. He wasn't doing well there at all.

Diana, the mother of two children, also found that the school was not effectively educating her children. They transferred to their neighborhood school after moving and her children struggled on classwork and standardized testing. Diana's children narrowly passed the FCAT and one of her children was retained. Since Diana's children had performed better at their previous school, she concluded that the neighborhood school was not adequately educating her children. She decided to transfer them back to the school they attended previously. 
Diana: They passed, but not really, you know. They were like in borderline. So that's why I want this year to be a little better, more focused on, you know, for their grades and stuff. So I want them to, you know be good at it. I seen that at Wright their grades dropped. And actually at Wright Elementary, Suzanne had failed the grade. That's why they both are at the same grade level. Yeah, so I didn't want her to, well both of them to continue going to Wright cause I knew the teaching there wasn't fine because I know she's a smart girl and I know she was doing her work every day and stuff so. Um, it all depends also on the teacher of how she teaches or he teaches, you know. So I felt that it was not, you know, not good. The main thing was that my daughter didn't pass the grade. Yeah, I didn't feel that she deserved that. Because she had worked so hard and you know, she was trying to be able to understand, you know the class and the teachings and stuff. And she just couldn't understand it and I know her better than that, you know so.

Eight parents stated that they were satisfied with how their child's school has improved. Pauline would have preferred to remain at her neighborhood school, but moved and had to transfer her children. She wished to remain in the neighborhood school since she saw the school making improvements. Pauline was aware of the school's struggles on standardized testing but felt the changes being made would help it to become a high achieving school. Jeneka, who had one non-transfer child, saw her child's school improve since the time her older children were attending. Jeneka did not want to transfer her child; instead she wanted the school to continue to improve. Angela, the mother of one child, wanted to transfer her son but was unable to find a proper match for his needs. She decided to suspend her search for an alternative schooling option and remain in the neighborhood school because she saw its potential. Additionally, Angela believed the changes to the administration would contribute to improving the school's overall academic quality. Gwen also believed that the changes to the administration at her children's school would help it to improve academically.

Pauline: I mean they were not the best performing school, but they were making strides to come up, I mean from where they started at. 
Jeneka: I feel like it's better. Yeah, cause now they have the intervention. Like reading and math intervention. Like the kids have to go there now, get prepared to do the FCAT.

Angela: I would say, probably B [or] C, cause LBJ Elementary, honestly has a lotta potential but the thing is, if you don't have nobody to push it, it ain't gonna be done. From what I see, they principal this year, is so much stricter than the principal that they had last year. And it's like a lotta things that they didn't do last year. They have portfolios that they work from now and whatever portfolio they're working on, we're aware of it. And it has to be approved by the principal. He's really hands on with most of the stuff that's going on versus him just looking in the computer and saying ok, do this. So I think, that this year will be better for them.

Gwen: I think they probably will do better cause my kids [are] doing better. So I'm like oh ok, they learning. If you ask them the next day, they remember what they learned.

Parents often have a long history at their child’s neighborhood school. The long history allowed them to evaluate how the school improved or failed to improve over time. Some parents also had the experience of multiple children to evaluate the school's quality. In several cases, the families' long history with the school was what compelled parents to stick with the school through difficult times. Relationships with teachers were built over time and comfort with the school made the experience personal and familiar, regardless of the state grade. This is important to note because school choice primarily emphasizes parents moving students to a new school.

\section{Academic Rigor}

Fifty percent of parents used the school's academic rigor as part of their evaluation of the school's academic quality. Five parents, 23\%, expressed dissatisfaction with the academic rigor provided at their child's school. However, the five parents handled the situation in different ways. Two parents transferred their children. One grandparent, who did not want to transfer her grandchild, asked the school to provide a 
more rigorous curriculum for her grandchild. Her grandchild was eventually tested and placed in a gifted program. Lastly, two parents who believed the work was too easy did not take any action to improve the rigor of their children's academic content.

Florida administrative code 6A-6.03019 identifies a gifted student as "one who has superior intellectual development and is capable of high performance (FLDOE 2014a).” Students must be tested to enter the gifted program. If the student meets the majority of the characteristics for gifted and has a need for a special program they can participate in the gifted program. Not all schools have the capacity or need for a gifted program. However, a gifted program can be brought to a student at a school not offering a gifted curriculum.

Barbara mentioned the lack of rigor as one of the main reasons she transferred her children. She was particularly dissatisfied with the small gifted program offered at her son's school. She felt that her son's education was suffering because he was not benefiting from a more comprehensive gifted program. Also, her son's academic level often led to bullying by other students. Barbara believed the gap between her son's academic ability and the other students created a poor learning environment for him, as stated earlier.

Barbara: So at Monroe Elementary it wasn't that many gifted kids there so he was only being serviced one day out of the week. He wasn't benefiting from it. He was tested and got approved for gifted. And a lotta kids in his class were kinda below level so it was a problem because they felt that he was trying to be too smart. That's what one of the kids told him, he was trying to be too smart. It was a problem to where he was constantly getting into fights and everything with them. And that was another reason why I purposely found somewhere, I was determined to move from that school...because it was a difference of education level between 
them. So now where he's at he hasn't had a problem because he's among kids that are gifted, that are on the same level as him. So that problem has totally stopped.

Like Barbara, Tamara was not satisfied with the rigor of her grandchildren's

school, but instead of transferring them, she asked the school to provide her

grandchildren with more advanced work. One of Tamara's grandchildren tested and

placed into gifted. At the time, the school did not offer a gifted program but Tamara did

not want to transfer her grandchild. Instead, Tamara had the gifted level work brought to her granddaughter's school.

Tamara: They already know. Cause see, when they first got here, by them being in Georgia school, because that's where they started going to school at, in Georgia, they had already knew what they were learning here. So I had to go to the school, I set up appointment with the teachers and the counselors. And I told them, I say... when we first moved here, they had already knew everything. Cause see, Miami’s behind Georgia. So they was like, they bored, so I had to tell them, go to the school and set up a meeting, say listen, what ya'll doing they done, done. Give them a challenge. Challenge they mind. Challenge them period because ya'll is like, not, they do the work so fast, then they bored. Because they already did what ya'll doing now. So, I need a challenge. They put Jude in it. Jude is still in the gifted program that they bring the work to her because I did not want her to be bused. I did not want to transfer her school. So I told them, they can do that

Jeneka also expressed concerns about the level of work that her child was

receiving at school. She thought the work was too easy and she believed her daughter should be tested for gifted. However, Jeneka had not taken any steps to get her daughter tested or placed in a more rigorously academic school. Jeneka did not want to transfer her because she believed that her daughter's grades would suffer if she had to become familiar with new teachers.

Jeneka: I think it's too easy cause she's already in advanced classes. I feel like that they should test her, cause she be scoring $4 \mathrm{~s}$ and $5 \mathrm{~s}$ on the FCAT. She real smart, she just gotta stay focused. [If transferred], I think she would fall behind 
because she know all the teachers. She been going there ever since pre-k. I just need to leave her there, until middle school.

It is important for parents to be aware of the level of academic rigor appropriate for their child and the level being provided by the school. The compatibility between the two can greatly hinder a child's ability to perform in school if it is too rigorous. A student also struggles when the curriculum is not rigorous enough. When the curriculum is too easy, students' needs are not being met and their academic potential is often stifled. However, parent knowledge of how school rigor matches with student needs is only the first step. Parents must also take action if the two do not match. Many parents do not have the knowledge or resources to find a more compatible curriculum and their children suffer. More information needs to be made available to parents so that they can effectively evaluate the academic rigor of their child's school. Assistance during the school evaluation process would also help parents better match their children to schools that meet their academic needs.

\section{Teacher Quality}

Teachers are an important aspect of how parents evaluate the quality of their child's education. All parents in the present study had some interaction with their child's teacher and were able to evaluate their ability to education their child. Some parents were dissatisfied with their child's teacher because their child was performing poorly academically. The majority of parents were satisfied with teachers' ability to meet their child's academic needs. Several parents listed their child's teacher as the reason they remained in the low-performing school. 
Four parents, 18\%, were skeptical of their child's teacher's ability to adequately educate their child. When a child's grades change unexpectedly, parents tend to look towards the teacher as the catalyst for this change. Charmaine, the mother of two elementary students, noticed that one of her children's grades were dropping and she worried that her child would not perform well on the FCAT. Charmaine cited the change in teachers as a primary concern. Staff turnover is common in low-performing schools and parents overwhelmingly disapproved of teacher changes (Corallo and McDonald 2001; Clotfelter et al. 2004; Boyd et al. 2005). Charmaine wanted to transfer her children but was not able to secure a spot for both of them in the same school. Although she was still dissatisfied with the academics at the school, her children remained at their neighborhood school because she could not find an alternative schooling option that met her needs. Charmaine expressed her concerns for her child's academic welfare below.

Charmaine: I feel right now, in the state, in the, you know, the way that she's being taught, I don't think she's going to do as well this year, like she did last year. Because the teachers that they had last year, they got rid of them and they brought new teachers in this year. And, if a child is so used to being taught one way, all of those years, and then all of a sudden you bring another, you know, other teachers in to teach them different, it throws them off tracks. You know, and the way that things are going now, when I seen that progress report, I'm like this is not my baby.

Tammy, the mother of two elementary students, questioned whether or not the teachers were teaching her daughter what she believed a fifth grade student should know. Unsure about who was at fault, Tammy also questioned whether or not her daughter was just behind. Although Tammy was dissatisfied with her children’s school she was uninformed about her alternative schooling options and transfer eligibility status so her child remained at her neighborhood school. Crystal, the grandmother of one student, felt 
that the teachers blamed her grandson for his lack of learning. But she felt they just did not want to put in the necessary time to teach him the way he needed to be taught. He is a special needs student and required additional help but was not receiving it. As a result, Crystal's grandson was suspended multiple times during the first two months of the school year. Like Tammy, Crystal left her grandson at the neighborhood school she was dissatisfied with because she was uninformed about alternative school options and her grandson’s transfer eligibility status. Both Tammy and Crystal expressed their disappointment with their respective neighborhood schools.

Tammy: I don't feel like they're teaching them everything they need to know. When I went to school, by the time I was in fifth grade, I knew how to count money, I knew how to multiply, divide and all of that and she don't even know how to count money and she in the fifth grade.

Crystal: I don't have no good experience with him really. Cause they don't really take time out, um, to um, teach him like they supposed to, tell you the truth. So I have a big problem with that. I really do. But, they don't seem to help. He has a learning disability anyway so that don't help make it no better. Instead of them trying to take time out with him, they always suspending him. He done been suspended 3 times already. Just went back yesterday. And he stayed back too, he's supposed to be in the $4^{\text {th }}$.

The majority of parents, $68 \%$, believed their child's teacher provided them with a quality education. Parents particularly cited the teacher's ability to educate their child as the primary reason for remaining at the school or preferring to keep their child at the school. Parents noted that teachers were familiar with their child's academic needs and learning style. Additionally, parents place a large amount of emphasis on how the teacher interacts with their child. Parents want teachers to be compassionate, caring, and understanding about the issues that students come to school with. 
Pauline, the mother of two transfer students, expressed her desire to keep her children in their neighborhood school because the teachers were familiar with her children and knew how to handle them in the classroom. Both of her children had behavior issues and she found that the teachers effectively managed her children's behavior while making sure they received the education they needed. Pauline was also familiar with the teachers and believed that they were good teachers who provided a good education.

Pauline: Honestly, like at LBJ Elementary, my kids went there from pre-k to pretty much $4^{\text {th }}$, it depends which child we're talking about. But pretty much pre-k to $4^{\text {th }}$, pre-k to $3^{\text {rd }}$. Um, so they knew me, they knew my kids, they knew their ways, they knew, you know, to call me in certain instances.

Additionally, one of the teachers helped diagnose Pauline's son with ADHD so she feels indebted to that teacher for taking the time to make sure her son got the help he needed. Personal connections often influenced how parents viewed teachers' teaching ability.

Pauline: It was actually initiated by a teacher at LBJ Elementary back when he was in kindergarten, you know because I had been having these issues with him and she was like, well hey I think it's ADHD and this is what you need to do to get the ball rolling. And it's stuff like that, you know, stuff like that that's really important. It really broke my heart to have to take them from that school.

Like Pauline, Leslie also had a teacher help her child with a special need. Leslie’s daughter was dyslexic and one of the teachers worked with her to improve her reading and writing. Parents were particularly fond of teachers who they believed went above and beyond to help their children address a personal problem that was hindering their academic achievement. 
Leslie: Because one of the teachers really helped my [younger] daughter Keisha, the fourth grader, she was left handed and she was dyslexic. She helped her cause she didn't, the fourth grader, didn't really know how to write with her left hand. And help her translate to that because she was writing upside down and Keisha didn't know how to use her left hand. Yeah they helped with that...the teacher herself. And I made her stay back one year. So she could get a better grip on it. Cause if not she would have just moved along, not really knowing. But the teacher explained to me what was going on, she told me, you know, this is to help her and we actually made a commitment for her to stay back. It really did help...she's fine now.

Parents value teachers who are going to stay on top of their child and not just let students' grades drop and look the other way. Parents expect teachers to inform them of problems and work with them to remedy problems. Leslie, the mother of three students, had to transfer one of her children because he got kicked out of their neighborhood school. However, Leslie preferred to leave him there with the other children because she is familiar with the school since her older children had attended. She was also familiar with the teachers; many of them had taught at the school for several years. Leslie believed that if her children's grades were to drop, the teachers would make sure they got back on track and raised their grades. Leslie had faith in the ability of the teachers to provide a quality education. Tamara, the grandmother of a non-transfer student also has faith in the teachers. She believed that the teachers would make sure that her granddaughter would get the education she needed.

Leslie: Oh I have no problem with the school, period. The teachers are great. Cause we stay in contact by personal cell phone numbers. Instead of trying to go to the office, I give them my straight direct number. So if something happens, I can always be right there on point. Yeah, long as they doing good then it's alright with me. But I don't think, even if they was to start slacking or anything like, those teachers, they not gon play with them. And that's what we need, more teachers like, really don't care.

Tamara: Oh I love the teachers. Very experienced teachers and they love their children. Monroe Elementary, it's the school where you go, like I say I had 
teachers that, I got mine and you're gonna get yours, those the kind of teachers you got there...those teachers make sure you get the education that you were sent there to get. And they have any kinda problem with any of the students, they call the parents. You might have certain parents come, some don't, but then they let you know it's not the parents that's interested in the child's education as well as the teacher.

Grace, the mother of two non-transfer students, valued the enthusiasm of teachers and their desire to teach. Like the other parents mentioned, Grace believed that the teachers would make sure that her children received a quality education. She also valued teachers' use of creative methods for educating her children; she could see how it enriched their overall academic experience.

Grace: Both of them are pretty young, but I love their enthusiasm for teaching. It's hard; you can't find teachers that wanna teach. They seem to be experienced because they teach them so many different things and what's funny, his language arts teacher was like you know, instead of us using the small words, I try to find the word for mad, there's anger. And instead of them using the word mad, I try to have them use other words and bigger words. And in open house when she's explaining that, I was like wow that's awesome. You know because sometimes he comes home and he wants to talk with a little slang and I'm like that's not proper English.

Teacher quality is one of the most important aspects of a student's academic achievement. Students spend the majority of their school day with their teachers. These teachers are tasked with providing a high quality education to assure students learn the necessary skills to pass standardized tests, and be promoted to the next grade level. How a parent views their child's teacher plays a major part in how that parent evaluated the overall quality of their child's school. Therefore, it is not only crucial for parents to get to know their child's teacher but also to evaluate how the teacher's methods affect a student's academic achievement. 


\section{Student Behavior}

Parents were asked about the behavior of students at their child's school and how it influenced their decision making process. Parents were also asked about how school structure or a lack of structure affected student behavior and ultimately their opinion of the school's ability to meet their child's needs. The majority of parents, 73\%, described the overall behavior of the students as good or normal. The remaining $37 \%$ of parents found student behavior to be bad and in some cases, detrimental to their child's education. Tammy and Regina explain how students’ bad behavior led to a lot of fighting at the school. For Regina, it led to her son being involved in a lot of fighting and she felt the administration did not do enough to curb the bad behavior. Tammy was concerned about her children's safety because of misbehaving students, bullying and fighting.

Regina: Yes, I think his school will do much better this year because last year I felt like the principal that they had last year, really didn't care. That was just my opinion, cause it was a lotta things that my son was getting in to, he young, he a boy, lotta play in him. But a lotta things that happened with him, I didn't know about until they was like, fed up with it. If it would have been addressed earlier, it would have prevented all the rest of the stuff that happened. Last year he had a lotta fights, that's what I meant by with the principal. He had a lotta fights in school, like one week, he had like 5 fights in one week. She didn't call me til that Friday. Like, he been fighting all week, why am I just finding out about this. They was a little more rougher last year, and then like I said the principal, it plays a lot, cause to me personally, not saying that I wanted my child to be suspended from school, but I think like when they go through stuff like that, it needs to be some discipline there so they can know that you can't just do what you wanna do. But if you ain't gone do nothing, I'm gonna continue to do what I wanna do so I think it played a lot into that.

Tammy: The kids, like, they, I'm not gon say I'm like high and mighty but it's a real ghetto school. They always fighting. My little boy, the 7 year old, in his class, it's another 7 year old, he take anger management and he be cursing, having fits. They have to call the people to put him out the classroom everyday so, and that's only a 7 year old kid. So imagine the ones older than that. So yeah, I worry about they safety all the time. Some of them kids over there, they act like they grown 
men and women. That done stayed back. Yeah they got bullies over there, it be a lotta fights.

Diana and Regina pointed out that their children’s schools lacked structure.

Students were not organized in the hallways and instead were left to roam around, which lead to chaos and misbehavior.

Diana: I thought it was, um, the perfect words to say for it, unorganized. Very unorganized with the entrance, you know when the kids get to the school, especially the lunch room, and when they are dismissed from school, it's very unorganized, I mean you get bum rushed, you know, like you'll be standing there, and trust me you fall down some, at some point. Instead of just putting the kids in line, you know, leaving classes, you know, more organization.

Regina: Last year when they got to the school, it was like they did what they wanna do in the morning. Now, you have to line up, you have to be in a straight line, it's more structure for them. Now versus them doing whatever they wanted to do. It's like now you have to do this and they do it. I think it's just they had a lot of play, like a lot of horse playing.

As mentioned in the Academics section, learning environment is an important aspect of how students perform in the classroom. The entire school affects the learning environment, specifically student behavior and the structure of the school. Whether it is in the classroom or in the hallways, the environment influences the culture of the school and can have a positive or negative effect on student performance.

The first hypothesis associated with research question one was supported by the findings of the interview data. The first hypothesis evaluated whether or not parents had access to information about their child's current school and whether or not parents were able to process current school information to make decisions about where their child attended school. State policy and county programs provided several means for parents to access and process current school information. The knowledge of parents interviewed for the current study demonstrated that state policy and county program provisions are 
sufficiently meeting the needs of parents as it relates to accessing and processing information about their child's current school.

\section{Accessing and Processing School Choice Information}

Hypothesis 2: The less state policy and county programs provide parents services to access and process information about school choice programs, the less likely the policy will adequately address parents' perceived needs to make an informed school choice decision.

The second hypothesis was assessed by evaluating whether or not parents knew about the variety of school choice options available to their child. Parents were asked if they were aware of specific school choice options, how to access additional information about these options, and how to utilize these options. The second hypothesis also was assessed by evaluating whether or not parents felt they were able to process the school choice information they had. Parents were asked to explain how they evaluate and use school choice information to make decisions about where their children attend school.

\section{Accessing Choice Information}

Access to school choice information is crucial to informing all parents of the available alternative schooling options in their district. Access to school choice information is particularly important for parents of students served by low-performing schools. Students have better schooling options available to them throughout the county but only if their parents are aware of them can they begin the process of making an informed decision about where to place their child. State policy includes several 
provisions that require local school districts to inform parents specifically about their choice options. The first provision is part of the Family and School Partnership for Student Achievement Act. The act's purpose is to "provide parents with comprehensive information about their choices and opportunities for involvement in their child's education (Florida State § 1002.23: 1b \{2012\}).” Additionally, local school districts are responsible for developing and disseminating "a parent guide to successful student achievement, which should include information about choices, be easy to understand, distributed to all parents, students and school personnel at the beginning of the school year and discussed with all parties in meetings (Florida State § 1002.23: 7 \{2012\}).” The school district must also "establish a clearinghouse of information designed to assist parents in making informed choices (Florida State § 1002.31: 5i \{2012\}).”

Miami-Dade County implements the state policy provisions through its school choice program by providing a wealth of information on its website. There is a place to access information solely about magnet school and a section specifically for charter schools. The district website provides all the information the district believes a parent should need to know about their child's schooling options, eligibility status for those options, and how to access those options. It is meant to be a one stop shop for all things school choice. Additionally, all parents should receive the district's Parent Resource Guide at the beginning of the school year to supplement the comprehensive information available online. The Parent Resource guide has information about school choice options and the website address for accessing additional information (MDCPS 2011). The Office of School Choice and Parental Options also provides information and parents can call or visit to obtain answers to questions about options, eligibility, resources, etc. 
To assess the second hypothesis, parents were asked questions to determine what they knew about various school choice options. Specifically parents were asked about their familiarity with each choice option, the eligibility requirements, and the application process. The next four sections focus on what parents knew about magnet schools, charter schools, the McKay scholarship program, and the choice options associated with NCLB.

\section{Magnet Schools}

Magnet schools have been available in Miami-Dade County since 1973 (Dunn 1997). The magnet school program was created to serve as the primary means of desegregating schools and it offered specialized courses to students in a limited number of schools (Moore 2004). Over the past 40 years, the magnet school program has grown to nearly 100 schools and over 300 programs. Therefore, most parents were familiar with magnet schools in general. However, they were unaware of their current magnet school options, the requirements or application process. Twelve of twenty-two (55\%) parents were unaware of the current magnet schools available to them. The remaining 10 parents learned about their magnet school options via the internet, their child's home school, family members, a community center, direct mail, and word of mouth. The majority of the parents, who learned about their magnet school options via the internet, 9 of 10 (90\%), were familiar with all of their magnet school options. The more options parents are familiar with, the more variety they have to choose from and the more likely they are to find the school/program that is most suitable for their children. Additionally, since parents in the current study faced transportation, child care, and neighborhood related 
constraints, the more options they have to choose from, the more likely they will find one that they can actually use. Parents' constraints to school choice options are discussed further in the Accessing Logistic Resources section.

Some parents simply did not know there were magnet schools for elementary students. These parents had older children who attended magnet schools so it was surprising they did not know. Additionally, parents would have had to fill out an application which includes all the magnet schools in the county, including the elementary schools. In most cases, others recommended the magnet schools for their older children so they actually only knew about that particular school and never inquired about any others during the application process. Diana has an older daughter who attended a magnet middle school and was currently in a magnet high school. However, she did not consider a magnet school for her elementary students when she decided she wanted to remove them from their home school. Gwen, who had considered transferring her daughter because the school was not meeting her daughter's special academic needs, also did not realize that she could consider a magnet school for her children in elementary school. She also had an older child in a magnet school. However, her older daughter's school was the only magnet school she was familiar with. A family member recommended it to her and it is in the area so she enrolled her child there. Gwen is an example of a parent who had some knowledge of alternative schooling options, but her knowledge was extremely limited.

Gwen: Oh yeah, that's what I looked up for Beacon Elementary. And I put my daughter in there cause I see they have like baccalaureate. Yeah, and I see they got that and they have other stuff like cheerleading, volleyball. This is like a middle school, I was expecting that from, she gotta wait til all the way to high school. So I 
looked into that at Beacon. I really didn't look then for elementary schools. It was just the middle school, cause I don't, I didn’t think no magnet for no elementary school.

Angela was aware of the magnet program and wanted to consider those schools for her son. However, she missed the application period multiple times. She noted that she had an opportunity to apply in the past but received the information without enough time to evaluate the school options. She did not want to rush her decision and put her son in the wrong school and have to transfer him again the following year.

Angela: Yeah, but I always find out about that at like the last minute when it's bout to be over. Because they had it for his school and they called me like that Monday and the last day was like that Friday. Yeah, not only that, you had to pick the schools, like how am I supposed to like find out anything within this short amount of time. I always seem to miss it. And then when I ask about it, it's either too early or it's too late cause like almost towards the end of the year I asked about it and they was like, it's not open yet so I'm thinking like ok when is it?

Access to magnet school information needs to be more accessible to parents of students served by low-performing school. All parents are not familiar with the extensive information on the district website. Therefore, another route to accessing district school choice information must be created. Word of mouth is not sufficient. It only provided limited options with limited detailed information. More information needs to be brought directly to parents in a format that gets them informed about their options, eligibility and the application information.

\section{Charter schools}

Like with magnet schools, parents have limited knowledge of the charter schools available to them, how they function, or the application process. However, unlike magnet schools, charter schools often times have 'charter school' in their name, making them more recognizable to the public. Therefore, more parents, 17 of 22 (77\%) were aware of 
their charter school options than those who were aware of their magnet school options, 10 of 22 (45\%). However, of the 17 parents who knew about charter schools, only 41\% knew detailed information about charter schools. Most parents, 59\% of the 17 , only knew about one or two charter schools they had driven by. Others were unaware that the schools they were considering were actually charter schools. Some parents thought charter schools were private schools they had to pay tuition for or that their child had to receive a scholarship in order to attend. Some parents lacked information about the public school status of charter schools and the enrollment process, which ultimately altered their consideration of charter schools.

Regina transferred her daughter to a charter school located directly behind the apartment complex where she lives. Regina's middle school child was attending the same school. She placed her there because it was close and convenient to have both children at the same school. However, it is the only charter school she is aware of because she passes it every day to go home. She explains, “This the only one I know about. It’s here.” In reference to only knowing about schools if she drives by them, she stated, “That's the only way, other than that I won't know nothing.” Regina was not alone in this assertion. Grace also learned about a charter school because of proximity. The one that she would like to consider for her son is located near her job.

Grace wanted to consider a charter school for her son but had not obtained any information about it. She believed that she had to pay tuition for it. As mentioned earlier, charter schools are public schools available at no cost. It is possible that the idea of having to pay tuition made her hesitate inquiring about the school. Half of the parents 
mentioned that they would like to consider a particular school or a particular type of school for their child. Of these parents, 36\% had not taken any action. Therefore, they lacked information about how the school or type of school works, if their child is eligible, or any important details necessary to make an informed decision about whether or not these schooling options were the best for their child.

Grace: If I can, I would love to send him, honestly to that charter school because I kinda see, I don't know, it has a little bit of everything. It's like an elementary to high school kinda thing. Central charter or Central Arts. I would love to like, really get information. You know, one day I'm just gonna have to go in and walk in and see. Usually, most you have to pay for those kinda schools right?

Kia and Angela both mentioned that they would like to consider a charter school for their sons. However, neither parent had conducted the necessary research. Kia had not gotten around to getting information about a particular charter school in her neighborhood. Angela tried to get information about various charter schools but she needs assistance getting additional information. Unfortunately, she did not know where to start. She had only gotten information from family and friends who have used charter schools before. Since her family members and friends had only had negative experiences with charter schools, she needed information about better options. However, she did not know where to get charter school information and she did not know who could help her with accessing charter school information.

Although the majority of parents were aware of charter schools, only $41 \%$ of those parents had detailed information about the charter school option. The rest of the parents lacked knowledge about the variety of charter school programs available, eligibility for attending those schools, and information about the resources available to 
them. Charter schools are tasked with recruiting students and must do a better job of informing parents about how charter school work. Additionally, schools should send out more documentation about their programs, sending parents more information right to their homes. Like magnet school information, charter school information needs to be provided in a way that parents served by low-performing schools can easily access it.

\section{McKay Scholarship}

The McKay Scholarship is available to students with special needs. It provides them with funding to transfer to a public or private school that better meets their needs than their current school. Six of twenty-two parents had students with special needs. Of these 6 parents, only 33\% were aware of the scholarship. The remaining $67 \%$ of parents were not aware of the McKay Scholarship program at all and ultimately struggled to find an academic program that met their child's special needs. Additionally, there was clear confusion among parents interviewed about the scholarship’s eligibility requirements.

Sylvia wanted to transfer her child, who has special needs, to a private school and was informed that she needed to obtain a McKay scholarship. Sylvia also wanted to send her other four children to the same school but did not understand they would not be able to use the McKay scholarship because they were not special needs students.

Sylvia: I tried to get them in a private school...the private school that I was trying to get them into, to me they were more concerned about the one who ADHD. They wasn't concerned about the other ones. And it made me feel that the school was paying them more money for the one who ADHD than they did the other ones. To me I felt it was about a money thing so I left them where they was. They told me to apply for the McKay scholarship. But I didn't do it after I felt he was trying to get the one for the money. 
While Angela was looking for alternative schooling options for her son, she came across a school that required the McKay scholarship. However, her son did not have a special need. Not knowing that the McKay scholarship was only for special needs students, she did not understand why she was having trouble applying for the school.

Angela: I first applied because I seen that they accept McKay scholarships on the billboard. And so I was like first let me see, before I even get, you know, take all those other steps, let me see if I can get approval for a scholarship first. And then with the McKay scholarship they had like a listing of like a whole bunch of schools, if you get approved for them, that takes the scholarship. So after I would've got approve for them then I would have took the next step but since I didn't it would've been a waste. Did it on the computer. When I checked the status of his application it was like denied because you don't have an IEP. And I don't even know what an IEP is.

An IEP is an Individualized Education Program, which all students with

disabilities have in their file. Jeneka, who has a middle school student with special needs, was able to successfully obtain a McKay scholarship. She used it to transfer her daughter from her home middle school to another public school that better met her needs.

The McKay Scholarship program opens many doors for students with special needs because it assists parents with getting their kids into schools that specialize in serving them. The most comprehensive information on the McKay scholarship can be found on the state website. However, none of the parents in the current study used the state website to access education information. All parents of students with special needs should be receiving McKay Scholarship information directly from their child's current school. Parents of students with special needs should also receive information about how to get assistance with completing the application, selecting a school, and getting their child enrolled into a school that better serves them. 


\section{No Child Left Behind Transfer Option}

Through the No Child Left Behind Act (NCLB), students can transfer to

alternative schooling options if their school is a Title I school and fails to meet Adequate Yearly Progress (AYP) for 2 consecutive year. Only one parent took advantage of the NCLB program. Information was sent home with her child and she was given the option of two schools to transfer her children to and transportation was provided. Barbara explains how she learned about the NCLB program and why she chose the school she chose.

Barbara: They're at Woodlawn Elementary. I transferred them there through the No Child Left Behind Program so they gave me an opportunity to get them from that school because it was a F school for more than, so many years. I think more than 3 years so it gave me an opportunity to take them to Woodlawn and it also provides transportation. One of my kids brought home a packet because Monroe Elementary was a F school for more than 3 years. They brought home a packet telling us, we had an opportunity to put them, change their school through the No Child Left Behind and they gave us a listing, the school Monroe and then it had two schools we had to choose from that was next to it. And by Woodlawn being the closest one, that was my first choice. Woodlawn and it was Springdale Elementary, so by it being the closest one, I gone ahead and chose that one. But I also had went up to their website and saw that it had been a A, that's a magnet school and my oldest son that's in the $5^{\text {th }}$ grade, he's in gifted. So at Monroe it wasn't that many gifted kids there so he was only being serviced one day out of the week. He wasn't benefiting from it but now at Woodlawn, he's in a gifted class all day long among other gifted kids. So that was like another, beneficial program that when I called they said they had a whole isolated gifted class. So that was a plus also.

Fortunately for Barbara, even if she had not received the packet from her

children's school, she would have had access to the necessary information. She explains how her mother, who is her primary source of education information, had already provided her with some information about the NCLB program. 
Barbara: I still, cause my mom works for the school board. She works in the administration building so I was already aware of the program because before he brought the paper home, I had already called to find out information about it. So she told me either I could go online and print it or I can come down to the school board and pick up a application, so it was gonna be done. It was gonna be done regardless

Unfortunately, only two other parents had even heard about the NCLB program. However, neither parent knew how it could help them. Additionally, the parents never did any research about the program so they were surprised to learn that they could have used it to transfer their children. Both parents wanted to transfer their children but didn't know all their options. Better advertising of program like these would be particularly helpful for parents who do not have the knowledge or the resources to do the necessary research of their schooling options. It is important to note that the NCLB program was discontinued after the 2012-2013 school year (MDCPSe).

\section{Parents’ Lack of Access}

The majority of parents either received choice information from resources other than the school district or they were not receiving this information at all. While the resources provided by the district are crucial to parents trying to make informed decisions about where their child will attend school, not all parents are utilizing them. The majority of the parents interviewed for the current study do not know about the school district's resources and those who do, rarely use them. Only 2 of 22 parents stated that they received choice information from their child's school. An additional 3 parents received their choice information directly from the school district via the website or direct mail. Parents primarily learned about choice options via word of mouth, driving by schools, and receiving information in the mail directly from alternative schooling options. 
Unfortunately, these means of learning about choice options were often associated with limited information. Most parents only knew of one or two alternative schooling options and even if parents had heard about a particular schooling option, they could provide no important details about them such as eligibility, academic programs, or tuition requirements.

State policy and county programs provide access to school choice information through a variety of means: internet, school personnel, the Office of School Choice and Parental Options, and mailed correspondence. However, the parents interviewed for the current study had limited access to school choice information. Only a few parents were utilizing the most useful resources to access information about choice options. For the majority of the parents, 73\%, their child's school is their primary source for educational related information. This is to be expected, as school personnel have information about their child's academics and behavior, what's going on at the school and additional information regarding their child's educational future. Having the school as their primary source of information is not a disadvantage in and of itself. However, parents who solely rely on their child's school for all information related to their child's education are at a great disadvantage when it pertains to information about alternative schooling options.

It is rare that parents will learn about alternative schooling options from their neighborhood school. However, two parents did state that they learned about their schooling options from their child's assigned school. There is a conflict of interest associated with neighborhood schools sharing information about alternative schooling options offering the same grade levels. Schools do not like to lose students because when students transfer to other schools, their per-pupil expenditure follows them (Cooper and 
Randall 2008). Therefore, schools would lose money and resources if they recommended students transfer to other schools.

Parents can supplement the information they receive from the school with information obtained from the internet and information from sources in their network. Parents who utilized the internet to obtain educational information usually have the greatest advantage for being informed. This was not true for the parents in the current study. The internet is increasingly becoming the primary source of information for many things and this is also true for Miami-Dade County Public Schools. There is a wealth of information on all available programs on the district's website. However, it can be overwhelming and confusing for parents who do not have more than a basic knowledge of how to use the internet. Eighteen percent of parents did not have access to the internet. Of the remaining $82 \%$ of parents who did have access to the internet, $83 \%$ knew how to use it, $78 \%$ used it for educational information, and 23\% stated it was their primary source of education information.

Parents' combination of resources utilized to learn about choice options primarily included the school, the internet, friends, family and/or coworkers. The school encompassed any resources associated with their child's assigned school. School resources included fliers/memos sent home, school personnel (teachers, administrators, counselors, security guards, etc.); information provided via their child, information obtained at school events, the school website, and phone calls. The internet primarily included the district website. However, most parents did not use the district website to obtain school choice information. Instead, parents primarily used it to access the parent portal, which allows them to view their child's grades. Twelve of twenty-two parents 
used the district website, with 9 of the 12 using it primarily to check their child's grades. Friends, family and coworkers often provided some general information about alternative schooling options. Although parents who obtained choice information from friends, family or coworkers, displayed limited knowledge of their alternative schooling options, this information was enough to get them thinking about school choice. In some cases, it even led to parents transferring their child to a school they felt better met their needs.

\section{Evaluating Choice Information}

Although most parents did not have a lot of information about their schooling options, they still needed to evaluate the information they did have. Evaluation of such information can be overwhelming. While each parent had his or her own priorities when making a schooling decision, help mining through the information would be useful to all parents. State policy places the responsibility on the Department of Education to establish "a parent-response center to answer parent questions and resolve issues related to the child’s education (Florida State § 1002.23: 4 \{2012\}).” At the district level, parents can utilize the services of the School Choice and Parental Options and Charter School Operations Offices. School Choice and Parent Options is an office within the school district that oversees the entire magnet program. Parents can utilize this resource to access all the information they need to consider and use any magnet school as an alternative schooling options for their child. The County’s Charter School Operations Office provides comprehensive information about charter school options.

Information about scholarships - Florida Tax Credit, McKay and Opportunity can be found on the state's Department of Education website. Also available on the 
state's website is additional information about magnet schools, charter schools, and various other schooling options available to parents. However, as mentioned in the previous section, the majority of parents interviewed for the current study did not use the internet to access information about alternative schooling options. Only 8 of the 22 parents used the internet to access information about other schools. The remaining 14 parents either didn’t use the internet at all, didn’t use the internet for educational purposes, or they only used the internet to access their child's grades. The wealth of information online needs to be more accessible to all parents. The parents who did use the internet to access information about other schools often went to a particular schools’ website for additional information. Parents who used the internet were not using the district website, state website or any basic internet search tools to access information about all of their school choice options. Most parents did not know that they could gain access to all schools via web resources.

The district has also made regional parent liaisons available to parents should they need additional information or assistance. Miami has an Office of Parental Involvement, which provides a point of communication for parents and can point them in the right direction for any issue. However, the office’s primary responsibility is to promote parental involvement and implement the district's parent involvement policy. Parent involvement training is also available to parents to help them become "successful advisors, advocates and partners in the decision-making process (MDCPS 2011a).” The district's policy emphasizes providing parents with the necessary support and resources 
for them to be meaningful collaborators in the decision-making process at all levels of the educational system.

Once parents access information about alternative schooling options, they must organize it into a format that is easy for them to evaluate so they can make an informed decision. It is implied that once given information, parents can understand it and use it to make a decision on where their child should attend school. Additionally, when a parent transfers their children, it is expected that some evaluation was done. However, of the 11 parents of transfer students interviewed for the current study, only four (36\%) actually completed some evaluation of their child's school. Of those who did not complete an evaluation, only two of seven - Diana and Regina -had some prior experience with the transfer school they chose. Diana transferred her children back to their previous school, while Regina transferred her daughter to the same school her older child was attending. Since the remaining five parents moved or were forced to remove their child from their pervious school, they simply transferred their child to their home school without doing any evaluation of the school at all.

Seven of eleven (64\%) of the parents of non-transfer students considered transferring their children. Three of the seven (43\%) who considered transferring their children completed an evaluation of alternative schooling options. Of the remaining four parents, only one parent had prior experience with the school she was considered. The remaining three parents who considered transferring their child did not do an evaluation of any alternative schooling options. 
The parents who evaluated their alternative schooling options used a variety of methods, with each parent focusing on a specific factor(s) during the evaluation process. Jennifer focused on the academic programs. Utilizing information she received from the school, online, and from a parent of a student attending the transfer school, she was able to determine that the one schooling option she had was the right one for her grandson. Charmaine also focused on the academic programs offered at the three charter schools she considered for daughters. She did not rate the schools but simply concluded they were all good options. She applied to all three. Unfortunately, she couldn’t find a space in the same school for both of her children so she did not transfer them.

Jennifer: I talked with one of the office personnel and I asked them what do they offer in their school and she gave me a little information, the academic part. And then they helped me to get online and to read a little literature about what was going on at the school and stuff like that. I did speak to a parent and she was telling me, cause that was my first time, transferring them out, because they had been in that school since they was babies. All of them. And I transferred him out and one lady was telling me that it was an excellent school. Her son works well at the school, he gets good grades and stuff like, he really wanna get good grades. I was at another place and I was just talking about, no I went to buy a shirt and the parent was saying, I just left Garfield Charter. And she started talking about what was going on at the school and stuff like that. Cause that's my first time ever transferring them into another school.

Charmaine: I looked at, like researched, I researched them on the internet, and I also had a agenda packages that I went to the schools and got. And I looked through the whole codes and everything. The package agenda stuff. Academics is basically all I look for. Basically all of them kinda like, sorta matched up together so it was really not, you know, a big factor, it was just the space. [If they] got in, I would have been ok.

Pauline, who had to transfer her children because her aunt moved, didn’t feel she had a choice. She had to use her aunt's address because she needs her children in schools that are located near the home of someone who can supervise them after school. Prior to transferring her children, she did talk to her family members who had children in the 
transfer school and she visited the school. She did not review any information specifically

about the school, just information about her cousins' experience and information she learned during her visit to the school.

Pauline: No, I didn't have any information on Columbus Elementary when I got them over there. I visited Columbus and it was just because my cousins had already went out there and I went out there and it seemed like a really, you know cool environment and my little cousins, they, you know they'd only been out there a week or two but they liked it and they, the teachers are nice and things like that. So I did visit it before I transferred them out there.

Barbara, who used the No Child Left Behind transfer option, was provided the

name of two schools that she could consider. Her main focus was getting her children into a new learning environment so she focused on the academic programs offered.

However, the schools' locations were also a primary factor that was focused on since she had concerns about having to travel a long distance to pick up her kids in an emergency.

Barbara: So that was my main two purposes of changing them. Different students, different environment, learning environment and everything, different teachers and attitudes and everything. I didn't pick any schools, I was basically I was gonna look into the charter schools again and when I heard about that program I researched it...they gave you an option of two schools. So when the list came home, I just picked that one, I was satisfied with that one. And by Woodlawn being the closest one, that was my first choice. Woodlawn Elementary and it was Springsdale Elementary, so by it being the closest one, I gone ahead and chose that one. Because even though they provided transportation, if something happen and I need to get there fast, it would be easy for me to get there. But I also had went up to their website and saw that it had been a A, that's a magnet school and my oldest son that's in the $5^{\text {th }}$ grade, he's in gifted. So at Monroe it wasn't that many gifted kids there so he was only being serviced one day out of the week. He wasn't benefiting from it but now at Woodlawn, he's in a gifted class all day long among other gifted kids. So that was like another, beneficial program that when I called they said they had a whole isolated gifted class. So that was a plus also.

Two parents allowed their children to participate in their evaluation process.

Tamara and Grace both placed a great emphasis on their child being comfortable and 
would not select a school that their child did not want to transfer to. After evaluating a schooling option, Tamara let her granddaughter attend the school for three days on a trial basis. The three-day trial allowed both Tamara and her granddaughter to evaluate the information they had about the schooling option and make an informed decision. Grace also evaluated schooling options with her son. She let him make the final decision about whether or not to transfer to a new school.

Tamara: Number one is the academics of the school. Because I need to know the academics of the school and what level they on and how they behavior. So the academics will be number one. And then I need to know what the principal, how he or she interact with these kids. So this is what you have to look in with the students and the teachers and the principal. So this is what I look for when I go to a school. They gave me a booklet, a whole heap of paperwork. And I actually sat down the day after and went through it all and read it all. And then I went back, I went back and we talked some more and they gave me more information. I never took her out [of her original school]. I just enrolled her for the summer. She went 3 days and she didn't like it so I went back to the principal, cause me and the principal talked and I had already told him that I'm not gonna make them, come. If she don't wanna come, I'm not gonna make her come because I want her to be comfortable to where she's at, so I know I'll get what I deserve from her. And I don't want her to rebel.

Grace: I got information, they're all A schools. They're all good schools, it's just, I don't know. And then I asked him, he's old enough to where he has his own opinion. He's like, I would like to keep going to my school cause my friends. I don't wanna make new friends. And I was like, you never know. New friends are good. He said, no but the friends I have, been with me since kindergarten and we're gonna go to fifth grade and you know everybody's pretty much the same. So I just, you know what ok, make you comfortable and it worked out.

Three parents had prior experience with the alternative schooling options they were considering for their children. The parents used their prior knowledge of these schools as their primary source of information. They did not evaluate any new information when making their decision to transfer their children or keep them in their current school. Diana was dissatisfied with her children's grades at their current school. 
Their grades had been better at their previous school so she decided to transfer them back. Regina also was dissatisfied with her child's grades at her current school and decided to transfer her to the school where her older sister attended. The new school was conveniently located and her older daughter was doing well there so she hoped that her younger daughter would as well.

Diana: Actually Mcnair Elementary was the first school that they attended when we first moved to Homestead. So they had a very good experience there when they first went to that school and then after that school, that's when they went to Wright Elementary, which they didn't have such a good experience in that school. So when I moved again they were very happy to go right back to Mcnair Elementary.

Regina: I just knew it was close that was my thing I looked for close. She could walk. Buses, my thing I was scared bout her getting on a bus. That's my thing, I'm scared bout that. I know how I am about my daughter, my kids period. Her sister there, since her sister there, the older sister, they can walk together. It's right there. Yeah I'm comfortable with the school. Her sister there. That was really, them two right there my concern. Cause if I would have took her where I would've had to drive, distance like different schools. So I say let me put her with her sister so they can be together and they can just walk together.

All of these parents were able to take the information they had about their schooling options and make informed decisions. Parents stated that they did not need assistance evaluating information. However, the remaining 8 parents who either transferred their child or considered transferring their child did not conduct any evaluation and the majority also stated that they did not need assistance. Five of the eight parents transferred their children. Of the five, two felt they had no choice in their schooling option. Their children attended their new home school after a move. Two other parents did not complete an evaluation but stated that they did not need assistance processing information. Leslie, the mother of a student who was expelled, chose to transfer her son to the closest school. She left her remaining children at the previous 
school. Kenneth simply ran out of time to evaluate alternative schooling options for his daughter. She was placed in her new neighborhood school after moving to live with her father.

The fifth parent, Sylvia, needed assistance processing alternative schooling options. She was not clear on how the McKay scholarship worked or the options for her special needs student. Sylvia also could have used assistance accessing information about schooling options. She tried to use a McKay scholarship to place her special needs student, along with her other children into a private school. She did not understand that only special needs students can used the McKay scholarship. Since she did not want to just transfer just one child, she had to find another option.

Sylvia: It took a long time. I was trying to get her in a setting like this ever since 2007. And she just got into the setting last year. It was difficult, it was hard, I had to fight. I had to talk to this one, talk to that one but eventually I got through. I was gone take them to the private school, but the private school only wanted the child with ADHD. And I wasn't going for that. They told me to go apply for the McKay this year for the rest of them but I say I ain't doing nothing. If I do it, it won't be at that school, I have to find another school.

Three parents who considered transferring their children needed help accessing information. They did not get an opportunity to do an evaluation because they were struggling to get the information they needed. Angela illustrates the struggles some parents have with finding a school for their child.

Angela: It was kinda hard because I was gonna put him at a charter school but dealing with the charter schools you never know what you gone get. I don't even know where to start. I was thinking about the sizes of the classes cause most charter school classes are small. So that was why I also was considering, cause I was thinking like maybe he get more attention. If I could've I would've moved him. I would've moved him. 
The majority of the parents who transferred their children or considered transferring their children did not feel they needed assistance evaluating the information they had. Focusing on the factors they found most important, they believed their evaluation process was sufficient and resulted in a satisfactory alternative schooling option. However, it is clear from the parents' limited number of school options and restricted evaluation processes that they would still benefit from assistance. With some assistance from those knowledgeable of school choice, parents could have had more schooling options to choose from and an evaluation strategy to determine which of those schooling option was best for their child. Additionally, with more information about resources available to help parents use alternative schooling options, parents could make choices focused more on their child's academic needs and less on location and convenience.

The second hypothesis associated with research question one was not supported by the findings of the interview data. The second hypothesis evaluated whether or not parents' perceived needs for accessing and processing school choice options were adequately addressed by state policy and county programs. While the state policy and county programs provided several services to assist parents in accessing school choice information, the parents interviewed for the current study were not accessing it. State policy and county programs also provided several services to assist parents in processing information about school choice. Several parents felt their perceived needs were being addressed. However, parents were unaware of many of their choice options and were only able to conduct limited evaluations of the information available to them. Because 
these parents seldom access educational information using the internet, they lack sufficient access to some of the most useful information for making an informed schooling decision.

The majority of parents were aware of at least one type of school choice option. However, few parents knew enough information to access information on available schools, eligibility requirements or the application process. The information that is available to parents is comprehensive and if it were accessed could substantially assist parents with making an informed decision. However, it was discovered that the parents in the current study, have special needs when it comes to accessing educational information. Parents' special needs include different resources to access school choice information and additional assistance evaluating the information. State policy and county programs must create additional means for the parents of students served by low-performing schools to access and process school choice information.

\section{Conclusion}

Parent knowledge of the quality of the academics, teachers, and overall learning environment of their child's current school is crucial to their decision making process about whether or not their child is receiving an adequate education. Parents who can assess the quality of their child's current school can make an informed decision about how school choice options could be useful to them. The findings of the interviews illustrate that parents had adequate access to information about the quality of their children's current school. Parents were also adequately equipped to process current 
school information to make a school choice decision. Therefore, the first hypothesis was supported by the interview findings.

For parents served by low-performing schools, the opportunity to place their child in a different school empowers parents to take control of their child's education. The diversity of options, located throughout the county, assure that parents can find something that meets their needs. When parents can take the information they have about school choice options and easily evaluate it, their child's educational future can be greatly improved. Parents' ability to access and process school choice information is crucial for parents to make an informed decision about the best school for their child to attend. Parents who have access to the wide variety of school choice options can consider the wide variety of programs that can meet their child's academic needs. However, without the ability to process school choice information parents are not always able to utilize the options that are available to them. Parents in the current study did not have adequate access to information about their school choice options. Parents were also not adequately equipped to process school choice information to make school choice decision. Therefore, the second hypothesis was not supported by interview findings.

Only a limited amount of the information provided by state policy and county programs actually reached the parents of students served by low-performing schools. The efforts of state policy and county programs were not sufficient to meet parents' needs. State policy and county programs appear to be unaware of the special needs of parents served by low-performing schools. More must be done to make parents aware of their resources so that when necessary, they can seek them out to access and process school 
choice information. Additionally, making choice information available to parents at their child's current school, where they are accessing the majority of their educational information would benefit them greatly. Although this is a conflict of interest for the schools, the district has an obligation to assure parents have the information they need to make an informed decision. If parents are not accessing school choice information through the current avenues provided, the district must change the means of informing parents so their children are not placed at a disadvantage. 


\section{Parents' Resources and Constraints to School Choice Options}

Chapter VI discusses the remaining findings from the parent interviews. The first research question in the current study evaluated whether or not state choice policy and county choice programs adequately address the perceived needs of parents served by lowperforming schools so they can access school choice options and make informed school choice decisions. Chapter VI will discuss the last two hypotheses that were tested to answer the first research question:

- The less state policy and county programs provide parents information to understand their eligibility to place their child in an alternative schooling option, the less likely the policy will adequately address parents’ perceived needs to access school choice options

- The less state policy and county programs provide parents logistical resources to utilize alternative schooling option, the less likely the policy will adequately address parents’ perceived needs to access school choice options

The fourth research question in the current study evaluated how economic and social factors differentiate the decision making process of parents who transfer their children from and those who keep their children in low-performing schools. However, only the portion related to social factors is evaluated using parent interview data. The hypothesis tested to answer the social factors portion of the research question is the following: Compared to parents of students who stay in low-performing schools, parents who transfer will have more useful social networks. 


\section{Understanding Eligibility}

Hypothesis 3: The less state policy and county programs provide parents information to understand their eligibility to place their child in an alternative schooling option, the less likely the policy will adequately address parents' perceived needs to access school choice options

In order for parents to assess alternative schooling options, they need to first know that they have the option to leave their child's neighborhood school. Once parents know that, then they can begin the task of finding a replacement. In Miami-Dade County, parents are offered a variety of alternative schooling options for their children. There are charter schools, magnet schools and private schools. Students can also access alternative options through the No Child Left Behind transfer program, controlled school choice, and opportunity scholarships. As mentioned in the previous chapter, state and county policy include provisions to inform parents about their child's education and their school choice options. The state and county websites provide all the information that parents need. Additionally, parents can get the information they need from dedicated offices within the local school district. Hypothesis three was assessed by evaluating whether or not parents knew that their child was not restricted to their neighborhood school. Additionally, parents were asked to demonstrate that they were aware of their child's eligibility to attend alternative schooling options.

Tammy was not happy with her children’s school and wanted to transfer them. However, her children remained in their neighborhood school because she believed they were required to attend their home school. Diana was also dissatisfied with her children's 
home school. Believing her children could only attend their neighborhood school, Diana moved near the school that she wanted to transfer her children to. By moving to a new neighborhood, Diana had an alternative schooling option she was happy with but the process could have been much easier for her if she knew there were other options. The method of moving is reminiscent of how parents made schooling choices prior to school choice policy. Parents with the necessary resources could "vote with their feet" by moving to the school district with the school of their choice (Vandenberghe 1999; Hoxby and Rockoff 2005).

Tammy: You know it's hard these days to get an education, especially at a school like that. If I had transportation and, you know they place kids by your address so they would automatically have to go there but if it was up to me, they would go somewhere else. But see, they have this thing about, you gotta go to the school that's in your district. That match your address so even if I wanted to get them out of there, I couldn't, unless I move. I know that I can call the school board but you know you not going to get too much from them, because they basically tell people that call they gotta be in the area where the address match. That been the thing with the school for years. Well I feel like they should know it shouldn't go by no address, it should go by how you feel about your child, like they performance and they safely and things like that. They shouldn't be worrying about no address, that's crazy.

Diana: I believe us parents should be able to choose which schools our children we would, you know, we would like our children to go to. Not that it'll be based on an address or zip code, you know, because sometimes an address or zip code is based on an F school and that is not, too good for the kids, you know. I moved so it's their zone school, which I was happy and the kids were also happy when they found out they were going back to Mcnair elementary. So they were happy with that. Intentionally so they could go back to that school cause it wasn't going well at Wright. That was my goal, is to move around Mcnair, to get them back into Mcnair.

Although only $36 \%$ of parents understood their child's eligibility to transfer to the majority of the alternative schooling options available to them, another $36 \%$ was aware of their child's eligibility to attend at least one alternative schooling option. Parents who believed their only alternative option was a charter or private school, were limited but 
still had a way out of their child's assigned home school, if they were interested. The academic opportunities of the children of the six parents who believed they had no options because their child was required to attend their neighborhood school were greatly limited. For those parents who are both misinformed and unhappy, they are often left feeling helpless and their child's education suffers.

Parent understanding of their child's eligibility to use various school choice options is an important part of the decision making process. When parents do not know that they can enroll their child in a school other than their assigned neighborhood, they lack control of their child's academic future. Even parents with limited knowledge of their child's eligibility to attend schools of choice are disadvantaged. Parents have to make do with their limited options and in some cases they are unable to use them. Only 8 of 22 parents, 36\% understood their eligibility requirements for the majority of their alternative schooling options. The majority of parents had limited or no information on their child's alternative schooling options. Twenty-seven percent of parents believed that the assigned home school was their only option for their child. Therefore, the third hypothesis was not supported by the findings of the interview data.

Although state policy and county programs provide resources to inform parents about school choice options eligibility, the majority of parents' needs were not adequately addressed. Eligibility information is closely related to school choice information. Therefore, it was no surprise that parents had limited information about both. As with accessing and processing choice information, more needs to be done to provide this information in a means that parents can access it. Parents in the current study have special 
needs as it pertains to access to educational information. At a bare minimum, parents should know that their child no longer has to attend his/her assigned neighborhood school. Especially when the school is low-performing and when parents are dissatisfied with the school.

\section{Accessing Logistic Resources}

Hypothesis 4: The less state policy and county programs provide parents logistical resources to utilize alternative schooling option, the less likely the policy will adequately address parents' perceived needs to access school choice options

Once parents have decided they want to consider alternative school options, their decision making process is influenced by their access to various forms of logistic resources. Logistic resources include, but are not limited to, transportation, child care, and time. State policy and county programs provide few services and resources to assist parents with their logistical constraints. Hypothesis four was assessed by evaluating what logistical constrains parents faced and the resources they had to address these constraints.

Parents were asked if the location of the school was an important factor in choosing a school. The majority of parents, 14 of 22, stated that the schools location was important. Sixty-four percent of the 14 parents also stated that location was the number one factor they consider when making decisions about where their children attend school; the reasons why varied among parents. These included transportation, proximity, neighborhood, and child care. Of the 14 parents, six stated the location was important because of its proximity to their home. Regina, the mother of two students who attended a school directly behind their apartment, did not want her kids on the bus. Since they 
lived so close they could walk to school with each other and other students who lived in their apartment complex. Regina felt transporting her children to different schools, while also getting herself to work would have been too much so she prioritized convenience.

Regina: Really close, she could walk. I just, I knew it was close, that was my thing I looked, close. She could walk. Buses, my thing I was scared bout her getting on a bus. That's my thing, I'm scared bout that. I know how I am about my daughter, my kids period. It's close [and] even though I have a car I have to get up, you know, it's a lot.

When Charmaine was choosing transfer schools to apply to, she was concerned about how close the schools were to her home. She worked far away from her home and her husband, who is paralyzed, could not drive. A school Charmaine was interested in had to be excluded because it was too far from her home. She expresses her concerns about proximity below. Because she worked in South Dade County and her home was located in Central Dade County, she needed her children to be able to get home on their own. Also, the majority of Charmaine's family lived in South Dade County so they were only able to provide assistance in an emergency situation.

Barbara was also concerned about proximity because she did not have a car and wanted to be able to get to her kids quickly in case of an emergency. She relied on borrowed cars to get from place to place. She explained why transportation provided by the school was not enough for her to consider it a viable option. She had two schools to choose from using the No Child Left Behind transfer program but she felt she could only choose the closest one.

Charmaine: But then I was thinking, I'm working now and my husband is paralyzed, I had to have them kinda close. Everybody's South. I'm from South. So everybody there. The only ones up here is my mother-in-law but actually she 
come from Broward. And then I have a sister-in-law but she, that's another case. You can’t depend on her. I have family members, my mom, my mother-in-law [for] emergencies.

Barbara: Even though they provided transportation, if something happen and I need to get there fast, it would [not] be easy for me to get there

Another five parents stated the location was important because of the type of neighborhood the school was located in. The parents were primarily concerned with the safety of the neighborhood where the school was located. Kenneth stressed the importance of finding a school that was located in a neutral area of the overall neighborhood. He lived in an inner-city neighborhood with a high level of crime. Kenneth wanted to make sure his daughter did not have to walk through or attend a school located in an unsafe part of the neighborhood. Mya also stressed the importance of the surrounding neighborhood of the school. Mya had several schooling options in her neighborhood, some of which were schools she would like to consider. However, safety concerns and her children's mode of transportation to school, which was walking, caused her to exclude some schools from her decision making. She believed the area surrounding some of the alternative schooling options in her neighborhood, were too dangerous for her children.

Kenneth: Yeah at least have her in a neutral place. We already over here, at least have her be in a neutral place where it's not too much, you know. Some schools...war zones. So it depends over here. You look for schools and try to hope that they be in a neutral place. Most peoples would not want they child in this type of community. I was raised up in it. So I know the good about it and I know the bad about it. I believe if you can really have them on that tight rope, I think it'll do some good cause it teach you to not run from issue but build up where you at. And then if you decide to leave cause you have enough to leave, you can always, you know, come back and see the fruits of your labor. So that's one way I see it. 
Mya: I wouldn't have my girl walk to school now. That's why they're right here. I don't even know if Wade Elementary was ok with their FCAT scores. I don't really think I was, I probably will put them there now because my mom is home, since she's unemployed but before, no, I just need something where they can just go in the gate and out the gate and [be] right here. So have to be able to maintain that work knowing that all they had to do was go in and out because it's a rough area.

Some parents need before and after school care for their children. However, before and after school care is often at a cost and not all parents can afford it. Angela and Pauline both were restricted in their schooling options because of difficulty finding sufficient and affordable child care for their children. Angela had to coordinate with her cousin to get her son to and from school. If she chose to transfer her son, her cousin's child would also have to transfer. Her son must attend school with her cousin's child so there is someone to assist with transportation. Angela had to exclude the school that was located within a 5 minute walk from her home because she did not want her son home alone after school.

Pauline used her aunt's address so her children could attend a school near her aunt's home. Her aunt was available to watch her kids when they got out of school, while Paulina is still at work. Pauline lived in Broward County but had to enroll her children in a Dade County school because that was where she had assistance. In Broward County, she lived directly across the street from an "A" school. However, Pauline could not even consider the " $\mathrm{A}$ " school because there was no one in the area to watch her children after school and she could not afford aftercare.

Angela: That's his home school, but I have no one to get him from there. Everybody's over there. I'm still trying to find childcare for him. I never even talked about transferring him to another public school. Never talked about it. Cause I don't know. Yeah, never talked about it because if he was gonna move, 
my cousin was also gonna move her daughter too. So wherever they go they was gonna go together. But my thing is, I work in Broward now. And I feel like the Broward school system is a little better than the Dade County school system and I wanna move him, I also wanna move. I'm planning on moving, but the thing about that is, my help is all here [in Dade County].

Pauline: I live in Hollywood right across the street from an A school. I don't have anybody to get them after school. And even though my 14 year old, he's autistic, you know, he's not able to see over them. My 11 year old, she's really responsible, but the other ones would run over her. I was actually having, going to have them transferred, but, like I tested them during the summer, I let them stay home for like 4 hours while I went to work and when I came home, my house was just like, torn down. The doorknob had been taken off the bathroom, I mean it was just ridiculous. I was like, ok, so that has made up my mind. They can't stay home by themselves.

While a variety of schooling options are available to parents throughout the county, it is important that parents have options in their neighborhood. As evidenced by the parents in the current study, the location of the school is important and in most cases, it goes beyond just access to transportation. The geographic evaluation in the next chapter illustrated that parents wanted to place their children in schools located near their home. Transfer students chose alternative schooling options that were located within half a mile of their homes. It will be the schools of choice located in close proximity that will attract parents who are constrained by limited logistical resources, like the parents in the current study.

Location was an important factor in the decision making process of the majority of the parents in this study. Parents also had to consider child care needs and the type of neighborhood schools were located in as they tried to select a school for their child. The logistics of using school choice options can be overwhelming, especially when there is a lack of resources to assist with constraints. State policy and county programs offered limited resources to alleviate the logistical constraints that parents faced in navigating the 
educational marketplace. Therefore, the findings of the interviews supported the hypothesis that the less state policy and county programs provide parents logistical resources to utilize alternative schooling options, the less likely the policy will adequately address parents’ perceived needs to access school choice options. Local school districts must do more to address logistical constraints so that all parents and students can have access to school choice options.

If local school districts offered more transportation or partnered with organizations that could help with child care needs some of the burden placed on parents with limited resources could be alleviated. Parents must also be made aware of the resources that do exist. As mentioned in Chapter $\mathrm{V}$, parents were often unaware of the resources that are available to them. Currently parents' most useful resources for alleviating logistical constraints and accessing information about school choice options are social networks. Social networks consist of the people that parents know who can provide assistance with child care, transportation, or information about resources and school options. The next section demonstrates the difference between the size and usefulness of the social networks of parents of transfers and parents of non-transfers. The social network section also illustrates how social networks can provide much needed support to parents attempting to use school choice.

\section{Social Networks}

Hypothesis: Compared to parents of students who stay in low-performing schools, parents of students who transfer will have stronger social networks. 
Research question four evaluates how economic and social factors differentiate the decision making process of parents who transfer their children from and those who keep their children in low-performing schools. The interview data only focuses on the evaluation of the social factors. The hypothesis states that compared to parents of students who stay in low-performing schools, parents who transfer will have more useful social networks. Parent school decision making often relies on other people. Therefore social networks are an important component of the school choice process. Parents with access to quality social networks have more schooling options to choose from, higher quality information about those schooling options, and assistance making an informed decision (Schneider et al. 1997; Horvat et al. 2003; Lee and Bowen 2006). Parents were asked who specifically they get education related information from and what their relationship to these sources was.

As mentioned in Chapter V, parent social networks were measured in two different ways. The first measurement was the number of people parent's spoke to about educational related issues. The second measurement was the strength of the relationship. Strong ties are family members, while weak ties are non-family members. Weak ties are often most useful as they provide access to new avenues of information (Schneider et al. 1997). While the parents of non-transfer students had larger social networks, the parents of transfer students had stronger social networks because they had more weak ties. The hypothesis was supported by the findings of the parent interviews.

The parents of non-transfer students had, on average, larger social networks than that of parents of transfer students. Non-transfer parents had a range of 0 to 8 individuals in 
their social network, with an average size of 2 people. Transfer parents had a range of 0 to 3 individuals with an average size of 1 person. Four of the 11 parents of transfers had no one to discuss education related issues with outside of school personnel at their child's assigned neighborhood school. Parents with no one to discuss education related issues were left to fend for themselves when making school choice decisions. Parents with limited or no ability to use the internet are at an even greater disadvantage.

When asked if she met other parents at school events, Grace explained that it was difficult because the parents at her sons' school were not sociable. Other parents could have played an important role as part of Grace's social network, potentially providing the type of information she needed to find a better school for her sons. Instead, Grace was left only with the resources she could find online and information provided to her by her supervisor and her mother-in-law.

Grace: I would love to, you know, there's nothing wrong with that but I guess the neighborhood that the school's in the parents are not sociable. They're more like get their kids and go home. I would love to because I would love for them to come home with a friend or so, you know, have that communication. But I'm not gonna bring some kid over and I don't know their parents. It's just not gonna go down like that but some people are not like that. I've tried and they're like oh well we don't have the time.

In addition to having larger social networks, parents of non-transfers had more useful networks. As mentioned before, family members make strong ties but less useful members of one's social network because an individual usually exhausts these ties more quickly (Schneider et al. 1997). Therefore, since the parents of non-transfers had more weak ties in their network, they had more useful networks. Weak ties offer parents access 
to more diverse individuals with new information. Weak ties can be particularly useful for parents in need of access to alternative schooling options.

Charmaine illustrated how weak ties can lead to quality information about alternative schooling options. She was informed about 3 charter schools that she would eventually try to get her daughters into. Unfortunately, none of the schools had room for both children so she was not able to transfer them. She explains how she learned about the schooling options.

Charmaine: It was other parents off to the school, the same time I was when we were picking up report cards over the summer and they was giving me the names of the school that they was, cause it was like, maybe about a hundred children got pulled out of that school. They're going to charter schools now. I looked at 3 charter schools. Basically they had an opening for my $4^{\text {th }}$ grader but the $3^{\text {rd }}$ grade spots were closed and I don't want them in separate schools. So that's why I didn't change them this year.

Mya explained that her primary source for educational information was her mother, who used to work for the school board. While her mother had provided her with useful information, it was her mother's access to other school board employees that provided the weak ties that could be helpful to Mya. School board employees can provide extensive and quality information. Mya’s access, through her mother, to these weak ties, ultimately increases the usefulness of her social network. Mya explained who she went to for educational information and how her mother linked her to new ties.

Mya: My mom cause she was with the school board for a while. So whenever I have like any like questionable doubts about what school or doing, I go to her. And she'll go, we have a lotta people who work for the school board.

Unfortunately, not everyone had access to weak ties. Tammy only had her mother in her social network. While she knew other parents at the school, she did not utilize them 
for educational information. Since Tammy was not satisfied with her children's school, it would benefit her to reach out to other parents for information that may help her find a better school. However, she preferred to keep to herself.

Tammy: Yeah I know some of the parents; I grew up with some of them. They live around here. I basically stay to myself, but if I see a person and I know them, I speak but far as hanging around people, I don't, I don't hang around no one, I stay home and be around my family.

When asked if she had anyone to discuss alternative schooling options with, Tammy stated, “No, I just can call, I guess information being given or call the school board and ask them.” However, since she believed that her children were required to attend their home school, at the time of the interview, she had not made any calls to inquire about alternative schooling options. She believed that whomever she called in the school district would tell her that her children have to attend their neighborhood school.

Donna transferred her son from his previous home school to his new home school after a move. However, she was not satisfied with his current school and wanted to transfer him back to his previous home school. Donna was also interested in finding a new school for her middle school students. However, she did not know about her options. Like Tammy, Donna's only source of information was a family member. Donna lacked weak ties who could potentially provide her with new information about alternative schooling options; information that her sister may not have been aware of.

Social networks provide parents with a variety of education related information. Although having a large network is beneficial, the quality of the people inside the network is more important. Family members and friends tend to have the same 
information and access to similar resources. Therefore, these individuals can be helpful but often cannot provide a lot of new information. These resources are dried up quickly. Tapping into ones other acquaintances can prove much more useful. People that are not as close to each other tend to have different resources (Schneider et al. 1997). New resources and information can produce more satisfactory outcomes. By diversifying ones social network, parents place themselves at a greater advantage for getting the most out of school choice programs. Parents are more likely to find a school that meets their child's needs. They are also more likely to be informed about eligibility, options and logistical resources, all of which is crucial for school choice decision making. The hypothesis was not supported by the findings from the interview data.

\section{Conclusion}

The semi-structured parent interviews provided first hand examples of how parents navigate the school choice landscape. These interviews also allowed parents to have a voice and tell their stories. Parents' struggles are important particularly because their students are served by low-performing schools. As evidenced by the findings, parents are uninformed and lack access to the resources necessary to take control of their child's education. State policy and county programs do not meet the needs of parents served by low-performing schools. Although there are a variety of ways for parents to access information about choice options and eligibility, the parents in the current study were uninformed. The school district and schools of choice must do more to inform these parents; their current efforts are insufficient to meet these parents' needs. New avenues for accessing this information must be used to meet the needs of parents who are not 
accessing information through the current means. State policy and county programs only provide a limited amount of information and resources to assist with logistical constraints. Therefore, parent's use of school choice options was hindered. Limited access to reliable transportation, child care and concerns about the safety of the surrounding neighborhood were all constraints that influenced parents' decision making about where their child should attend school. Social networks can provide assistance with these constraints and accessing information about school choice options.

The parents of non-transfer students had larger and stronger social networks than those of the parents of transfer students. As explained in the social networks section, nontransfer parents had more weak ties that they used for educational information. Weak ties are often most useful as they provide access to new avenues of information (Schneider et al. 1997). Social networks with more weak ties can provide parents served by lowperforming schools new information about school choice options. However, parents must first know that their child is eligible to use school choice. Accessing basic eligibility information, along with detailed information about the variety of school choice programs can help parents make informed decisions about where their child attends school.

Chapter VII presents the findings of the statistical and geographic analyses. These analyses were used to evaluate the characteristics that differentiate students who transfer from and those who stay in low-performing schools. Chapter VII also presents the findings of the analyses that evaluated the characteristics that are most influential in predicting the type of school transfer students attended. 


\section{Comparing the Demographic, Academic, and Geographic Characteristics of Transfer and Non-Transfer Students}

Chapter VII discusses the findings from the statistical and geographical analyses. The second research question in the current study evaluated the characteristics that differentiate students who transfer from and those who stay in low-performing schools. The following hypotheses were tested to answer the second research question:

- Compared to students who stay in low-performing schools, students who transfer will exhibit higher socioeconomic status, controlling for gender, race/ethnicity, ESE status, LEP status, FCAT math scale scores, and FCAT reading scale scores.

- Compared to students who stay in low-performing schools, students who transfer will have higher academic achievement on the state standardized tests, controlling for gender, race/ethnicity, ESE status, LEP status and FRL status.

- Compared to students who stay in low-performing schools, students who transfer will live closer to alternative public schooling options, controlling for gender, race/ethnicity, ESE status, LEP status and FRL status.

The third research question in the current study evaluated the characteristics that are most influential in predicting the type of school those who transfer will attend. The following hypotheses are tested to answer the third research question:

- The race/ethnicity, free and reduced lunch status, exceptional student status and English language learner status of the students will influence the type of school that a transfer student chooses. 
- The school grade will influence the type of school that a transfer student chooses, controlling for gender, race/ethnicity, ESE status, LEP status and FRL status.

- The number of miles away from the student's home the school is will influence the type of school that a transfer student chooses, controlling for gender, race/ethnicity, ESE status, LEP status and FRL status.

Two datasets consisting of 2010-2011 and 2011-2012 data for 980 students from 8 low-performing public elementary schools were evaluated. Chapter VII presents the results of the hypotheses that utilized a statistical and geographic analysis. The first section provides the results of the statistical and geographic analyses evaluating the characteristics that differentiate transfer students from non-transfer students. The following section provides the results of statistical and geographic analyses evaluating the characteristics that determine the type of school a transfer student will select.

\section{Differentiating Transfer and Non-Transfer Students}

Research question two evaluated the characteristics that differentiate students who transfer from and those who stay in the eight low-performing schools in the sample. The current section illustrates the prevalence estimates and logistic regression results associated with this research question. Of the total sample of 980 students, $27.2 \%$ were transfer students between the 2010-2011 and 2011-2012 school years.

\section{Free and Reduced Lunch Status}

Hypothesis 1: Compared to students who stay in low-performing schools, students who transfer will exhibit higher socioeconomic status, controlling for gender, race/ethnicity, 
ESE status, LEP status, FCAT math scale scores, and FCAT reading scale scores.

For the purpose of this analysis, a student's Free and Reduced Lunch Status (FRL) was used as a proxy for socioeconomic status. Students who receive free or reduced lunch come from economically disadvantaged households and this measure has been used in previous studies to illustrate students’ poverty level (Caldas and Bankston III 1997; Orfield, et al. 2003). Eligibility for the free and reduced price meal program with MiamiDade County Public Schools is determined by the number of members in a household and the total household income (MDCPSg). Total household income includes any earnings from jobs before deductions, welfare, child support, alimony, pension, social security, permanent disability, child social security income, and any other source of income.

Prevalence estimates for demographic and academic characteristics by transfer status are in Table 11. The first hypothesis is not supported by the findings. Compared to transfer students, non-transfer students had a significantly higher proportion of students who did not apply for free or reduced lunch ( $4.1 \%$ vs. $0.7 \%$; $\mathrm{p}=0.008)$ compared to students who either received free or reduced lunch or were denied free or reduced lunch. Compared to non-transfer students, transfer students had a significantly higher proportion of students who received free lunch (96.3\% vs. $92.6 \%$; $p=0.036$ ) compared to those who either received reduced lunch, were denied free or reduced lunch, or did not apply for the program. 
Table 11. Distributions of demographic characteristics and academic achievement by transfer status for students attending a sample school during the 2010-11 school year (n $=980$ )

\begin{tabular}{|c|c|c|c|c|c|c|}
\hline & \multicolumn{2}{|c|}{$\begin{array}{l}\text { Non-Transfer } \\
\text { Students }\end{array}$} & \multicolumn{2}{|c|}{$\begin{array}{l}\text { Transfer } \\
\text { Students }\end{array}$} & \multirow[b]{2}{*}{$P$ value } \\
\hline & & $\mathrm{N}^{\dagger}$ & Prevalence & $\mathrm{N}^{\dagger}$ & Prevalence & \\
\hline \multicolumn{2}{|l|}{ Overall Totals } & 713 & $72.8 \%$ & 267 & $27.2 \%$ & 0.0001 \\
\hline \multicolumn{7}{|c|}{ Demographic Characteristics } \\
\hline \multirow[t]{2}{*}{ Sex } & Male & 376 & $52.7 \%$ & 141 & $52.8 \%$ & 0.984 \\
\hline & Female & 337 & $47.3 \%$ & 126 & $47.2 \%$ & \\
\hline \multirow[t]{4}{*}{ Race/Ethnicity } & Black, Non- & & & & & \\
\hline & Hispanic & 471 & $66.2 \%$ & 182 & $68.2 \%$ & 0.39 \\
\hline & Hispanic & 234 & $32.9 \%$ & 80 & $30.0 \%$ & \\
\hline & Other & 7 & $1.0 \%$ & 5 & $1.9 \%$ & \\
\hline Exceptional & Gifted & 27 & $3.8 \%$ & 6 & $2.2 \%$ & 0.408 \\
\hline \multirow{2}{*}{$\begin{array}{l}\text { Student Education } \\
\text { (ESE) Status }\end{array}$} & Other-ESE & 97 & $13.6 \%$ & 41 & $15.4 \%$ & \\
\hline & Non-ESE & 589 & $82.6 \%$ & 220 & $82.4 \%$ & \\
\hline \multirow{3}{*}{$\begin{array}{l}\text { Limited English } \\
\text { Proficiency (LEP) } \\
\text { Status }\end{array}$} & Currently LEP & 132 & $18.5 \%$ & 44 & $16.5 \%$ & 0.247 \\
\hline & Former LEP & 86 & $12.1 \%$ & 24 & $9.0 \%$ & \\
\hline & Non-LEP & 495 & $69.4 \%$ & 199 & $74.5 \%$ & \\
\hline \multirow{4}{*}{$\begin{array}{l}\text { Free/Reduced } \\
\text { Lunch Status }\end{array}$} & Free Lunch & 660 & $92.6 \%$ & 257 & $96.3 \%$ & 0.043 \\
\hline & Reduced Lunch & 13 & $1.8 \%$ & 6 & $2.2 \%$ & \\
\hline & Denied & 11 & $1.5 \%$ & 2 & $0.7 \%$ & \\
\hline & Did not apply & 29 & $4.1 \%$ & 2 & $0.7 \%$ & \\
\hline \multicolumn{7}{|c|}{ Academic Achievement } \\
\hline \multirow{2}{*}{$\begin{array}{l}\text { FCAT Scal } \\
\text { Scores }\end{array}$} & Math & 706 & 298.6 & 254 & 297.9 & 0.635 \\
\hline & Reading & 691 & 276.2 & 253 & 271.6 & 0.86 \\
\hline
\end{tabular}

${ }^{\dagger}$ Differences in sample sub-totals are caused by missing items.

In Table 12, results from the binary logistic regression model for transfer status by free/reduced lunch status and academic achievement are shown. A seven-predictor model was fitted to the data to test the research hypothesis regarding the relationship between the likelihood that a student will transfer from a low-performing school and his/her free and reduced lunch status. This model controlled for gender, race/ethnicity, Limited English Proficiency (LEP) status, Exceptional Student Education (ESE) status, FCAT 
math scale scores, and FCAT reading scale scores. Sex was coded as male and female. Race/ethnicity was coded as black, Hispanic, and Other. Other included Asian/Pacific Islander, American Indian/Alaskan, Multi-Racial/Ethnic, and white. Combined, these groups only made up $1.2 \%$ of the total sample. The LEP variable was coded as current LEP students, former LEP students, and non-LEP students. The ESE variable was coded as Gifted, Other ESE, and non-ESE. Other ESE included orthopedically impaired, speech impaired, language impaired, emotionally handicapped, specific learning disabled, traumatic brain injured, and other health impaired. The FCAT math and reading scale scores were measured from 100 to 500 with 100 being the lowest a student could score and 500 being the highest.

Transfer students had a significantly higher adjusted odds of receiving free lunch compared to not applying for the lunch program at all [odds ratio (OR): 5.33; Standard Error (SE): 0.737]. Transfer students also had significantly higher adjusted odds of receiving reduced lunch compared to not applying for the lunch program at all [OR: 6.07; SE: 0.887]. This does not necessarily mean that transfer students are more economically disadvantaged than non-transfer students. There is no way to know if students who did not apply would be denied or receive free or reduced lunch. Additionally, as shown in Table 11, the large majority of both transfer and non-transfer students received free or reduced lunch. 
Table 12. Binary logistic regression of transfer status among students served by low-performing elementary schools in Miami-Dade County, FL

\begin{tabular}{|c|c|c|c|}
\hline & \multicolumn{3}{|c|}{$\begin{array}{l}\text { Transfer Status } \\
\text { (ref = Transfer) }\end{array}$} \\
\hline & OR & $\begin{array}{l}\text { Std. } \\
\text { Error }\end{array}$ & $P$ value \\
\hline \multicolumn{4}{|l|}{ Sex (ref = Female) } \\
\hline Male & 1.012 & 0.152 & 0.936 \\
\hline \multicolumn{4}{|l|}{ Race (ref = Hispanic) } \\
\hline Black & 0.794 & 0.268 & 0.389 \\
\hline Other & 1.209 & 0.687 & 0.782 \\
\hline \multicolumn{4}{|c|}{ Exceptional Student Education (ESE) } \\
\hline \multicolumn{4}{|l|}{ Status (ref = Non-ESE) } \\
\hline Gifted & 0.619 & 0.476 & 0.313 \\
\hline Other ESE & 0.848 & 0.235 & 0.484 \\
\hline \multicolumn{4}{|c|}{$\begin{array}{l}\text { Limited English Proficiency (LEP) Status } \\
\text { (ref = Non-LEP) }\end{array}$} \\
\hline Current LEP & 0.607 & 0.304 & 0.101 \\
\hline Former LEP & 0.614 & 0.337 & 0.147 \\
\hline \multicolumn{4}{|c|}{$\begin{array}{l}\text { Free and Reduced Lunch (ref = Did not } \\
\text { apply) }\end{array}$} \\
\hline Free Lunch & 5.331 & 0.737 & 0.023 \\
\hline Reduced Lunch & 6.066 & 0.887 & 0.042 \\
\hline Denied Free or Reduced Lunch & 2.644 & 1.072 & 0.364 \\
\hline \multicolumn{4}{|l|}{ Academic Achievement } \\
\hline FCAT Math Scores & 1.001 & 0.002 & 0.523 \\
\hline FCAT Reading Scores & 0.998 & 0.002 & 0.233 \\
\hline
\end{tabular}

\section{Academic Achievement}

Hypothesis 2: Compared to students who stay in low-performing schools, students who transfer will have higher academic achievement on the state standardized tests, controlling for gender, race/ethnicity, ESE status, LEP status and FRL status.

Math and reading standardized test scores range from 100 to 500. The mean for reading scores for non-transfers was 276.15 , which was 4.51 points higher than transfers were. The mean for the math scores for non-transfers was 298.57, which was also higher 
than that of transfers, but only by 0.72 points. However, neither the math nor the reading scale score means for non-transfer students were significantly different from those of transfer students.

The same seven-predictor model described above was used to evaluate the association between a students' transfer status and his/her academic achievement on the state standardized reading and math tests. This model controlled for sex, race/ethnicity, LEP status, ESE status, and FRL status. After controlling for these variables, both reading and math standardized tests scores were not significantly different between transfers and non-transfers. However, if a student were to increase his/her FCAT math scale score, he or she is expected to be more likely to transfer than not transfer [OR: 1.001; SE: 0.002]. Additionally, if a student were to increase his/her FCAT reading scale score, he or she is expected to be more likely to not transfer than transfer [OR: 0.998; SE: 0.002]. Since there were no significant differences, this hypothesis is not supported by the findings. Table 12 illustrates the output.

\section{Distance to Alternative Schooling Options}

Hypothesis 3: Compared to students who stay in low-performing schools, students who transfer will live closer to alternative public schooling options, controlling for gender, race/ethnicity, ESE status, LEP status and FRL status.

The third hypothesis utilized a geographical analysis to determine if transfers lived closer to alternative public school options when compared to non-transfers. The mean distance away from alternative public schools for non-transfers was 0.57 miles, 
while the mean distance for transfers was only 0.44 miles. An independent group t-test was run to compare the mean distance between transfers and non-transfers. These results found that the difference in means is statistically different from $0(p=.000)$. A sixpredictor model was fitted to the data to test this hypothesis. This model controlled for sex, race/ethnicity, LEP, ESE, and FRL. After controlling for these variables, transfer students had a significantly higher likelihood of living closer to an alternative schooling option $(\mathrm{b}=2.107, \mathrm{p}=.000)$. These findings support the hypothesis that transfer students are more likely to live closer to alternative public schooling options. See Table 13 for the results of the binary logistic regression.

Table 13. Binary logistic regression comparing the distance transfers and nontransfers lived from alternative schooling options

\begin{tabular}{|c|c|c|c|}
\hline & \multicolumn{3}{|c|}{$\begin{array}{l}\text { Transfer Status } \\
\text { (Ref = Transfer) }\end{array}$} \\
\hline & OR & Std. Error & $\begin{array}{l}\mathrm{P} \\
\text { value }\end{array}$ \\
\hline \multicolumn{4}{|l|}{ Sex (ref = Female) } \\
\hline Male & 0.936 & 0.152 & 0.662 \\
\hline \multicolumn{4}{|l|}{ Race (ref = Hispanic) } \\
\hline Black & 1.160 & 0.261 & 0.569 \\
\hline Other & 0.555 & 0.659 & 0.371 \\
\hline \multicolumn{4}{|c|}{$\begin{array}{l}\text { Exceptional Student Education (ESE) Status } \\
\text { (ref = Non-ESE) }\end{array}$} \\
\hline Gifted & 1.639 & 0.474 & 0.297 \\
\hline Other ESE & 0.902 & 0.215 & 0.630 \\
\hline \multicolumn{4}{|c|}{$\begin{array}{l}\text { Limited English Proficiency (LEP) Status (ref } \\
=\text { Non-LEP) }\end{array}$} \\
\hline Current LEP & 1.308 & 0.293 & 0.360 \\
\hline Former LEP & 1.638 & 0.331 & 0.136 \\
\hline \multicolumn{4}{|c|}{ Free and Reduced Lunch (ref = Did not apply) } \\
\hline Free Lunch & 0.624 & 0.796 & 0.553 \\
\hline Reduced Lunch & 0.534 & 0.938 & 0.504 \\
\hline Denied Free or Reduced Lunch & 3.729 & 1.082 & 0.224 \\
\hline \multicolumn{4}{|l|}{ Distance } \\
\hline Miles between home and school & 8.222 & .324 & 0.000 \\
\hline
\end{tabular}




\section{Transfer School Type}

Research question three evaluated the characteristics that differentiate the type of school students who transferred chose. Of the 262 students who were transfers, $60 \%$ transferred to a traditional public school. Ten percent transferred to a combination school, $13 \%$ to a charter school, $11 \%$ to a magnet school, and the remaining $6 \%$ transferred to a combination magnet school, respectively. Combination schools are schools that do not have the traditional grade levels. For example, schools serving $4^{\text {th }}$ to $8^{\text {th }}$ grade or Kindergarten to $8^{\text {th }}$ grade.

\section{Demographic Characteristics}

Hypothesis 1: The race/ethnicity, free and reduced lunch status, exceptional student status and English language learner status of the students will influence the type of school that a transfer student chooses.

Prevalence estimates for demographic and transfer school type can be seen in

Table 14 . There were no statistically significant differences between the school type students chose and their demographic characteristics. However, there were some notable differences. Black non-Hispanic students were more likely to transfer to charter and magnet schools compared to Hispanic students and students of other races/ethnicities. Of the students who transferred to charter schools, 79\% were black non-Hispanic students and of the students who transferred to magnet schools $86 \%$ were black non-Hispanic students. 
A six-predictor model was fitted to the data to test the research hypothesis regarding the relationship between the likelihood that a student will transfer to a traditional public school versus another type of school and his/her demographic characteristics. This model controlled for sex, race/ethnicity, LEP status, ESE status, FRL status, and school grade. When compared to Hispanic students, black non-Hispanic students were significantly more likely to attend charter schools compared to traditional public schools [OR: 8.411; SE: 1.097]. When compared to non-LEP students, current LEP students were significantly more likely to attend magnet schools compared to traditional public schools [OR: 0.079; SE: 1.283]. Therefore, the hypothesis was supported by the findings.

\section{School Grade}

Hypothesis 2: The school grade will influence the type of school that a transfer student chooses, controlling for gender, race/ethnicity, ESE status, LEP status and FRL status.

Prevalence estimates for transfer school grade and transfer school type can be found in Table 14. Students transferring to charter schools were significantly less likely than students transferring to non-charter schools to attend an A school (0\% to 32.5\%; $\mathrm{p}=0.001$ ). Charter school transfers were also significantly less likely to attend a C school when compared to students transferring to non-charter schools (6.5\% to $39.4 \% ; \mathrm{p}=0.001)$. Charter school transfers were significantly more likely than non-charter transfers to attend a B school (45.2\% to $11.2 \%$; $=0.0001)$ or an F school $(32.3 \%$ to $5.2 \%$; $\mathrm{p}=0.0001$ ), respectively. Students transferring to magnet schools were significantly more likely than students transferring to non-magnet schools to attend an A school (62.1\% to 
24.5\%; $\mathrm{p}=0.0001$ ). Magnet transfers were significantly less likely than non-magnet transfers to attend a B school ( $0 \%$ to $17.6 \%$; $\mathrm{p}=0.01$ ).

The same six-predictor model described above was used to evaluate the association between transfer school type and transfer school grade. This model controlled for sex, race/ethnicity, LEP status, ESE status, and FRL status. There were some transfer school type and transfer school grade combinations that were significantly different. Compared to students transferring to traditional schools, charter school transfers had significantly higher adjusted odds of transferring to a B school when compared to an A school [OR: 24.69; SE: 1.103]. Compared to students transferring to traditional schools, charter school transfers also had significantly higher adjusted odds of transferring to a F school when compared to an A school [OR: 18.38; SE: 1.046]. Compared to students transferring to traditional schools, magnet school transfers had a significantly lower adjusted odds of transferring to a F school when compared to an A school [OR: 0.052; SE: 1.444]. Table 15 illustrates the output. This hypothesis is supported by the findings, school grade did influence transfer school type. 
Table 14. Distributions of demographic characteristics, academic achievement, and school characteristics by transfer school type for students who transferred from a sample school during the 2011-12 school year $(\mathrm{n}=267)$

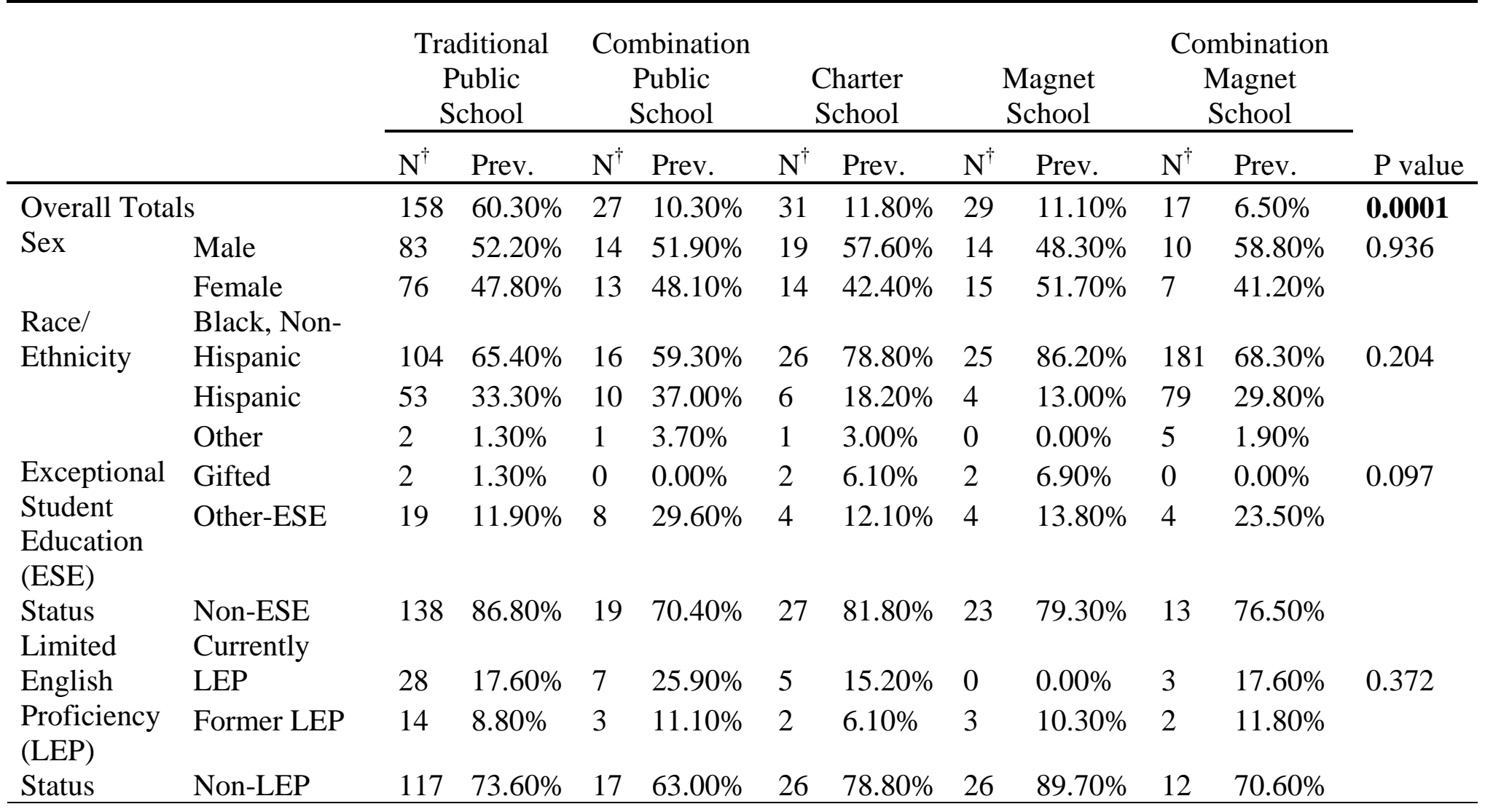

${ }^{\dagger}$ Differences in sample sub-totals are caused by missing items.

Prev. $=$ Prevalence. 
Table 14 (cont.). Distributions of demographic characteristics, academic achievement, and school characteristics by transfer school type for students who transferred from a sample school during the 2011-12 school year $(\mathrm{n}=267)$

\begin{tabular}{|c|c|c|c|c|c|c|c|c|c|c|c|c|}
\hline & & \multicolumn{2}{|c|}{$\begin{array}{c}\text { Traditional } \\
\text { Public School }\end{array}$} & \multicolumn{2}{|c|}{$\begin{array}{c}\text { Combination } \\
\text { Public School } \\
\end{array}$} & \multicolumn{2}{|c|}{$\begin{array}{l}\text { Charter } \\
\text { School }\end{array}$} & \multicolumn{2}{|c|}{$\begin{array}{c}\text { Magnet } \\
\text { School }\end{array}$} & \multicolumn{2}{|c|}{$\begin{array}{c}\text { Combination } \\
\text { Magnet } \\
\text { School } \\
\end{array}$} & \multirow[b]{2}{*}{ P value } \\
\hline & & $\mathrm{N}^{\dagger}$ & Prev. & $\mathrm{N}^{\dagger}$ & Prev. & $\mathrm{N}^{\dagger}$ & Prev. & $\mathrm{N}^{\dagger}$ & Prev. & $\mathrm{N}^{\dagger}$ & Prev. & \\
\hline \multirow{5}{*}{$\begin{array}{l}\text { Free/Reduced } \\
\text { Lunch Status }\end{array}$} & Free Lunch & 154 & $96.90 \%$ & 27 & $100.00 \%$ & 31 & $93.90 \%$ & 27 & $93.10 \%$ & 16 & $94.10 \%$ & 0.263 \\
\hline & Reduced & & & & & & & & & & & \\
\hline & Lunch & 4 & $2.50 \%$ & 0 & $0.00 \%$ & 1 & $3.00 \%$ & 1 & $3.40 \%$ & 0 & $0.00 \%$ & \\
\hline & Denied & 0 & $0.00 \%$ & 0 & $0.00 \%$ & 1 & $3.00 \%$ & 0 & $0.00 \%$ & 1 & $5.90 \%$ & \\
\hline & $\begin{array}{l}\text { Did not } \\
\text { apply }\end{array}$ & 1 & $0.60 \%$ & 0 & $0.00 \%$ & 0 & $0.00 \%$ & 1 & $3.40 \%$ & 0 & $0.00 \%$ & \\
\hline \multirow[t]{5}{*}{ School Grade } & A & 42 & $26.60 \%$ & 8 & $29.60 \%$ & 0 & $0.00 \%$ & 18 & $62.10 \%$ & 7 & $41.20 \%$ & 0.0001 \\
\hline & $\mathrm{B}$ & 25 & $15.80 \%$ & 1 & $3.70 \%$ & 14 & $45.20 \%$ & 0 & $0.00 \%$ & 1 & $5.90 \%$ & \\
\hline & $\mathrm{C}$ & 61 & $38.60 \%$ & 14 & $51.90 \%$ & 2 & $6.50 \%$ & 7 & $24.10 \%$ & 9 & $52.90 \%$ & \\
\hline & $\mathrm{D}$ & 18 & $11.40 \%$ & 4 & $14.80 \%$ & 5 & $16.10 \%$ & 4 & $13.80 \%$ & 0 & $0.00 \%$ & \\
\hline & $\mathrm{F}$ & 12 & $7.60 \%$ & 0 & $0.00 \%$ & 10 & $32.30 \%$ & 0 & $0.00 \%$ & 0 & $0.00 \%$ & \\
\hline
\end{tabular}

${ }^{\dagger}$ Differences in sample sub-totals are caused by missing items.

Prev. $=$ Prevalence 
Table 15. Multivariate logistic regression of transfer school type among students who transferred from low-performing elementary schools in Miami-Dade County, FL between the 2009-2010 and 2011-2012 school years

\begin{tabular}{|c|c|c|c|c|c|c|c|c|c|c|c|c|}
\hline & \multicolumn{3}{|c|}{$\begin{array}{c}\text { Combination Public } \\
\text { School }\end{array}$} & \multicolumn{3}{|c|}{ Charter School } & \multicolumn{3}{|c|}{ Magnet School } & \multicolumn{3}{|c|}{$\begin{array}{l}\text { Combination Magnet } \\
\text { School }\end{array}$} \\
\hline & OR & $\begin{array}{l}\text { Std. } \\
\text { Error }\end{array}$ & $\begin{array}{l}\mathrm{P} \\
\text { value }\end{array}$ & OR & $\begin{array}{l}\text { Std. } \\
\text { Error }\end{array}$ & $\begin{array}{l}\mathrm{P} \\
\text { value }\end{array}$ & OR & $\begin{array}{l}\text { Std. } \\
\text { Error }\end{array}$ & $\begin{array}{l}\mathrm{P} \\
\text { value }\end{array}$ & OR & $\begin{array}{l}\text { Std. } \\
\text { Error }\end{array}$ & $\begin{array}{l}\mathrm{P} \\
\text { value }\end{array}$ \\
\hline \multicolumn{13}{|c|}{ Sex (ref = Female) } \\
\hline \multicolumn{13}{|c|}{ Race (ref = Hispanic) } \\
\hline Black & 2.064 & 0.864 & 0.4 & 8.411 & 1.097 & 0.05 & 0.655 & 0.608 & 0.49 & 0.383 & 1.04 & 0.36 \\
\hline Other & 2.725 & 1.706 & 0.56 & 4.895 & 3.06 & 0.6 & 0.015 & 7.606 & 0.58 & 1.388 & 1.68 & 0.85 \\
\hline \multicolumn{13}{|c|}{ Exceptional Student Education $(\mathrm{ESE})$ status $(\mathrm{ref}=\mathrm{Non}-\mathrm{ESE})$} \\
\hline Gifted & 0.132 & 4.665 & 0.66 & 3.464 & 1.336 & 0.35 & 3.037 & 1.081 & 0.3 & 0.204 & 7.333 & 0.83 \\
\hline Other ESE & 3.513 & 0.504 & 0.01 & 1.537 & 0.7 & 0.54 & 1.346 & 0.577 & 0.61 & 2.095 & 0.761 & 0.33 \\
\hline \multicolumn{13}{|c|}{ Limited English Proficiency (LEP) status (ref = Non-LEP) } \\
\hline Current LEP & 2.533 & 0.945 & 0.33 & 6.84 & 1.147 & 0.09 & 0.079 & 1.283 & 0.05 & 0.604 & 1.157 & 0.66 \\
\hline Former LEP & 2.419 & 0.975 & 0.37 & 7.895 & 1.19 & 0.08 & 1.085 & 0.777 & 0.92 & 1.072 & 1.201 & 0.95 \\
\hline
\end{tabular}


Table 15 (cont.). Multivariate logistic regression of transfer school type among students who transferred from low-performing elementary schools in Miami-Dade County, FL between the 20092010 and 2011-2012 school years

\begin{tabular}{|c|c|c|c|c|c|c|}
\hline & \multicolumn{3}{|c|}{ Combination Public School } & \multicolumn{3}{|c|}{ Charter School } \\
\hline & OR & $\begin{array}{l}\text { Std. } \\
\text { Error }\end{array}$ & $\begin{array}{l}\mathrm{P} \\
\text { value }\end{array}$ & OR & $\begin{array}{l}\text { Std. } \\
\text { Error }\end{array}$ & $\begin{array}{ll}\mathrm{P} \\
\text { value } \\
\end{array}$ \\
\hline \multicolumn{7}{|c|}{ Free and Reduced Lunch (ref = Did not apply) } \\
\hline Free Lunch & 42.363 & 10.671 & 0.73 & 15.939 & 8.502 & 0.75 \\
\hline Reduced Lunch & 4.438 & 11.486 & 0.9 & 23.855 & 8.859 & 0.72 \\
\hline $\begin{array}{l}\text { Denied Free or Reduced Lunch } \\
\text { School Grade (ref = A) }\end{array}$ & 139.486 & 0 & . & $1.94 \mathrm{E}+12$ & 47653.31 & 1 \\
\hline B & 0.13 & 1.082 & 0.06 & 24.69 & 1.103 & 0.04 \\
\hline $\mathrm{C}$ & 0.578 & 0.482 & 0.26 & 16.303 & 1.133 & 0.01 \\
\hline $\mathrm{D}$ & 0.946 & 0.692 & 0.94 & 1.589 & 1.177 & 0.69 \\
\hline $\mathrm{F}$ & 0.021 & 3.559 & 0.28 & 18.38 & 1.046 & 0.01 \\
\hline
\end{tabular}


Table 15 (cont.). Multivariate logistic regression of transfer school type among students who transferred from low-performing elementary schools in Miami-Dade County, FL

between the 2009-2010 and 2011-2012 school years

\begin{tabular}{|c|c|c|c|c|c|c|}
\hline & \multicolumn{3}{|c|}{ Magnet School } & \multicolumn{3}{|c|}{$\begin{array}{c}\text { Combination Magnet } \\
\text { School }\end{array}$} \\
\hline & OR & $\begin{array}{l}\text { Std. } \\
\text { Error }\end{array}$ & $\mathrm{P}$ value & OR & $\begin{array}{l}\text { Std. } \\
\text { Error }\end{array}$ & $\begin{array}{l}\mathrm{P} \\
\text { value }\end{array}$ \\
\hline \multicolumn{7}{|c|}{ Free and Reduced Lunch (ref = Did not apply) } \\
\hline Free Lunch & 1.064 & 1.53 & 0.97 & 12.408 & 13.665 & 0.85 \\
\hline Reduced Lunch & 2.256 & 1.816 & 0.65 & 1.407 & 15.148 & 0.98 \\
\hline $\begin{array}{l}\text { Denied Free or Reduced Lunch } \\
\text { School Grade (ref = A) }\end{array}$ & 4.221 & 0 & . & 542332 & 47665.4 & 1 \\
\hline $\mathrm{B}$ & 0.02 & 3.012 & 0.19 & 0.035 & 5.105 & 0.51 \\
\hline $\mathrm{C}$ & 1.247 & 0.554 & 0.69 & 0.2 & 2.363 & 0.5 \\
\hline $\mathrm{D}$ & 0.492 & 0.448 & 0.11 & 1.614 & 0.73 & 0.51 \\
\hline $\mathrm{F}$ & 0.052 & 1.444 & 0.04 & 0.52 & 1.223 & 0.59 \\
\hline
\end{tabular}




\section{Distance to School Type}

Hypothesis 3: The number of miles away from the student's home the school is will influence the type of school that a transfer student chooses, controlling for gender, race/ethnicity, ESE status, LEP status and FRL status.

The third hypothesis utilized a geographical analysis to determine if distance influenced the school type a transfer student chose. Table 16 illustrates the mean distances students lived from each school type.

Table 16. Mean Distance students lived from transfer school by school type

\begin{tabular}{lr}
\hline School Type & $\begin{array}{r}\text { Mean } \\
\text { Difference }\end{array}$ \\
Traditional Public School & 0.43 \\
Combination School & 0.43 \\
Charter School & 0.53 \\
Magnet School & 0.41 \\
Combination Magnet School & 0.51 \\
\hline
\end{tabular}

A one-way ANOVA was run to compare the mean distance between the types of schools transfer students chose. The difference in means was not statistically different $(p=.244)$. A six-predictor model was fitted to the data to test this hypothesis. This model controlled for sex, race/ethnicity, LEP, ESE, and FRL. After controlling for these variables, there were no significant differences in the distance of the school to a student's home when comparing combination, charter, magnet, or combination magnet schools to traditional schools. Therefore, this hypothesis is not supported by the findings. The results of the multinomial logistic regression can be found in Table 17. 
Table 17. Multivariate logistic regression comparing the distance transfer schools lived from different school types

\begin{tabular}{|c|c|c|c|c|c|c|}
\hline & \multicolumn{3}{|c|}{ Combination Public School } & \multicolumn{3}{|c|}{ Charter School } \\
\hline & OR & Std. Error & $P$ value & OR & Std. Error & P value \\
\hline \multicolumn{7}{|l|}{ Sex (ref = Female) } \\
\hline Male & 1.577 & 0.422 & 0.28 & 0.936 & 0.403 & 0.871 \\
\hline \multicolumn{7}{|l|}{ Race (ref = Hispanic) } \\
\hline Black & 0.117 & 1.52 & 0.158 & 0.179 & 1.768 & 0.33 \\
\hline Other & 0.229 & 1.299 & 0.256 & 0.818 & 1.526 & 0.895 \\
\hline \multicolumn{7}{|c|}{ Exceptional Student Education (ESE) status (ref = Non-ESE) } \\
\hline Gifted & 0.303 & 0.485 & 0.014 & 0.906 & 0.601 & 0.869 \\
\hline Other ESE & 1.98E-05 & 252.103 & 0.966 & 3.63 & 1.236 & 0.297 \\
\hline \multicolumn{7}{|c|}{ Limited English Proficiency (LEP) status (ref = Non-LEP) } \\
\hline Current LEP & 0.399 & 0.935 & 0.326 & 0.444 & 0.973 & 0.404 \\
\hline Former LEP & 0.883 & 0.796 & 0.876 & 1.329 & 0.975 & 0.771 \\
\hline \multicolumn{7}{|c|}{ Free and Reduced Lunch (ref = Did not apply) } \\
\hline Free Lunch & $9.27 \mathrm{E}-06$ & 13505.045 & 0.999 & $3.04 \mathrm{E}-13$ & 4906.514 & 0.995 \\
\hline Reduced Lunch & 0.653 & 13491.653 & 1 & $1.34 \mathrm{E}-08$ & 4875.695 & 0.997 \\
\hline Denied Free or Reduced Lunch & 3.51E-05 & 13493.626 & 0.999 & 1.03E-08 & 4875.695 & 0.997 \\
\hline $\begin{array}{l}\text { Distance between home and } \\
\text { school }\end{array}$ & 1 & 0 & 0.855 & 1 & 0 & 0.207 \\
\hline
\end{tabular}


Table 17 (cont). Multivariate logistic regression comparing the distance transfer schools lived from different school types

\begin{tabular}{|c|c|c|c|c|c|c|}
\hline & \multicolumn{3}{|c|}{ Magnet School } & \multicolumn{3}{|c|}{ Combination Magnet School } \\
\hline & OR & Std. Error & $P$ value & OR & $\begin{array}{l}\text { Std. } \\
\text { Error }\end{array}$ & $\mathrm{P}$ value \\
\hline \multicolumn{7}{|l|}{ Sex (ref = Female) } \\
\hline Male & 1.202 & 0.387 & 0.634 & 0.587 & 0.656 & 0.418 \\
\hline \multicolumn{7}{|l|}{ Race (ref = Hispanic) } \\
\hline Black & $1.95 \mathrm{E}+05$ & 241.042 & 0.96 & 0.149 & 1.576 & 0.227 \\
\hline Other & $1.16 \mathrm{E}+05$ & 241.041 & 0.961 & 0.071 & 1.361 & 0.051 \\
\hline \multicolumn{7}{|c|}{ Exceptional Student Education (ESE) status (ref = Non-ESE) } \\
\hline Gifted & 0.728 & 0.562 & 0.571 & 0.52 & 0.747 & 0.381 \\
\hline Other ESE & 3.828 & 1.177 & 0.254 & 0 & 260.292 & 0.972 \\
\hline \multicolumn{7}{|c|}{ Limited English Proficiency (LEP) status (ref = Non-LEP) } \\
\hline Current LEP & 1.003 & 0.732 & 0.996 & 0.562 & 1.13 & 0.61 \\
\hline Former LEP & $1.90 \mathrm{E}-05$ & 66.013 & 0.869 & 0.53 & 0.991 & 0.521 \\
\hline \multicolumn{7}{|c|}{ Free and Reduced Lunch (ref = Did not apply) } \\
\hline Free Lunch & 2.927 & 1.746 & 0.538 & $3.57 \mathrm{E}-14$ & 4950.041 & 0.995 \\
\hline Reduced Lunch & 0.951 & 0.97 & 0.959 & 1.86E-09 & 4875.695 & 0.997 \\
\hline Denied Free or Reduced Lunch & 3.254 & 0 & & $2.37 \mathrm{E}-13$ & 4882.298 & 0.995 \\
\hline $\begin{array}{l}\text { Distance between home and } \\
\text { school }\end{array}$ & 1 & 0 & 0.875 & 1 & 0 & 0.99 \\
\hline
\end{tabular}




\section{Discussion: Addressing Parents' School Choice Needs}

Utilizing a mixed-methods approach, the present study examined the decisionmaking process and school-choice options utilized by parents of students served by lowperforming public elementary schools in Miami-Dade County. The study tested several hypotheses to answer four research questions: (1) Do Florida state statutes on school choice and Miami-Dade County school choice programs adequately address the perceived needs of parents of students served by low-performing schools so they can access school choice options and make informed school choice decisions? (2) What characteristics differentiate students who transfer from and those who stay in low-

performing schools? (3) What characteristics are most influential in predicting the type of school those who transfer will attend? (4) How do economic and social factors differentiate the decision making process of parents who transfer their children from and those who keep their children in low-performing schools? The research questions were addressed using semi-structured interviews with parents, a statistical analysis of student demographic and academic data, and a geographic analysis of the proximity of schooling options to student homes. Chapter VII provides an overview of the implications of the findings, the contributions this study makes to current research, recommendations for making school choice more accessible, and future research.

\section{The Implications of the Study Findings}

There were two sets of data used to analyze how parents served by lowperforming schools access school choice options. The first set of data was quantitative and illustrated that transfer and non-transfer students share many of the same 
characteristics. The second set of data was qualitative and illustrated that both the parents of transfer and non-transfer students had limited access to school choice information and needed assistance making school choice decisions. Parents of students who transferred from and those who remained in the low-performing schools serving their neighborhoods were confused about their eligibility to leave their neighborhood schools, the alternative schooling options that were available to them, and the best way to use school choice information to make an informed decision about where to enroll their children. The majority of parents in the current study were more concerned with how their child's lowperforming school was improving and less concerned with the alternative schooling options available to them. The majority of parents wanted a high performing school near their home.

\section{Accessing School Choice Options}

The statistical analysis conducted for the current study compared the demographic and academic characteristics of transfer and non-transfer students. The study also compared the demographic and academic characteristic and transfer school grades of students transferring to traditional, magnet, combination, charter, and combination magnet schools. The analysis was conducted on a sample of 980 students. Prevalence estimates, binary logistic regression and multinomial logistic regression were used to compare groups. The geographic analysis conducted for this study evaluated the distance between student home addresses and the nearest alternative schooling option. Alternative schooling options included charter schools, magnet schools, and public schools. A logistic regression model was run to evaluate whether or not distance to alternative 
schools significantly influenced whether or not a student transferred from their lowperforming home school.

Low-performing schools serve a high proportion of low-income students as evidenced by the percentage of students receiving free and reduced lunch (FRL) in this study. Both transfers and non-transfers exhibited high percentages of students using the Free or reduced lunch program $-96.3 \%$ and $92.6 \%$, respectively. There is a direct link between socioeconomic status and school choice usage (Ball et al. 1995; Reay 1996; Schneider et al. 1997; Buckley and Schneider 2003). The binary logistic regression found that transfer students had significantly higher adjusted odds of receiving free lunch compared to non-transfer students who did not apply for the lunch program at all. However, when compared to non-transfer students who did not qualify for free or reduced lunch, transfer students who received free or reduced lunch were not significantly more likely to transfer. Students from higher socioeconomic social groups were not more likely to transfer than students from lower socioeconomic social groups. Additionally, students who did transfer were not likely to end up at a high achieving school. All students served by low-performing schools need greater access to higher achieving schools regardless of FRL status. Efforts must be made at the local level to break down the barriers to school choice that students served by low-performing schools face. Very few of these students are accessing high performing schools via school choice. Therefore, the majority still do not have equal access to a high quality education.

Parents' needs, as they pertain to school choice decision making, include access to knowledge about the quality of their child's current school, the ability to evaluate their 
child's current school, access to school choice information, the ability to evaluate school choice information, understanding of their child's eligibility to use school choice, and resources to combat logistical constraints so that they can use school choice options. The findings of the interview data clearly illustrate that parents' needs are not being adequately addressed by state policy and county programs. A review of state choice policy and county choice programs found that there are several provisions focused on meeting the needs of parents. There are resources for parents to research and utilize school choice options. Despite this, the parents who were interviewed were not accessing these resources. The parents exhibited special needs as it pertained to accessing information. Unfortunately, parents' special needs are not sufficiently addressed by state policy or county programs.

Parents were only able to access and process information about the quality of their child's current school. This was no surprise because it is easier for parents to gather and evaluate information about their child's school while their child is enrolled. Parents were uninformed about alternative schooling options, eligibility, and resources. They also did not know where or how to access this information. The parents who stand to benefit the most from choice are not using it.

Parents did not fully understand their schooling options and the resources available to assist them in using those options. Parents also did not always know that their child is not required to attend their neighborhood school. Students can attend magnet, charter, and private schools. They can also utilize a variety of scholarship options to pay for transportation and tuition. Uninformed parents are at a great disadvantage for utilizing 
the expansive choice program available to them. Parents believed that their only alternative options were private schools that charged tuition. Parents cannot be expected to utilize school choice options if they do not even know that they are not required to keep their child in their neighborhood school. The freedom to leave ones assigned neighborhood school is one of the most fundamental aspects of school choice programs; students are no longer bound by their home address and the school that serves their neighborhood. The knowledge that parents are so misinformed about school choice should encourage policymakers and school district personnel to make more of an effort to assure parents know their child's eligibility and alternative schooling options. The parents of students served by low-performing public elementary schools need more direct access to school choice information and resources that assist parents in making informed decisions about where their child should attend school.

The majority of parents in this study, 73\%, primarily get their education related information from their child's current school. Accessing information at their child's current school is not a problem when trying to access information about their child's academic achievement and the quality of their child's current school. However, when accessing information about alternative schools, parents must seek resources elsewhere. Parents put themselves at a great disadvantage if they do not reach out to other parents, district personnel and utilize the websites. The current school should not be obligated to provide parents information about alternative schooling options. There is a conflict of interest associated with one school providing parents with information about schools serving the same grade levels. The students' current schools would essentially be 
encouraging parents to remove their child from the school to place them in another school. When students leave one school for another, their per-pupil expenditure follows them (Cooper and Randall 2008). The students' current schools would lose money and resources if they recommended students transfer to other schools. Therefore, schools have little incentive to inform parents of alternative school options. Alternatively, schools are more focused on improving the quality of the school to keep the currently enrolled students and attract new ones.

The model for informing parents about school choice options takes for granted that parents know where to access information. A lot of information is online but some parents do not use the internet. In the current study, of parents who do use the internet, the majority do not use it for educational information. Eighty-two percent of parents had access to the internet but only $23 \%$ used it as their primary source of education information. A few of the parents have access to other people who are useful in providing information about alternative schooling options. Other parents believe that if they need to get information, they could find it.

Parents in the current study primarily learned about school choice options via word of mouth, driving by schools and receiving information in the mail directly from alternative schooling options. Informal methods can help parents learn about schools, but more information is needed for parents to make an informed decision. Additional research is necessary for parents to understand the academic programs offered and details about the school that can inform decision making. Family, friends, and coworkers often only provided general information about alternative schooling options. Informal methods 
only provide a limited amount of school options to parents. The district and state websites provide a more comprehensive list of school options and these websites provide information about eligibility and the application process. Parents in the current study usually only knew about one or two schooling options because they were unaware of the wealth of information available to them online or through the office of School Choice and Parental Options. Nevertheless, several parents were able to make school choice decisions with the limited information they had.

There is a wealth of information on all choice programs on the web, including detailed information about who to contact, eligibility, applications, resources, and more. However, one of the main barriers to school choice among parents served by lowperforming schools is the lack of information. It was apparent by the interview findings that these parents are not going to access this information on the web. Although information is mailed infrequently, parents may be more likely to receive school choice information via mail. Schools of choice can target students served by low-performing schools by mailing information to their homes. Schools of choice can also invite parents to take tours and visit with teachers so parents can be provided more information. Some schools did contact parents interviewed for this study via mail.

In cases where parents were informed about their options, they lacked specific details about eligibility, the application process, and academic programs offered. Detailed information is crucial to parents' ability to utilize various schooling options. Parents in the current study wasted time applying for schools and programs their children were not eligible for. Additionally, some parents missed the application deadline because they 
were unaware of the due date. Being misinformed often left parents feeling helpless and without control of where their child attends school. In the current study, $45 \%$ of parents of transfer students wanted to keep their child in their current neighborhood school. The same percentage of parents of non-transfer students wanted to transfer their child to a different school but did not. Without more information about available schooling options, eligibility requirements, or resources available to utilize schools of choice, parents are often left confused about what they can do and their child's education will likely suffer.

\section{The Importance of Location}

The findings of the binary logistic regression demonstrated that transfer students were significantly more likely to live closer to alternative school options. The finding is particularly important for local school district as they plan new schools of choice and add choice programs to existing schools. The majority of parents expressed a desire for their children to attend school near their homes. Parents need and want better schooling options in their neighborhoods. Currently parents’ neighborhoods are served by charter schools, magnet schools and schools offering within school magnet programs. However, schools of choice are not always high performing. The school district must make a greater effort to provide high performing schooling options in all neighborhoods.

The current study found that some transfer school type and transfer school grade combinations were significantly different. When compared to traditional public schools, students who transferred to charter schools were more likely to attend a school with a lower grade. The charter schools serving the neighborhoods that the parents in this study lived in were not high achieving. Therefore, it is no surprise that charter school transfers 
often ended up in schools with lower state grades when compared to traditional schools. On the contrary, students who transferred to magnet schools were more likely to attend a higher performing school when compared to traditional public schools. Since location and convenience dictated how parents made schooling decisions, the quality of the transfer school was not always better than the school they attended previously. The findings reemphasize the need to offer high-performing schooling options near student homes.

The distance between student homes and transfer schools did not significantly influence the type of school transfer students chose. The mean distance between student homes and each transfer school type ranged from 0.41 and 0.53 miles. Students transferred to schools located near their homes. The majority of the parents in this study wanted their children in schools located near their home. While transfer schools' academic programs and learning environments were factors parents considered, they often placed more emphasis on location and convenience. The findings of the current study supported parents' desire to enroll their children in nearby schools.

High performing schooling options must be located near the homes of all students to increase the likelihood that parents would consider them. More conveniently located high-performing schools, coupled with the resources to make informed decisions would improve access to better schooling options for students served by low-performing schools. There are many efforts being made throughout the county to improve education by expanding the school choice program. Parents should be encouraged to consider high performing schools. However, it is important that the school district continues to also 
focus on making changes that improve the education of existing schools especially since the majority of the students are not utilizing school choice options. Most parents exhibited a desire to see their neighborhood schools improved instead of having to switch their child's school. They were more concerned with changes being made to the school so that the school grade improved.

\section{Parent Evaluation}

Parents in the current study did not conduct thorough evaluations of their child's schooling options. Some parents simply did not know that their child had options. Therefore, they believed they did not have any schools to evaluate. Other parents were content with their child's school because it was conveniently located, they were familiar with the school, and/or their child was doing well at the school. Parents who were transferring their children also did little evaluation of the school(s) they were considering. A parent who moved and believed their child's only schooling choice was their new neighborhood school did not do any evaluation at all because they felt they had no choice but to transfer,.

The parents who did conduct some evaluation reviewed a variety of factors. Some parents were specifically looking for better academics for their child so they focused on academic factors such as curriculum, gifted programs, and teachers. Other parents were more concerned with the learning environment so they were more concerned with how the students behaved and the structure of the school. A few parents were primarily concerned with the surrounding neighborhood of the school because their child walked to

school and they wanted to make sure they would be safe. Additionally, these parents were 
concerned how the kids from neighborhoods they described as "bad" would influence the structure of the school.

Without more assistance processing school choice information, parents are likely to waste time and possibly transfer their child to a school they will ultimately be dissatisfied with. Parents need to focus their evaluation of alternative schooling options on the same types of factors they evaluate their child's current school on, such as the school grade, learning environment, academic improvement, teacher quality, and student behavior. Since parents are not familiar with schools of choice, they must tap into their social networks to gain access to the information that weak ties may have. Parents can learn information about schools by taking tours, talking to parents with students currently in the school, and doing online research. Without more knowledge of the types of academic programs schools offer, parents risk putting their children in a program that is not rigorous enough or too rigorous for their child. School choice requires parents to get involved with schools in different ways than they have in the past. The information gathering process, evaluation of information and ultimate decision making empowers parents to take control of their child's academic future.

The District should consider providing school choice workshops for the parents of students served by low-performing schools. School choice workshops should educate parents on their alternative schooling options, their child's eligibility, and a step-by-step school evaluation process. Personal assistance can mean the difference between students remaining in inadequate schools and accessing a high performing school earlier in their academic career. By equipping parents with the tools to navigate the education market, the District can help to alleviate some of the barriers that create a stratified education 
system. Unfortunately, the current school choice policy contributes to the very same educational stratification that it set out to combat. Students served by low-performing schools should be targeted for school choice options by the school district and by the choice schools themselves. The school district has an obligation to assure that all students are receiving an adequate education. If they are not, parents need to be directly informed about alternative options.

\section{Contributions}

The current research contributes to school choice and educational equality literature. School choice literature primarily compares choosers and non-choosers (Ball et al. 1995; Reay 1996; Schneider et al. 1997; Buckley and Schneider 2003). The characteristic differences between these groups are usually very obvious. The present study provides a closer look at the comparison between parents and students with very similar characteristics, regardless of school choice usage. Additionally, the present study focuses exclusively on students who stand to gain the most from choice opportunities. School choice policy proponents emphasize the opportunity for students in lowperforming schools to access a better education (Ben-Porath 2009; Loeb et al. 2011; Ravitch 2013). However, the literature illustrates that the most disadvantaged students are not the ones who are utilizing or benefitting from school choice policy (Deluca and Rosenblatt 2010; Ravitch 2010; Holme et al. 2013; Horn et al. 2014). In line with school choice literature, the current study found that the students who were transferring from low-performing schools were still not utilizing choice options to access better schools. 
The reason students did not transfer to school choice options was often the consequence of parents being misinformed about their options.

The current research also contributes to the literature on educational equality. The study illustrates how the needs of students served by low-performing schools are not being met within school choice programs. Even with expanded choice, the students in the current study remained in low-performing schools. Low-performing schools serve high proportions of low-income and racial/ethnic minorities (Massey and Denton 1993; Kao and Thompson 2003; Deluca and Rosenblatt 2010; Stuit 2010). The students in the current study are disproportionately affected by educational stratification because lowperforming schools are often the only schools available in their neighborhoods. There is a strong correlation between socioeconomic status and academic achievement (Massey and Denton 1993; Kao and Thompson 2003). With low-performing schools serving the neighborhoods of students with low socioeconomic status, it was no surprise that the achievement gap between students from different socioeconomic statuses continues to grow. Even some of the schools of choice serving the neighborhoods of the students in the current study struggled to provide a high quality education. School choice, like other reforms, contributes to the stratified structure of the education system. School choice policy makes better schooling options available to students who already have access to high-performing schools, while not doing enough to assure students without access can use choice. 


\section{Recommendations}

The findings of the current study point to a few recommendations that could improve the likelihood that parents of students in low-performing schools will have access to schools of choice. First, state policy needs to have explicit provisions to address the needs of low-performing parents. While there are many provisions to address the needs of parents, the needs of the parents in this study are still not being met. Second, local districts need to better inform parents by providing information in a format that these parents utilize. Suggested formats include mailing information to the home, utilizing the child's current school, and partnering with local organizations that can reach these parents.

The last recommendation would be for local programs to focus on improving the quality of education at existing schools. School choice requires parents to transfer their children to a new school. Parents often want to keep their child in their neighborhood school and it is convenient to do so. However, much more emphasis is placed on new schools of choice and choice programs created in existing schools. Providing students a high quality education in their existing school is more likely to reach more students than most school choice options. Therefore, new school choice programs in these lowperforming schools could be the catalyst for the academic improvement that these schools need. 


\section{Future Research}

Future research should focus on the evaluation of local school districts that are successful in providing low-performing school students better access to choice programs. Future research should investigate the methods of effectively informing parents about their school choice options and resources to alleviate barriers to usage of choice options. Additionally, the research should evaluate if and how local school districts assist parents during the school choice evaluation process, making a final school choice, and completing the application. Lastly the research should review the results of the efforts of local districts. Particularly whether or not students are transferring to higher performing schools, whether or not parents are satisfied, and whether or not students are staying in the schools their parents choose. 


\section{REFERENCES}

Andre-Bechely, Lois. 2005. "Public School Choice at the Intersection of Voluntary Integration and Not-so-Good Neighborhood Schools: Lessons from Parents' Experiences." Educational Administration Quarterly 41 (2): 267-305.

. 2007. "Finding Space and Managing Distance: Public School Choice in an Urban California District." Urban Studies 44 (7): 1355-1376.

Apple, Michael W. 1982. Education and Power. Boston: Routledge \& Kegan Paul.

_ 2001. "Educational and Curricular Restructuring and the Neo-liberal and Neoconservative Agendas: Interview with Michael Apple.” Currículo sem Fronteiras 1(1):i-xxvi.

_ 2001a. "Markets, Standards, Teaching, and Teacher Education." Journal of Teacher Education 52 (3): 182-196.

_ 2004. "Creating Difference: Neo-Liberalism, Neo-Conservatism and the Politics of Educational Reform." Educational Policy 18 (1): 12-44.

Arce, Josephine, Debra Luna, Ali Borjian, and Marguerite Conrad. 2005. "No Child Left Behind: Who Wins? Who Loses?." Social Justice 32 (3): 56-71.

Babbie, Earl R. 2005. The Basics of Social Research. 3rd ed. ed. Belmont, CA: Thomson/Wadsworth.

Ball, Stephen J. 1993. "Education Markets, Choice and Social Class: The Market as a Class Strategy in the UK and the USA." British Journal of Sociology of Education 14 (1): 3-19.

Ball, Stephen J., Richard Bowe, and Sharon Gewirtz. 1995. "Circuits of Schooling: A Sociological Exploration of Parental Choice of School in Social Class Contexts." Sociological Review 43 (1): 52-78.

Bartlett, Lesley, Marla Frederick, Thaddeus Gulbrandsen, and Enrique Murillo. 2002. "The Marketization of Education: Public Schools for Private Ends." Anthropology \& Education Quarterly 33 (1): 5-29.

Bell, Courtney A. 2007. "Space and Place: Urban Parents' Geographical Preferences for Schools." Urban Review 39 (4): 375-404.

Ben-porath, Sigal. 2009. "School Choice as a Bounded Ideal." Journal of Philosophy of Education 43 (4): 527. 
Berger, Eugenia Hepworth. 1991. "Parent Involvement: Yesterday and Today." Elementary School Journal 91 (3): 209-219.

Bernard, H. R. 1999. Handbook of Methods in Cultural Anthropology. Walnut Creek, Calif: AltaMira Press.

- 2002. Research Methods in Anthropology: Qualitative and Quantitative Methods. 3rd ed. Walnut Creek: AltaMira Press.

Bernstein, Basil. 1960. "Aspects of Language and Learning in the Genesis of the Social Process." Journal of Child Psychology and Psychiatry 1 (4): 313-324.

- 1964. "Elaborated and Restricted Codes: Their Social Origins and some Consequences."American Anthropologist 66 (6): 55-69.

Betebenner, Damian W., Kenneth R. Howe, and Samara S. Foster. 2005. "On School Choice and Test-Based Accountability." Education Policy Analysis Archives 13 (41):1-22.

Borman, Kathryn M., Tamela Mcnulty Eitle, Deanna Michael, David J. Eitle, Reginald Lee, Larry Johnson, Deirdre Cobb - Roberts, Sherman Dorn, and Barbara Shircliffe. 2004. "Accountability in a Postdesegregation Era: The Continuing Significance of Racial Segregation in Florida's Schools." American Educational Research Journal 41 (3): 605-631.

Bourdieu, Pierre. 1986. “The Forms of Capital.” Pp. 46-58 in Education: Culture, Economy, and Society, edited by A.H. Halsey, H. Lauder, P. Brown, and A.S. Wells. New York: Oxford University Press.

Bowles, Samuel 1971. "Unequal Education and the Reproduction of the Social Division of Labor.” Pp. 137 - 153 in Power and Ideology in Education, edited by Jerome Karabel and A.H. Halsey. New York: Oxford University Press.

. 1972. "Schooling and Inequality from Generation to Generation." Journal of Political Economy 80 (3): 219-251.

Boyd, Donald, Hamilton Lankford, Susanna Loeb, and James Wyckoff. 2005.

"Explaining the Short Careers of High-Achieving Teachers in Schools with LowPerforming Students." The American Economic Review 95 (2): 166-171.

Buckley, Jack and Mark Schneider. 2003. "Shopping for Schools: How do Marginal Consumers Gather Information about Schools?" Policy Studies Journal 31 (2): 121145. 
Bulkley, Katrina and Jennifer Fisler. 2003. "A Decade of Charter Schools: From Theory to Practice." Educational Policy 17 (3): 317-342.

Bulman, Robert C. 2004. "School-Choice Stories: The Role of Culture." Sociological Inquiry 74 (4): 492-519.

Burks, Charlene. 2011. FTE Procedures. Miami: Miami-Dade County Public Schools.

Caldas, Stephen J. and Carl Bankston III. 1997. "Effect of School Population Socioeconomic Status on Individual Academic Achievement." Journal of Educational Research 90 (5): 269-277.

Campbell, David E., Martin R. West, and Paul E. Peterson. 2005. "Participation in a National, Means-Tested School Voucher Program." Journal of Policy Analysis and Management 24 (3): 523-541.

Chubb, John E. and Terry M. Moe. 1990. Politics, Markets, and America's Schools. Washington, D.C.: Brookings Institution.

Clotfelter, Charles T., Helen F. Ladd, Jacob L. Vigdor, and Roger Aliaga Diaz. 2004. "Do School Accountability Systems make it More Difficult for Low-Performing Schools to Attract and Retain High-Quality Teachers?" Journal of Policy Analysis and Management 23 (2): 251-271.

Coleman, James S. 1987. "Families and Schools." Educational Researcher 16 (6): 32-38. 1988. "Social Capital in the Creation of Human Capital." American Journal of Sociology 94: S95-S120.

Collins, Randall. 1971. "Functional and Conflict Theories of Educational Stratification." American Sociological Review 36 (6): 1002-1019.

Cooper, Bruce S. and E. Vance Randall. 2008. "Fear and Privatization.” Educational Policy 22 (1): 204-227.

Corallo, Christopher and Deborah Mcdonald. 2001. "What Works with Low-Performing Schools: A Review of Research Literature on Low-Performing Schools." Charleston, WV: AEL, Regional Educational Laboratory, Region IV Comprehensive Center.

Darling-Hammond, Linda. 2007. "Race, Inequality and Educational Accountability: The Irony of "no Child Left Behind"." Race, Ethnicity and Education 10 (3): 245-260.

Davidson, Elizabeth, Randall Reback, Jonah E. Rockoff, and Heather L. Schwartz. 2012. Fifty Ways to Leave a Child Behind: Idiosyncrasies and Discrepancies in States' 
Implementation of NCLB. Cambridge, Mass., USA: National Bureau of Economic Research.

Dee, Thomas S., Brian Jacob, and Nathaniel L. Schwartz. 2012. "The Effects of NCLB on School Resources and Practices." Educational Evaluation and Policy Analysis (2): 252.

Deluca, Stefanie and Peter Rosenblatt. 2010. "Does Moving to Better Neighborhoods Lead to Better Schooling Opportunities? Parental School Choice in an Experimental Housing Voucher Program." Teachers College Record (5): 1443.

Desimone, Laura. 1999. "Linking Parent Involvement with Student Achievement: Do Race and Income Matter?" Journal of Educational Research 93 (1): 11-30.

Dunn, Marvin. 1997. Black Miami in the Twentieth Century. Gainesville: University Press of Florida.

Ferryman, Kadija S., Xavier de Souza Briggs, Susan J. Popkin, and Maria Rendon. 2008. Do Better Neighborhoods for MTO Families Mean Better Schools? Washington, DC: Urban Institute.

Finn, Chester E. Jr. and Frederick M. Hess. 2004. "On Leaving no Child Behind." Public Interest 157: 35-56.

Fix, Michael and Randy Capps. 2005. "Immigrant Children, Urban Schools, and the No Child Left Behind Act.” Migration Information Source. http://www.migrationinformation.org/Feature/display.cfm?id=347 (accessed November 15, 2006).

Florida Department of Education (FLDOE). 2010. Getting Ready for Your Child's IEP Meeting. Tallahassee: Florida Department of Education.

. 2011. 2011 Guide to Calculating School Grades: Technical Assistance Paper. Tallahassee: Florida Department of Education.

. 2013. Closed Charter Schools in Florida. Tallahassee: Florida Department of Education.

. 2013a. 2012 - 2013 School Grades. Tallahassee: Florida Department of Education. 
_ 2013b. Opportunity Scholarship Program Fast Facts. Tallahassee: Florida Department of Education.

_ 2013c. Florida Tax Credit Scholarship Program Fast Facts. Tallahassee: Florida Department of Education.

— 2013d. Florida Tax Credit Scholarship Program June 2013 Quarterly Report. Tallahassee: Florida Department of Education.

_ 2013e. School Choice Options: Florida Continues to Lead the Nation. Tallahassee: Florida Department of Education.

—_. 2013f. McKay Scholarship Program June 2013 Quarterly Report. Tallahassee: Florida Department of Education.

_ 2014. Florida Charter School List by District. Tallahassee: Florida Department of Education.

- 2014a. A Resource Manual for the Development and evaluation of Exceptional Student Education Programs, Volume I-B: Florida Statutes and State Board of Education Rules. Tallahassee: Florida Department of Education.

Florida Department of Education (FLDOEa). "McKay Scholarship Program FAQs.” Florida Department of Education. http://www.floridaschoolchoice.org/Information/mckay/faqs.asp (accessed July 17, 2014).

Florida State § 1002.01 - 1002.79. 2012.

Frankfort-Nachmias, Chava and Anna Leon-Guerrero. 2006. Social Statistics for a Diverse Society. 4th ed. Thousand Oaks: Pine Forge Press.

Fusarelli, Lance D. 2004. "The Potential Impact of the no Child Left Behind Act on Equity and Diversity in American Education." Educational Policy 18 (1): 71-94.

Gerth, Hans Heinrich and C. W. Mills. 1958. From Max Weber: Essays in Sociology. New York: Oxford University Press.

Goldhaber, Dan D. 1999. "School Choice: An Examination of the Empirical Evidence on Achievement, Parental Decision Making, and Equity." Educational Researcher 28 (9): 16-25. 
Goldhaber, Dan D. and Eric R. Eide. 2002. "What do we Know (and Need to Know) about the Impact of School Choice Reforms on Disadvantaged Students?" Harvard Educational Review 72 (2): 157-176.

Goldring, Ellen B. and Kristie J. R. Phillips. 2008. "Parent Preferences and Parent Choices: The Public-Private Decision about School Choice." Journal of Education Policy 23 (3): 209-230.

Goyette, Kimberly A. 2008. "Race, Social Background, and School Choice Options." Equity \& Excellence in Education 41 (1): 114-129.

Guthrie, James W. and Matthew G. Springer. 2004. "Returning to Square One: From Plessy to Brown and Back to Plessy." Peabody Journal of Education 79 (2): 5-32.

Hansen, Michael. 2012. "Key Issues in Empirically Identifying Chronically LowPerforming and Turnaround Schools." Journal of Education for Students Placed at Risk 17 (1): 55.

Hernández, R. A. (2013). Maintaining a focus on subgroups in an era of Elementary and Secondary Education Act waivers. Washington, DC: Campaign for High School Equity.

Hess, Frederick M. and Michael Q. Mcshane. 2013. "Common Core in the Real World: Created to Fix Problems that NCLB either Started Or Couldn't Fix itself, the Common Core Faces its Own Challenges--seen and Unseen--during Implementation." Phi Delta Kappan 95 (3): 61.

Hiatt-Michael, Diana. 2008. "Families, their Children's Education, and the Public School: An Historical Review." Marriage \& Family Review 43 (1-2): 39-66.

Holme, Jennifer Jellison, Rian Carkhum, and Virginia Snodgrass Rangel. 2013. "High Pressure Reform: Examining Urban Schools' Response to Multiple School Choice Policies." Urban Review: Issues and Ideas in Public Education 45: 167.

Horn, Keren Mertens, Ingrid Gould Ellen, and Amy Ellen Schwartz. 2014. "Do Housing Choice Voucher Holders Live Near Good Schools?" Journal of Housing Economics 23: 28.

Horvat, Erin Mcnamara, Elliot B. Weininger, and Annette Lareau. 2003. "From Social Ties to Social Capital: Class Differences in the Relations between Schools and Parent Networks." American Educational Research Journal 40 (2): 319-351.

Howell, William. 2006. "Switching Schools?: A Closer Look at Parents' Initial Interest in and Knowledge about the Choice Provisions of no Child Left Behind." Peabody Journal of Education 81 (1): 140-179. 
Hoxby, Caroline M. 2003. "School Choice and school competition: Evidence from the United States," Swedish Economic Policy Review 10:9-65.

Hoxby, Caroline M. and Jonah E. Rockoff. 2005. "Findings from the City of Big Shoulders: Younger Students Learn More in Charter Schools." Education Next 5 (4): 52-58.

Hursh, David, and Camille Anne Martina 2003. "Neoliberalism and Schooling in the U.S.:

How State and Federal Government Education Policies Perpetuate Inequality.” Journal of Critical Education Policy Studies 1(2): 30-52.

Kantor, Harvey. 1991. "Education, Social Reform, and the State: ESEA and Federal Education Policy in the 1960s." American Journal of Education 100 (1): 47-83.

Kao, Grace and Jennifer S. Thompson. 2003. "Racial and Ethnic Stratification in Educational Achievement and Attainment." Annual Review of Sociology 29: 417442.

Karabel, Jerome and A.H. Halsey. 1977. Power and Ideology in Education. New York: Oxford University Press.

Kozol, Jonathan. 1992. Savage Inequalities: Children in America's Schools. 1st ed. New York: Harper Perennial.

Kuperminc, Gabriel P., Adam J. Darnell, and Anabel Alvarez-Jimenez. 2008. "Parent Involvement in the Academic Adjustment of Latino Middle and High School Youth: Teacher Expectations and School Belonging as Mediators." Journal of Adolescence 31 (4): 469-483.

Lacireno-Paquet, Natalie, Thomas T. Holyoke, Michele Moser, and Jeffrey R. Henig. 2002. "Creaming Versus Cropping: Charter School Enrollment Practices in Response to Market Incentives." Educational Evaluation and Policy Analysis 24 (2): $145-158$.

Ladner, Matthew and Dan Lips. 2009. "Demography as Destiny?" Education Next 9 (3): 20-27.

Lee, Jung-Sook and Natasha K. Bowen. 2006. "Parent Involvement, Cultural Capital, and the Achievement Gap among Elementary School Children." American Educational Research Journal 43 (2): 193-215.

Loeb, Susanna, Jon Valant, and Matt Kasman. 2011. "Increasing Choice in the Market for Schools: Recent Reforms and their Effects on Student Achievement." National Tax Journal 64 (1): 141. 
Long, J. S. and Jeremy Freese. 2006. Regression Models for Categorical Dependent Variables using Stata. 2nd ed. College Station: StataCorp LP.

Lubienski, Christopher. 2005. "Public Schools in Marketized Environments: Shifting Incentives and Unintended Consequences of Competition-Based Educational Reforms." American Journal of Education 111 (4): 464-486.

Lubienski, Christopher, Charisse Gulosino, and Peter Weitzel. 2009. "School Choice and Competitive Incentives: Mapping the Distribution of Educational Opportunities Across Local Education Markets." American Journal of Education 115 (4): 601-647.

MacLeod, Jay. 2009. Ain't no Makin' it: Aspirations \& Attainment in a Low-Income Neighborhood. 3rd ed. Boulder, CO: Westview Press.

Marshall, Catherine and Cynthia I. Gerstl Pepin. 2005. Re-Framing Education Politics for Social Justice. Boston: Pearson/Allyn and Bacon.

Massey, Douglas S. and Nancy A. Denton. 1993. American Apartheid: Segregation and the Making of the Underclass. Cambridge, Mass: Harvard University Press.

Miami-Dade County Public Schools (MDCPS). 2011. Parent Resource Guide 20112012: Connecting you to Miami-Dade County Public Schools. Miami: Miami-Dade County Public Schools.

- 2011a. The School Board of Miami-Dade County Bylaws and Policies: 2111 Parent Involvement - A Home-School-District Partnership. Miami: Miami-Dade County Public Schools.

—. 2012. Statistical Highlights 2011-12. Miami: Miami-Dade County Public Schools.

_. 2013. Statistical Highlights 2012-13. Miami: Miami-Dade County Public Schools.

Miami-Dade County Public Schools (MDCPSa). "Current Listing of All 128 Charter Schools.” Miami-Dade County Public Schools. http://charterschools.dadeschools.net/allcs14.html (accessed July 17, 2014).

MDCPSb. "Charter Schools Support: FAQs for Parents.” Miami-Dade County Public Schools. http://charterschools.dadeschools.net/allcs14.html (accessed July 17, 2014).

MDCPSc. "Magnet Schools Overview.” Miami-Dade County Public Schools: School Choice and Parental Options. http://www.yourchoicemiami.org/index.php?/index/department/2 (accessed July 17, 2014). 
MDCPSd. “Magnet Schools Frequently Asked Questions.” Miami-Dade County Public Schools: School Choice and Parental Options.

http://www.yourchoicemiami.org/index.php?/index/department/2/6 (accessed July 17, 2014).

MDCPSe. “NCLB Parental Choice.” Miami-Dade County Public Schools. http://nclbchoice.dadeschools.net (accessed July 17, 2014).

MDCPSf. “VPrep Virtual Offerings.” Miami-Dade County Public Schools: School Choice and Parental Options. http://www.yourchoicemiami.org/index.php?/index/department/2/63 (accessed July 17, 2014).

MDCPSg. “Miami-Dade County Public School: Online Meal Application.” Miami-Dade County Public Schools. https://freeandreducedmealapp.dadeschools.net (accessed July 17, 2014).

Michael, Deanna L. and Sherman Dorn. 2007. “Accountability as a Means of Improvement: A Continuity of Themes.” Pp. 83 - 116 In Education Reform in Florida: Diversity and Equity in Public Policy, edited by Bruce Fuller, Richard F. Elmore, and Gary Orfield. New York: Teachers College Press.

Michelman, Barbara. 2012. “The Never-Ending Story of ESEA Reauthorization.” Association for Supervision and Curriculum Development 18 (1): 1.

Moe, Terry M. 2008. "Beyond the Free Market: The Structure of School Choice. (Educational Choice: Emerging Legal and Policy Issues)." Brigham Young University Law Review 2008 (2): 557.

Moore, James. 2004. "50 Years After "Brown": Segregation in the Miami-Dade County Public Schools." Equity and Excellence in Education 37 (3): 289-301.

Neal, Derek and Diane Whitmore Schanzenbach. 2010. "Left Behind by Design: Proficiency Counts and Test-Based Accountability." The Review of Economics and Statistics 92 (2): 263.

Neild, Ruth Curran. 2005. "Parent Management of School Choice in a Large Urban District." Urban Education 40 (3): 270-297.

Orfield, Myron, Anne Discher, and Tom Luce. 2003. Economic and Racial Segregation in Greater Miami's Elementary Schools: Trends Shaping Metropolitan Growth. Washington, DC: Brookings Institution. 
Orfield, Gary and Chungmei Lee. 2005. Why Segregation Matters: Poverty and Educational Inequality. Massachusetts: Civil Rights Project Harvard University.

Orfield, Gary and John T. Yun. 1999. Resegregation in American Schools. Massachusetts: Civil Rights Project Harvard University.

Polikoff, Morgan S., Andrew J. Mceachin, Stephani L. Wrabel, and Matthew Duque. 2013. "The Waive of the Future? School Accountability in the Waiver Era." Educational Researcher 43 (1): 45.

Ravitch, Diane. 2000. Left Back: A Century of Failed School Reforms. New York: Simon \& Schuster.

Ravitch, Diane. 2010. The Death and Life of the Great American School System : How Testing and Choice are Undermining Education. New York: Basic Books.

Ravitch, Diane author. 2013. Reign of Error : The Hoax of the Privatization Movement and the Danger to America's Public Schools. First edition. ed. New York: Alfred A. Knopf.

Reay, Diane. 1996. "Contextualising Choice: Social Power and Parental Involvement." British Educational Research Journal 22 (5): 581-596.

Salinas, Roselia A. 2006. "All Children can Learn...to Speak English." National Forum of Educational Administration and Supervision Journal 23 (2):20-24.

Schneider, Mark, Paul Teske, Christine Roch, and Melissa Marschall. 1997. "Networks to Nowhere: Segregation and Stratification in Networks of Information about Schools." American Journal of Political Science 41 (4): 1201-1223.

Schneider, Mark, Melissa Marschall, and Paul Eric Teske. 2000. Choosing Schools: Consumer Choice and the Quality of American Schools. Princeton, N.J: Princeton University Press.

Sikkink, David and Michael O. Emerson. 2008. "School Choice and Racial Segregation in US Schools: The Role of Parents' Education." Ethnic and Racial Studies 31 (2): 267-293.

Sims, David P. 2013. "Can Failure Succeed? Using Racial Subgroup Rules to Analyze the Effect of School Accountability Failure on Student Performance." Economics of Education Review: 262.

Stuit, David A. 2010. Are Bad Schools Immortal? The Scarcity of Turnarounds and Shutdowns in both Charter and District Sectors Thomas B. Fordham Foundation \& Institute. 
Tedin, Kent L. and Gregory R. Weiher. 2011. "General Social Capital, Education-Related Social Capital, and Choosing Charter Schools." Policy Studies Journal 39 (4): 609.

Teske, Paul, Jody Fitzpatrick, and Gabriel Kaplan. 2007. Opening Doors: How LowIncome Parents Search for the Right School. Center for Reinventing Public Education.

Toma, Eugenia and Ron Zimmer. 2012. "Two Decades of Charter Schools: Expectations, Reality, and the Future." Economics of Education Review (2): 209.

Tucker, Robert C., Karl Marx, and Friedrich Engels. 1978. The Marx-Engels Reader. 2d ed. New York: Norton.

Urban, Wayne J. and Jennings L. Wagoner. 2009. American Education: A History. 4th ed. New York: Routledge.

United States Department of Education (USDOE). 2004. New No Child Left Behind Flexibility: Highly Qualified Teachers. Washington DC: United States Department of Education.

United States Department of Education (USDOE). 2009. Race to the Top Program Executive Summary. Washington DC: United States Department of Education.

USDOE. “ESEA Flexibility.” United States Department of Education. http://www2.ed.gov/policy/elsec/guid/esea-flexibility/index.html (accessed September 30, 2014).

Utts, Jessica M. 2004. Seeing through Statistics. Belmont: Duxbury Press.

Valverde, Leonard A. 2004. "Equal Educational Opportunity since Brown: Four Major Developments." Education \& Urban Society 36 (3): 368-378.

Vandenberghe, Vincent. 1999. "Combining Market and Bureaucratic Control in Education: An Answer to Market and Bureaucratic Failure?" Comparative Education 35 (3): 271-282.

Verstegen, Deborah A. 1994. "Reforming American Education Policy for the 21st Century." Educational Administration Quarterly 30 (3): 365-390.

Walters, Pamela Barnhouse. 2001. "Educational Access and the State: Historical Continuities and Discontinuities in Racial Inequality in American Education." Sociology of Education 74: 35-49. 
Weidner, Virginia R. and Carolyn D. Herrington. 2006. "Are Parents Informed Consumers: Evidence from the Florida McKay Scholarship Program." Peabody Journal of Education 81 (1): 27-56.

Weiss, Michael J. and Henry May. 2012. "A Policy Analysis of the Federal Growth Model Pilot Program's Measures of School Performance: The Florida Case." Education Finance and Policy (1): 44.

Wong, Kenneth K. and Anna C. Nicotera. 2004. "Brown v. Board of Education and the Coleman Report: Social Science Research and the Debate on Educational Equality." Peabody Journal of Education 79 (2): 122-135.

Wright, Erik. 1996. "The Continuing Relevance of Class Analysis — Comments." Theory and Society 25 (5): 693-716.

Zimmer, Ron W. and Cassandra M. Guarino. 2013. "Is there Empirical Evidence that Charter Schools "Push Out” Low-Performing Students?" Educational Evaluation and Policy Analysis 35 (4): 461.

Zimmer, Ron, Brian Gill, Kevin Booker, Stephane Lavertu, and John Witte. 2012. "Examining Charter Student Achievement Effects Across Seven States." Economics of Education Review (2): 213. 


\section{APPENDICES}

Semi-Structured Interview Instrument 


\section{SEMI-STRUCTRED INTERVIEW INSTRUMENT}

Making Choices: The School Choice Experience of Families Served By Low-Performing Schools and Their Access to Better Schooling

Name:

Date:

Relationship to student: 1 . Mother $\quad$ 2. Father $\quad 3$. Grandmother $\quad$ 4. Grandfather $\quad$ 5. Male relative 6. Female Relative 7 . Other

\section{BACKGROUND}

I'm going to start the interview with some questions about your background and the overall household. These questions will focus on your employment, education, and current and past places of residency.

1. What is the highest level of education you have completed?

2. Are you currently employed?

a. If yes, what do you do?

b. Is it full-time or part-time?

c. Is it permanent, temporary, or seasonal?

3. What is your yearly income?

4. Who else lives in this household? (Gender, age, occupation, household position)

a. If there are any school age children in the household, what school(s) do they attend?

5. May I use your home address for this study?

a. If so, what is it?

b. If you do not want to provide your exact home address, please identify the area in which you live on the following school boundary map.

6. How long have you lived at this address?

a. (If less than 2 years) Where did you live prior?

b. (If moved around a lot) Can you explain why you have moved around so often? 
7. How long have you lived in Miami-Dade County?

8. Did you attend school in Miami-Dade County?

a. If so, which school(s) did you attend?

b. What was your experience like?

c. How would you describe the quality?

d. How would you describe the safety/environment?

e. Did any of your family members attend any of these schools with you or before you?

\section{RESOURCES AND CONSTRAINTS}

This next section will focus on the resources you have access to and that you use to make schooling decision. It also will focus on any difficulties you might experience in accessing resources.

9. Where do you get information about your child's school? (from your child, the internet, at the school, friends, family, etc.)

a. What is the school grade?

10. Do you attend events at your child's school?

a. What type of events do you attend? (PTA meetings, parent-teacher conferences, student exhibitions, parent meetings, etc.)

b. About how many of these events did you attend last year?

i. Can you tell me about the events that you did not attend? Describe them.

c. What was your role in the events? (Attendee, volunteer, organizer)

i. Was your participation required in any way?

d. Is it easy for you to get to these events?

i. Do you have transportation?

ii. Do you have child care?

e. Did you meet other parents at these events?

i. If so, was it useful for getting information that you needed?

f. What type of information did you receive at the events you attended?

g. How did you hear about the events at the school?

11. Would you like to have more information about your child's school? (maybe through a newsletter, phone call, flyer, updates on the school website)

12. What is your primary source of transportation?

13. Do you have access to an alternative means of transportation? Describe 
14. Can you leave your job in the middle of the day to attend an event at your child's school?

15. Can you miss a day of work to attend a school event either at your child's school or at another school located in the County?

16. Do you talk to people at work about education related issues or your child's school?

17. Who specifically do you get education related information from? (family, friends, coworkers, school personnel, etc.)

a. What is your relationship to that person?

b. What is his/her level of education?

c. What does he/she do for a living?

18. Is there anyone else you can get education related information from?

19. Who was the most influential person to you when you made the decision about where your child would attend school this year? Explain.

a. How often do you talk to this person?

b. Is it a close relationship?

20. Who was the second most influential person? Explain.

a. How often do you talk to this person?

b. Is it a close relationship?

21. Whom else do you consult? Maybe someone you only talk to occasionally?

22. Given all that you've told me, do you think you had enough information to judge the quality of your child's school? Explain.

a. To judge the environment and safety of your child's school?

\section{Decision-making Process}

\section{This section will focus on the steps you took to chose your child's current school.}

23. Tell me about the academics at your child's current school.

a. Do children do well on FCAT?

b. Do they read well?

c. What kinds of grades do they get? As and Bs? Cs? Ds and Fs?

24. Tell me about the teachers at your child's current school.

a. Are they experienced? Have they been teaching for 5 or more years?

b. Do they have advanced degrees?

c. Students learn a lot in their classes.

25. Tell me about the students at your child's current school.

a. Are they well behaved?

b. Are they nice?

26. Tell me about the environment and safety at your child's current school. 
a. Is there bullying? An unusual amount?

b. Is there a lot of fighting?

c. Tell me about the surrounding neighborhood.

27. Is there anything else you would like to know about your child school that you don't know now?

28. Why does your child attend the school he/she currently attends?

a. Did you consider other schools? If so, how many?

b. What factors did you consider while making the decision? Why?

c. Where did you get the necessary information to evaluate the factors you mentioned? (reference previous answers)

d. Was the location of the school important? Why or why not? (neighborhood, distance, etc.)

e. What is the means of transportation your child uses to travel to and from school?

f. Did you consider whether or not your child could do the work at specific schools?

g. Did you consider whether the course work would be too easy or too difficult? Explain.

h. Did you think your child's grades would be better at this school as compared to other schools?

i. What was the most important factor that you considered in the decision to choose your child's current school? (academic, quality, safety, distance, etc.)

j. What was the second most important factor that you considered?

$\mathrm{k}$. If other schools were considered, explain the process of comparison. Was it based on FCAT scores, demographics, safety, etc.?

l. In general, was it easy to understand the information you obtained about the school? Explain.

i. What, if anything, did you find difficult?

29. Are you satisfied with your child's school? Why or why not? If no, are you considering removing him/her or have you made plans to remove him/her from this school? Explain.

30. If you could send your child to any school, which would it be? Why?

\section{Questions for parents of transfer students only}

These next few questions will focus on how you made the choice to transfer your child to a new school. 
31. Why did you transfer your child from his/her previous school?

32. What steps did you take to make the decision to leave your child's previous school? (visit previous school, visit possible alternatives, obtain information from the district website, etc.)

33. How would you describe the process of transferring your child to a new school? Was it smooth, complicated, stressful, or satisfying?

34. Did you obtain any information from his/her previous school to assist in this process? If so, what information?

35. Did you obtain any information from the school district to assist in this process? If so, what type of information? (demographic data, FCAT scores, boundary information) From what specific department did you receive information from? (school choice office, parent academy, etc.)

36. What was the most difficult thing that you experienced during the process of transferring your child? Explain.

a. Was there anything else that was difficult?

b. What would have made the process easier?

\section{Additional Questions}

37. Have you ever been to the school's website?

38. Have you ever been to the district's website?

39. Are you familiar with the Parent Academy?

40. Are you familiar with the district's school choice programs? If so, how, mail, news, radio, flyer, recruitment event?

41. Are you familiar with the magnet programs?

42. Are you familiar with charter school options?

43. That's the end of the interview. Is there anything else that you think is important to add? 
VITA

\section{LETANIA P. SEVERE}

$2000-2004$

B.A., Anthropology and Film \& Television University of Notre Dame

South Bend, Indiana

$2004-2005$

Production Assistant

Towers Productions

Chicago, Illinois

$2005-2006$

$6^{\text {th }}$ Grade Math Teacher Jose de Diego Middle School

Miami, Florida

$2006-2008$

M.A., Comparative Sociology

Florida International University

Miami, Florida

$2007-2009$

Research Associate (part-time)

Camillus House, Inc.

Miami, Florida

$2008-2013$

Research Assistant (part-time)

Miami-Dade County Public Schools Office of Program

Evaluation

Miami, Florida

$2009-2014$

Research Manager (part-time)

Camillus House, Inc.

Miami, Florida

2014 - present

Management Systems Analysts

City of Seattle Human Services Department Seattle, WA

\section{PRESENTATIONS}

2007 "School Segregation, Educational Disparities, and Impacts on Haitian Youth in South Florida.” Panel presentation at the Haitian Studies Association Annual Conference, Boca Raton, FL., 5 October. 
2007 "School Segregation and the Education of Haitian Immigrants." Panel presentation at the American Anthropological Association Annual Meetings, Washington, D.C., 2 December. (Coauthor with Tekla Nicholas)

2008 "School Segregation, Educational Disparities, and Impacts on Haitian Youth in South Florida.” Presentation at the McKnight Doctoral Fellowship Program Mid-Year Research and Writing Conference, Tampa, FL, 1 March.

2008 "School Segregation, Educational Disparities, and Impacts on Haitian Youth in South Florida." Presentation at the Florida International University College of Education Research Conference, Miami, FL, 26 April. (Coauthor with Tekla Nicholas)

2008 "The Invisible Borders of School Segregation: Educational Disparities and Haitian Youth in South Florida." Panel presentation at the Society for the Study of Social Problems Annual Meetings, Boston, MA, 31 July. (Coauthor with Tekla Nicholas)

2008 "How Home Address Shapes Destiny: Residential Clustering, School Segregation, and the Education of Haitian Youth in South Florida.” Panel Presentation at the Race, Ethnicity, and Place Conference IV, Miami, FL, 7 November. (Coauthor with Tekla Nicholas)

2009 "Separate and Unequal: Haitian Students Left Behind in South Florida's Segregated Schools." Panel presentation at the 30th Annual Ethnography in Education Research Forum, Philadelphia, PA, 28 February. (Coauthor with Tekla Nicholas) 